\title{
CHARACTERISTICS OF THE DEEP SCATTERING LAYER IN THE GULF OF MEXICO AS THEY RELATE TO SPERM WHALE DIVING AND FORAGING BEHAVIOR
}

\author{
A Thesis \\ by \\ ALYSON JULIE AZZARA \\ Submitted to the Office of Graduate Studies of \\ Texas A\&M University \\ in partial fulfillment of the requirements for the degree of \\ MASTER OF SCIENCE
}

December 2006

Major Subject: Oceanography 


\title{
CHARACTERISTICS OF THE DEEP SCATTERING LAYER IN THE GULF OF MEXICO AS THEY RELATE TO SPERM WHALE DIVING AND FORAGING BEHAVIOR
}

\author{
A Thesis \\ by \\ ALYSON JULIE AZZARA \\ Submitted to the Office of Graduate Studies of \\ Texas A\&M University \\ in partial fulfillment of the requirements for the degree of \\ MASTER OF SCIENCE
}

\begin{abstract}
Approved by:
Co-Chairs of Committee, Douglas Biggs

Steven DiMarco

Committee Members, $\quad$ Aaron Thode

Antonietta Quigg

Head of Department, John Morse
\end{abstract}

December 2006

Major Subject: Oceanography 


\author{
ABSTRACT \\ Characteristics of the Deep Scattering Layer in the Gulf of Mexico as They Relate to Sperm \\ Whale Diving and Foraging Behavior. (December 2006) \\ Alyson Julie Azzara, B.A., Temple University \\ Co-Chairs of Advisory Committee: Dr. Douglas Biggs \\ Dr. Steven DiMarco
}

This research was carried out in support of fieldwork in the Gulf of Mexico in summers 2004 and 2005 as part of the multidisciplinary Sperm Whale Seismic Study (SWSS). Important aspects of SWSS research include oceanographic habitat characterization and studies of sperm whale foraging and diving patterns. During the SWSS 2005 cruise, acoustic volume backscatter data were collected using a $38 \mathrm{kHz}$ ADCP for comparison with XBT, MODIS ocean color data, and whale dive profiles extrapolated from analysis of towed passive acoustic hydrophone array recordings of whale vocalizations. This unique data set, collected from a cyclonic eddy, was compared with non-upwelling conditions surveyed in the western Gulf and the Mississippi Canyon in summer 2004. My focus was to examine the relationship between acoustic backscatter intensity from the deep scattering layer (DSL; usually 400-600 m deep) and the depths to which whales dived. The results of the study investigate differences in DSL characteristics between divergent zones and non-divergent zones, and examine connections relating to variations in sperm whale dive patterns. The analysis of $38 \mathrm{kHz}$ ADCP data showed that there were 
significant differences in some characteristics of the main DSL dependent on time of day. There were no significant differences in characteristics of the main DSL between divergent and non-divergent areas or between 2004 and 2005. The comparison of the 38 $\mathrm{kHz}$ ADCP and the $70 \mathrm{kHz}$ Simrad echosounder data yielded a relationship of 4 ADCP counts for every $1 \mathrm{~dB}$ of $\mathrm{S}_{\mathrm{v}}$. This relationship was a promising start to a potential calibration for the ADCP instrument. Lastly, the analysis of localized sperm whale dive profiles identified three basic dive profiles; Deep ( $>800 \mathrm{~m}$ ), Mid-water dives to DSL depths $(500-800 \mathrm{~m})$ and Shallow $(<500 \mathrm{~m})$. The analysis also showed that whale dive behavior did not change based on time of day or location. It showed that whales are diving above the DSL as well as through and below, however these dives are independent of differences in DSL characteristics. 


\section{ACKNOWLEDGMENTS}

I would like to acknowledge and thank Doug Biggs and Steve DiMarco for co-chairing my committee and for their enduring patience and support throughout the last 2 years. I would also like to thank Aaron Thode and Antonietta Quigg for comprising the rest of my committee and for offering their support and guidance in the writing of this thesis.

I would like to acknowledge the Minerals Management Services for funding the SWSS project under cooperative agreement 1435-01-02-CA-85186 and making the research for this thesis possible.

I would especially like to thank the crew and technical support staff of the $R / V$ Gyre, particularly Captain Dana Dyer, Paul Clarke, Billy Green, Eddie Webb, and Marty Bohn, for safely conveying me to the middle of the ocean and back without either injury or accident and for always being around to help me with anything, including; winching, plankton tows, flow-though emergencies, burning ADCP data, and of course, letting me drive the ship while we followed the whales.

I want to thank the science parties from the SWSS 2004 and 2005 summer cruises, especially the visual team for all their sightings data, the tagging team for their data, and small boats crews for letting me out on the RHIB boats. I want to express particular gratitude to the acoustics team for all the experience and great times, not to mention the 
cool data. In addition, I want to thank Ann Jochens for heading the science party in 2005 and keeping everything working like clockwork while I was collecting data.

Specifically, I want to thank Aaron Thode and Tom Norris for heading the acoustic efforts and for tirelessly working with me to make sure that the GUI was working and giving back good data. I would also like to thank Kelly Benoit-Bird and Chris Wingard for lending me the Simrad systems and teaching me how to use them and how to incorporate that data into my thesis.

I want to thank Louise McGarry who worked hour upon hour with me over the summer to figure out what the heck to do with 30 days of ADCP data and for her 'on call' help these past two semesters lending her support to me whenever I needed it.

Lastly, but certainly not least, I want to thank my mom, dad, Patrice and my grandparents for their shipments of encouragement, pizza dough, coffee and chocolate and their words of support, which helped me, above all to complete this thesis. Also, Kathryn Henneberger, Jennifer Pitkewicz, Julia O’Hern, Kelly Cole, Ruth Mullins, Laura Rubiano-Gomez and the rest of the breakfast club for getting me through all the tough times, and for always having a cold one to bring me 'round. 


\section{TABLE OF CONTENTS}

Page

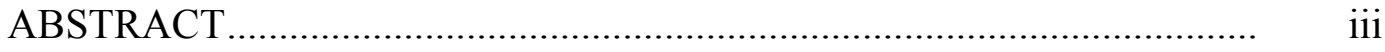

ACKNOWLEDGMENTS ................................................................. $\mathrm{v}$

TABLE OF CONTENTS ................................................................... vii

LIST OF FIGURES ........................................................................... ix

LIST OF TABLES ......................................................................... xiii

CHAPTER

INTRODUCTION ........................................... 1

Short History and Background.................... 1

II

RESEARCH GOALS AND METHODS .................. 9

Backscatter Analysis ................................ 9

Acoustic Investigation .............................. $\quad 10$

Hypotheses ............................................ 12

Materials .................................................... 12

Methods................................................. 15

III ANALYSIS OF $38 \mathrm{KHZ}$ BACKSCATTER DATA

IN THE WESTERN GULF OF MEXICO

COLLECTED DURING SUMMER 2005 ............... 20

Introduction........................................... 20

Results................................................... 21

Discussion ............................................... 31

IV COMPARISON OF BACKSCATTER DATA

BETWEEN 2004 AND 2005 ................................ 37

Introduction............................................ $\quad 37$

Results.................................................. $\quad 38$

Discussion ........................................... 50 
V COMPARISON OF BACKSCATTER DATA FROM 38 KHZ ADCP AND 70 KHZ SIMRAD FISHERY ECHOSOUNDER

Introduction.............................................. 53

Methods.................................................. 53

Results................................................ 54

Discussion ................................................ 63

VI ANALYSIS OF ACOUSTIC DATA AND

INTERPRETATION OF SPERM WHALE

DIVE PROFILES............................................... 66

Introduction............................................. 66

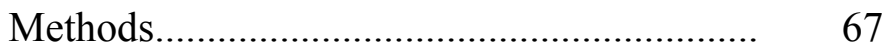

Results................................................. 78

Discussion ............................................... $\quad 87$

VII $\quad$ SUMMARY AND CONCLUSIONS ...................... 91

REFERENCES .................................................................... 97

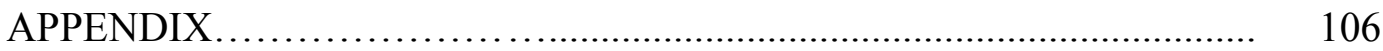

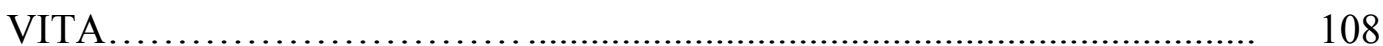




\section{LIST OF FIGURES}

FIGURE

Page

1 Map of the Gulf of Mexico showing study area regional names and the $1000 \mathrm{~m}$ isobath

Schematic of cyclonic cold-core eddy.

6

MODIS image (USF, 2005) showing the cyclonic eddy between the two anticyclonic eddies.

Sea surface height plot of the 2005 study area on 16 June 2005 with cruise track superimposed showing velocity vectors of currents in the area.

$5 \quad$ Example of sperm whale clicks displayed by Ishmael software designed by David Mellinger (NOAA/PMEL Newport, Oregon).

6 Demonstration of the three scattering layer characteristics to be tested, average depth, vertical thickness and average intensity in counts.

Graphical representation of the t-test results for main deep scattering layer mean depth shown in Table 3.

Graphical representation of the t-test results for main deep scattering layer thickness shown in Table 4.

9 Graphical representation of t-test results for main deep scattering layer intensity shown in Table 5.

Graphical representation of the $90 \%$ confidence interval for t-test results of the main deep scattering layer depth comparison by location shown in Table 6

11 Graphical representation of the $90 \%$ confidence interval for t-test results of the main deep scattering layer intensity comparison by location shown in Table 7 .

12 Graphical representation of the $90 \%$ confidence interval for t-test results of the main deep scattering layer thickness comparison by location shown in Table 8 . 
13 ADCP current plot of the recorded data from the horizontal ship track from $96^{\circ} \mathrm{W}$ to $94^{\circ} \mathrm{W}$.

SWSS cruise 2004 ship track in the northeastern Gulf of Mexico.

15 Graphical representation of t-test results for Day/Night comparison of main DSL depth in 2005 shown in Table 10.

16 Graphical representation of t-test results for Day/Night comparison of main DSL depth in 2004 shown in Table 11.

17 Graphical representation of t-test results for Night comparison of main DSL depth between 2004 and 2005 ......

18 Graphical representation of t-test results for Day comparison of main DSL depth between 2004 and 2005.....

19 Vertical section of SWSS ADCP acoustic amplitude backscatter data from the Mississippi Canyon on 28-29 May 2004.

(A) Ship track from the 28-29 of May 2004 (B) Sea surface color and height plot five day composite from 29 May 2004

21 Vertical section of SWSS ADCP acoustic amplitude backscatter data from the western Gulf of Mexico on 9 June 2005

22 (A) Ship track from 9 June 2005. (B) Sea surface color and height plot five-day composite from 15 June 2005

23 Vertical section of acoustic backscatter during 2004 in the northeast Gulf of Mexico entering into Desoto Canyon.

24 (A) Ship track entering Desoto Canyon 31 May 2004.

(B) Sea surface color and height plot five day composite from 29 May 2004.

$25 \quad$ Vertical section of acoustic backscatter during 2004 in the northeast Gulf of Mexico, Desoto Canyon 
(A) Ship track surveying Desoto Canyon 1 June 2004

(B) Sea surface color and height plot five day composite

from 29 May 2004.

27 Plot of the 22 June 2005 nighttime comparison for the period of Midnight to 1 AM (12, five-minute samples). . 56

28 Modified plot of the 22 June 2005 nighttime comparison for the period of Midnight to $1 \mathrm{AM}$ (12, five-minute samples).

29 Modified plot of the 22 June 2005 nighttime comparison from Midnight to 1 AM (12, five-minute samples) showing the relationship between $\mathrm{S}_{\mathrm{A}}$ values and counts above 160 .

30 Plot showing 9 June 2005 data comparison between the ADCP and Simrad data sets from Noon to 1 PM (12, five-minute samples).

31 Plot of fishery echosounder $\mathrm{S}_{\mathrm{A}}$ values vs. Depth, Noon to 1 PM June $9^{\text {th }}$ (12, five-minute samples)

Plot of Counts vs. Depth at Noon on June $9^{\text {th }}$

(12, five-minute samples)

Plot of ADCP counts $>$ than 120 versus $S_{A}$ for 9 June 2005 (12, five-minute samples)

34 Plot of $S_{v}(d B)$ vs. Counts on June 21, for the time period of Midnight to 1 AM (12, five-minute samples)....... 63

Diagram of passive acoustic hydrophone array setup

GUI Viewer window as it appears after one whale track has been selected. 
FIGURE Page

$41 \quad$ Raw whale dive profile June 9 2005.................................... 76

42 Quality controlled (edited) whale dive profile 9 June 2005 .. 77

43 Superimposed plot of quality controlled localized dive profile over ADCP backscatter for 9 June 2005 .................... 77

$44 \quad$ A combination sperm whale dive of deep and shallow movement recorded 9 June 2005 in the late afternoon from 4:15 to 4:45 PM.......................................................... 80

45 Deep dive recorded 9 June 2005 from 4:50-5:20 PM............ 81

$46 \quad$ Example of extended shallow diving on 9 June 2005 from 4:10 to 4:40 PM.......................................................... 81

47 Dive profile from 12 June 11:00-11:30 AM.......................... 82

$48 \quad$ Whale dive profile of three simultaneous dives superimposed over ADCP backscatter 9 June 2005 ............... 83

49 A pair of nighttime whale dive plots from 9 June 2005 during the same time period from 10:50-11:20 PM... 84

50 Superimposed simultaneous dive profiles from Figure 49 on 9 June 2005 ...............................................................

51 Plot of nighttime profile from 8 June 2005 11:00 -11:30 PM 85

52 Dive plots of sperm whales D-tagged by WHOI in the northeast Gulf of Mexico, June 2003 and September 2002, respectively 


\section{LIST OF TABLES}

TABLE

Page

1 Summary of instrumentation used in thesis

2 Results of the Kolmogorov-Smirnov parametric test of normal distribution for the ADCP data sets....

T-test results of the night/day comparison of main deep scattering layer depth

T-test results of night and day comparison for main deep scattering layer thickness

T-test results of night and day comparison for main deep scattering layer intensity

T-test results for divergent/non-divergent main deep scattering layer depth comparison

T-test results for divergent/non-divergent main deep scattering layer intensity comparison

T-test results for divergent/non-divergent main deep scattering layer thickness comparisons.

Results of One-Sample Kolmogorov -Smirnov test for normal distribution of night/day main deep scattering layer depth data from 2004 and 2005.

10 Results of t-test comparing Night and Day mean depth to the bottom of the main DSL in 2005

11 Results of t-test comparing Night and Day mean depth to the bottom of the main DSL for 2004 .

12 Comparison of day and night integrated intensity values for 2004 and 2005

13 Summary of correlation coefficients and slope of the ADCP counts versus $\mathrm{S}_{\mathrm{A}}$ regression by data set beginning at either noon or midnight local time and extending for a period of one hour. 
14 Figure number, Date, Time, Duration, and Min and Max dive depth for each dive profile........................ 


\section{CHAPTER I}

\section{INTRODUCTION}

\section{Short History and Background}

The Sperm Whale Seismic Study (SWSS) research program was funded by the U.S. Minerals Management Service (MMS) to investigate the potential effects that offshore seismic surveys may have on the spatial and temporal distributions of sperm whales in the northern Gulf of Mexico. Past MMS sponsored studies, such as GulfCet I and II, (Davis and Fargion, 1996; Davis et al., 2000) have shown that approximately one thousand sperm whales live in the northern Gulf (Davis et al., 2000). These animals are most often encountered over the continental slope in water depths averaging $1000 \mathrm{~m}$ (Jochens et al., 2006). As a result, there is a potential for interaction between the petroleum exploration industry and marine mammal populations, which increases as industry exploration moves off shelf and into the deeper waters of the continental slope. In light of this, it is necessary to better understand sperm whale behavior so that possible changes in response to anthropogenic stimuli can be more accurately evaluated.

Important aspects of SWSS research include habitat characterization and studies of sperm whale behavior. In order to understand the mesoscale patterns of the habitat used by whales, it is important to understand their local, fine scale foraging and diving patterns. Several methods are being used to accomplish these local investigations, including analyses of relative acoustic backscatter intensities (RABI) recorded by an acoustic Doppler current profiler (Kaltenberg, 2004) and coincident recordings of sperm whale 
vocalizations by a towed acoustic array system (Thode, 2004).

Recent work in the Gulf of Mexico has utilized acoustic Doppler current profilers (ADCP) of various frequency ranges to try to distinguish individual scattering layers at depths to correlate estimates of acoustic backscatter with the organisms found within them (Zimmerman, 1993; Greene et al., 1998; Ressler, 2002; Sindlinger, 2003; Kaltenberg, 2004). The ADCP operates using a principle of sound waves known as the Doppler effect. The instrument emits 'pings' of sound into the water column at a constant frequency, $38 \mathrm{kHz}$ in this case, and records the sound reflected back by particles or organisms in the water. Particles moving toward the instrument reflect the sound back at a higher frequency, while those moving away reflect back at a lower frequency. The difference between the transmitted frequency and the reflected frequency is the Doppler shift. The ADCP instrument uses this shift to calculate the speed of the particle in relation to the motion of the boat and the time difference between the transmitted signal and the received signal gives the location (Brierley et al., 1998).

Organisms that scatter sound are those with densities that are markedly different from the density of water. Fish and other animals with air bladders or lungs are particularly strong scatterers, but smaller organisms like zooplankton and phytoplankton can also show strong scattering when they are aggregated in dense groups or layers (Stanton et al., 1996). This aggregated grouping is particularly important for my study because my primary interest lies in detecting scattering layers of organisms, rather than the detection of individuals. 
Theoretically, however, given the operating frequency of the instrument, it is possible to calculate the minimum size organism detectible. Using the equation:

$$
\mathrm{c}=\mathrm{f} \lambda \quad 150,000 \mathrm{~cm} / \mathrm{s}=38,000 \text { cycles } / \mathrm{s} * \lambda
$$

where $\mathrm{c}$ is the speed of sound in seawater $(\sim 150,000 \mathrm{~cm} / \mathrm{s})$ and $\mathrm{f}$ is the frequency of the signal ( $38 \mathrm{kHz}$ ), one can solve for $\lambda$, the wavelength. Solving this equation yields a wavelength of approximately $4 \mathrm{~cm}$, making the minimum individual resolution power of the instrument between 1 and $2 \mathrm{~cm}$, according to the theoretical resolution rule of $1 / 4$ the wavelength (R.D. Instruments, 1996). This theoretical resolution is degraded by the thickness of the vertical 'bin' (slice of the water column) that is imaged acoustically. Thicker vertical bins confound fine-scale target imaging making resolution of individual scatterers impossible.

The combined use of ADCP and net trawls allows for the ground truthing of backscatter intensity readings with observed biological counts of organisms (Green et al., 1998; Ressler, 2002; Ressler and Jochens, 2003; Fielding et al., 2004). Backscatter is defined as the deflection of acoustic radiation in a scattering process through an angle greater than 90 degrees (Fish and Carr, 1991). The backscatter of interest in this thesis research is reflected from zooplankton and nekton in the deep scattering layer (DSL), which is usually most concentrated at a daytime depth of approximately $500 \mathrm{~m}$.

Using data from 2002 and 2003, Kaltenberg (2004) showed that a ship-mounted $38 \mathrm{kHz}$ ADCP could resolve scattering layers of tens of meters thickness at several places throughout the water column down to approximately 800 meters. She was able to identify 
the major zooplankton scattering layers and she gave some examples of areas of strong scattering below that layer.

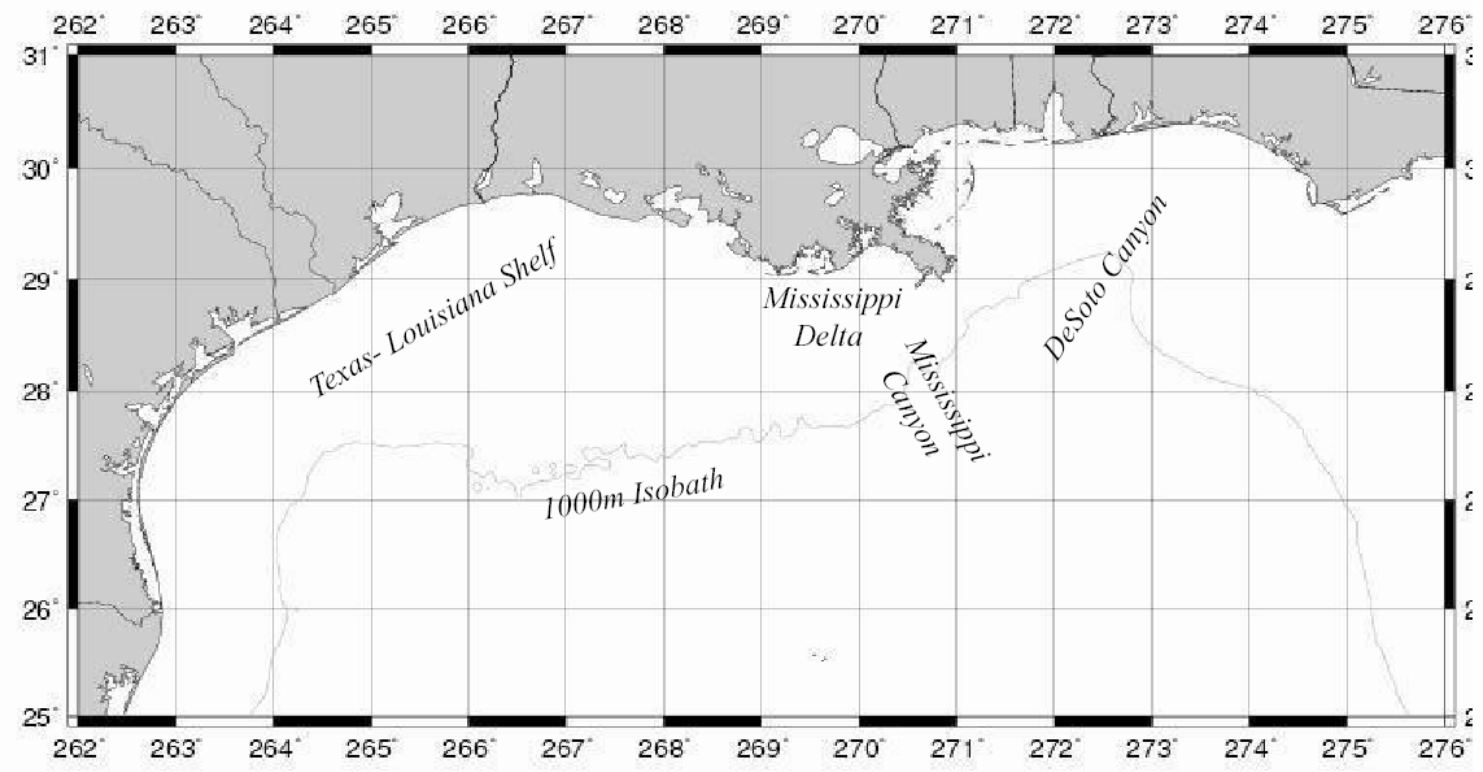

FIG.1. Map of the Gulf of Mexico showing study area regional names and the $1000 \mathrm{~m}$ isobath.

The same ADCP was subsequently used in summer 2004 to survey for the DSL in the Mississippi Canyon area of the northern Gulf of Mexico, and again in June 2005 in the western Gulf of Mexico (Figure 1). The 2005 western Gulf survey was the first of this type. A divergent upwelling system was surveyed during the 2005 cruise (3 -30 June) and its surface waters were further characterized by measuring flow-through chlorophyll fluorescence and by using expendable bathythermographs (XBTs), ConductivityTemperature-Depth recorder (CTD) on board the ship, and Moderate Resolution Imaging Spectroradiometer (MODIS) and altimeter imagery remotely sensed from space. 
There are several major forcings for physical processes in the Gulf of Mexico. The most prominent is the Loop Current, which is a precursor of the Gulf Stream that enters through the Yucatan Channel and exits through the Florida Straits. When the Loop Current extends very far north or northwest, large scale $(\sim 200 \mathrm{~km})$ anti-cyclonic eddies separate from the Loop Current and propagate west or southwest through the Gulf of Mexico (Hamilton, 1992). The dominant dynamic mechanism controlling the separation of Loop Current eddies from the Loop Current are instabilities within the Loop Current produced by horizontal sheer from the natural tendency of the water masses to propagate west with the Coriolis force and not to the east and out the Florida Straits (Sturges and Leben, 2000). Additionally, variation in the flow through the Yucatan Channel influences the strength and extension of the Loop Current to the northwest, which also affects the frequency of Loop Current eddy detachment (Leben, 2005). Interaction of these anticyclonic eddies with the Texas shelf often generates secondary cyclones and anticyclones of smaller dimension ( $\sim 50-100 \mathrm{~km}$ diameter). Eddies in the Gulf of Mexico typically extend downward from the surface to depths of 500 to $600 \mathrm{~m}$. Eddies can interact with the Loop Current bathymetry and other eddies. These secondary eddies are often the main forcing factors along the shelf-edge and may influence the circulation of shallower continental shelf waters (Hamilton, 1992).

The area sampled in 2005 was a cyclonic eddy; part of a combination of three eddies. The sampled cyclonic eddy was flanked by two anticyclonic eddies. Movement of the southern anticyclonic eddy onto the Texas slope in April contributed to the formation of the cyclonic eddy through a transfer of vorticity as the anticyclone interacted frictionally with the shoaling bathymetry of the continental slope (Jochens and Biggs, 2006a, 
submitted). The cold core eddy is a region of current divergence and is influenced by the Coriolis force which drives its counter clockwise rotation as well as the clockwise rotation of the anticyclonic eddies. The divergence caused by the oppositely directed currents of the interacting cyclonic and anticyclone eddies facilitates the doming of midwater, which is generally richer in nutrients than the displaced surface water, promoting biological production (Picard and Emery, 1990). Upwelling (Figure 2) is the active upward movement of deeper (i.e. coming from below the mixed layer) waters to compensate for the divergent movement of surface waters (Levinton, 2001).

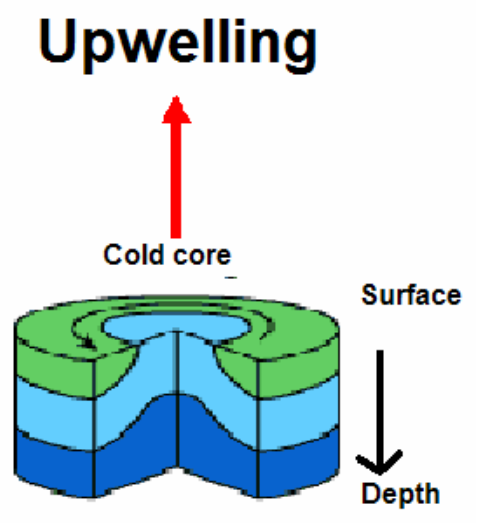

FIG.2. Schematic of cyclonic cold-core eddy. This example shows the upward doming of deeper, cold water to the surface as a result of upwelling (www.oc.nps.navy.mil). 


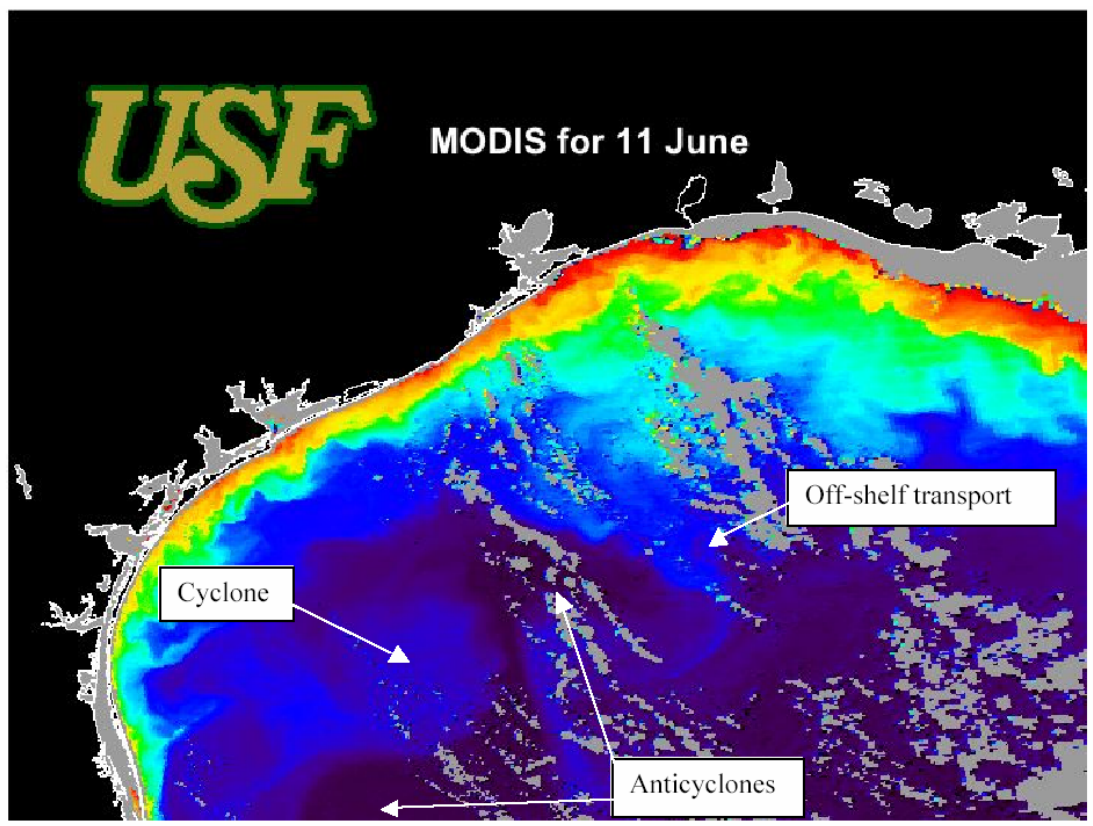

FIG.3. MODIS image (USF, 2005) showing the cyclonic eddy between the two anticyclonic eddies. The light blue within the cyclone indicates the cyclonic motion of the eddy is entraining high chlorophyll shelf water. The change from light blue to dark blue represents the divergent boundary between the eddy and the surrounding oceanic waters (Jochens et al., 2006).

The use of satellite imagery allows tracking of eddies and other systems occurring in the Gulf of Mexico (Figure 3). Knowledge of the location of these events makes XBT and chlorophyll sampling easier, because we are able to more completely sample areas of interest. Past SWSS studies had found that sperm whales congregated more frequently and in larger groups at these boundaries (Davis et al., 2002). Having satellite imagery showing the location of the cyclonic eddy while at sea allowed the ship track to be modified in near real time for better sampling and observation of whale populations (Figure 4). 


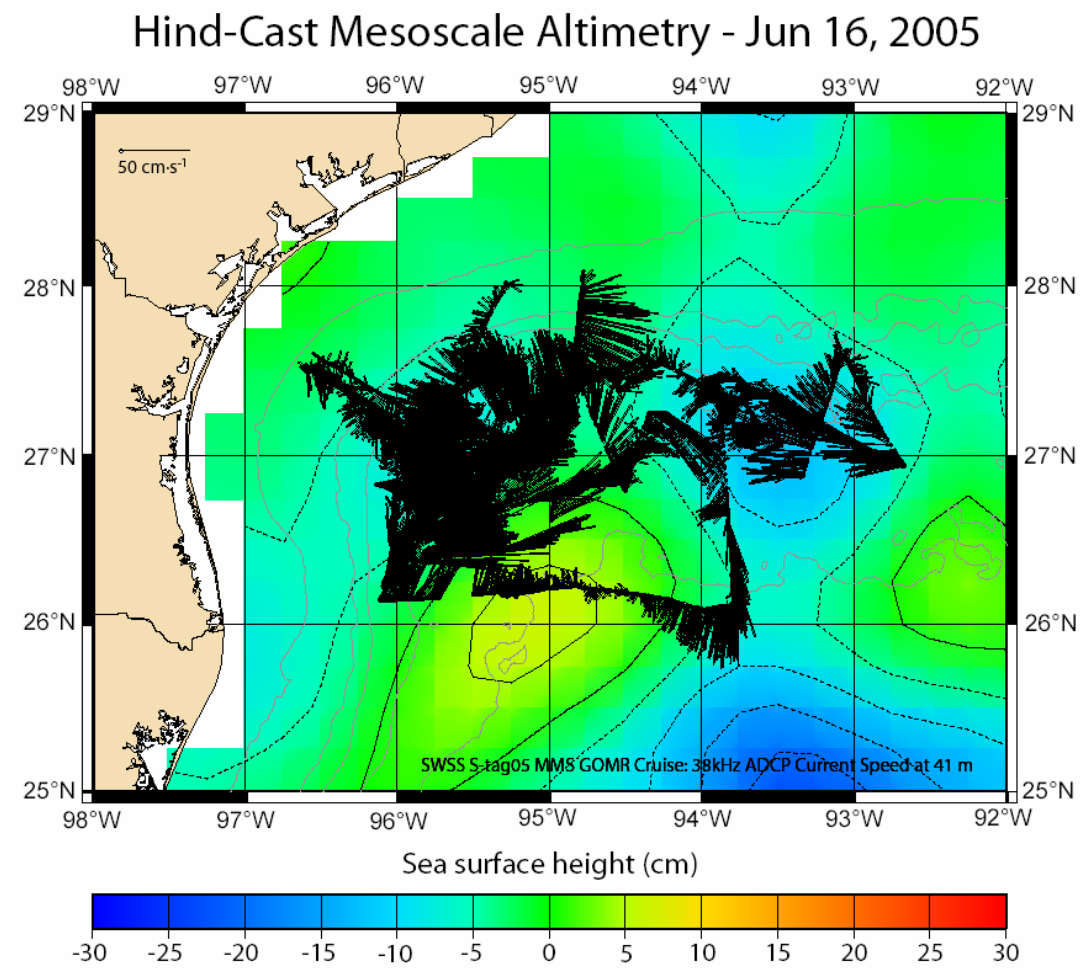

FIG.4. Sea surface height plot of the 2005 study area on 16 June 2005 with cruise track superimposed showing velocity vectors of currents in the area. The majority of ship track is concentrated in the cold-core, cyclonic eddy located between $26.5^{\circ} \mathrm{N}$ and $27.5^{\circ} \mathrm{N}$ and $95^{\circ} \mathrm{W}$ and $96^{\circ} \mathrm{W}$, which is a local area of low sea surface height (Plot provided by X. Zhang, TAMU). 


\section{CHAPTER II}

\section{RESEARCH GOALS AND METHODS}

\section{Backscatter Analysis}

The purpose of this chapter is to provide background on the analytical and statistical methods used in my research, as well as a description of the instrumentation used to collect the data. I will also present the null hypotheses tested in the following chapters. The research presented in this thesis expands on previous research done in the Gulf of Mexico using an ADCP to observe biological aspects of volume backscatter (Ressler, 2002; Sindlinger, 2003; Kaltenberg, 2004). Ressler (2002) analyzed volume backscatter intensity by comparing net trawls and ADCP readings. No net trawls collections were made during either the 2004 or 2005 SWSS cruises. I analyzed ADCP acoustic volume backscatter intensity from the summers of 2004 and 2005. I compared the deep scattering layers between years and the different regions of the northern and western slopes of the Gulf of Mexico.

Using similar analysis procedures developed by Kaltenberg (2004), I have determined the average scattering depth of the main DSL. The main layer is located at about 500 meters, and exhibits evidence that some of its scatterers migrate vertically to a depth of 200 meters or shallower at night. Using the data collected from 2005, I compared the depth and strength of the main deep scattering layer within the cyclonic eddy to locations outside this area. I also made comparisons between the depth of the main DSL in the western Gulf of Mexico and the depth of the main DSL in the Mississippi Canyon using data collected in the 2004 field season. This comparison is important for understanding 
the different types of habitats that sperm whales prefer, and also for understanding patterns in their diving behavior.

\section{Acoustic Investigation}

A passive acoustics team aboard the $R / V$ Gyre during summers 2004 and 2005 helped

track sperm whale movement by finding and following whale "click" sounds. This team operated two towed hydrophone arrays on board the vessel and recorded vocalizations made by sperm whales in the area (Thode, 2004). Using this towed array system, the whales were tracked for extended periods of time ranging from an hour to multiple hours by following their vocalizations. The towed arrays could track individual whales or whales within small groups. In addition to the ability to follow these whales, it is also possible to make observations about the type of behavior they are exhibiting. Based on the type and frequency of their calls, inferences can be made concerning foraging patterns, social interactions, and patterns of surfacing and resting. By using the combination of the two arrays, it is also possible to calculate and maintain left and right bearings on the whales (Thode, 2004).

Dive paths and patterns such as depth and frequency were constructed using algorithms based on the recorded clicks, their surface reflections, and their bottom bounces. Dr. Aaron Thode of Scripps Institution of Oceanography, who headed the acoustics team, has developed methods for creating these dive profiles. Figure 5 shows sperm whale clicks as a sonogram image using the Ishmael software (Developed by David Mellinger of NOAA/PMEL Newport, Oregon). By looking at the intensities and the frequency of the clicks, it is often possible to determine the approximate number of whales, and determine 
whether or not bottom or surface bounces of the click are being recorded. Surface bounces are utilized in the localization process for sperm whale dive profiles and bottom bounces are used to truth the occurrence of recorded clicks. Occasionally, the sonogram also shows recordings of other sounds such as buzzes or codas (Miller et al., 2004), which can indicate feeding efforts or socialization, respectively.

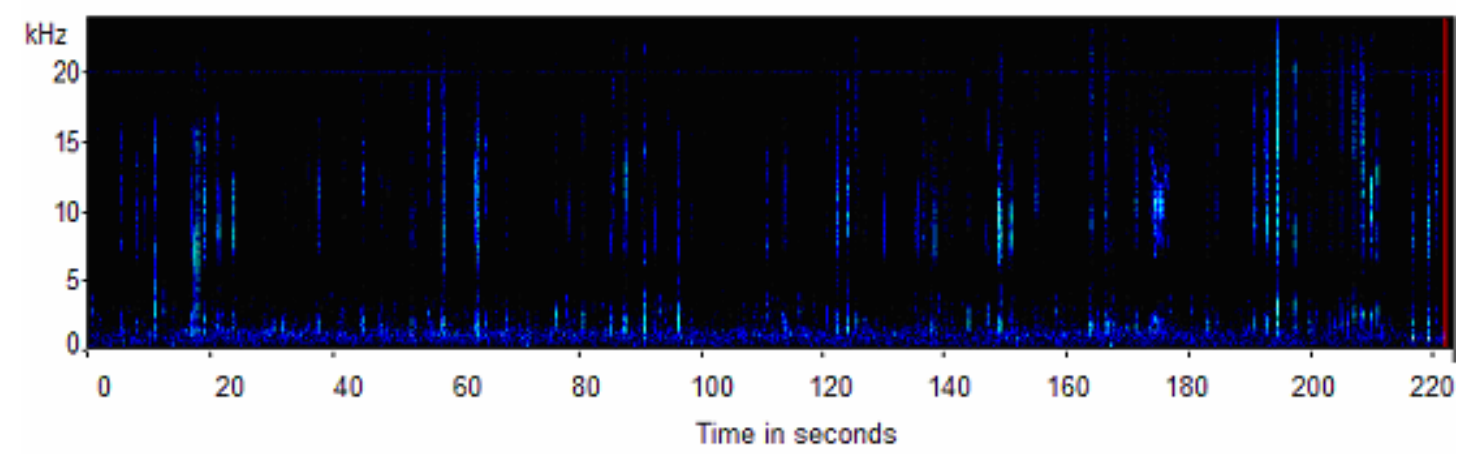

FIG.5. Example of sperm whale clicks displayed by Ishmael software designed by David Mellinger (NOAA/PMEL Newport, Oregon). The bright white vertical lines indicate the source click (6-10 ms sound pulse (Thode el al., 2002)) while the shorter lines indicate bottom or surface bounces. The x-axis represents a time period of approximately 3.6 minutes and the y-axis shows the intensity of the click recorded from 0 to $20 \mathrm{kHz}$.

This thesis also focuses on the integration of ADCP backscatter data with whale dive data. In Chapter VI, I analyze the diving behavior of sperm whales and comment on whether certain behaviors are location dependant or phenomena dependant. A comparison of variation within the western Gulf between divergence areas and nondivergence areas is the first step to determining whether sperm whales adjust their diving habits based on physical events occurring near them. 


\section{Hypotheses}

There are several hypotheses addressed in this research. They are addressed in an order from least to most complex, beginning with the analysis of a single data set and moving through the analysis and connection of multiple data sets over a period from 2004 to 2005. The hypotheses addressed (formulated as null hypotheses) are listed in the order in which they are discussed in this thesis.

1. There is no significant difference(s) between characteristics of the main deep scattering layer based on time of day (i.e. night and day).

2. There is no significant difference(s) between characteristics of the main deep scattering layer based on location (i.e. within the divergent eddy or outside)

3. There is no significant difference(s) between locations along the frontal zone of the two locations, within the divergent eddy, and outside the eddy.

4. There is no significant difference(s) in the characteristics of the main deep scattering layer between the eastern, central, and western Gulf of Mexico, or between summer 2004 and summer 2005.

5. There is no significant difference(s) in depths to which whales dived inside and outside divergent eddies.

\section{Materials}

The data used in this project consist of $38 \mathrm{kHz}$ ADCP data collected during the 2004 and 2005 SWSS surveys. The $38 \mathrm{kHz}$ ADCP ran continuously throughout the 2004 cruise with the exception of a few instances, usually a few hours, when the instrument was turned off while the ship passed within a few $\mathrm{km}$ of sperm whales. The RABI data were 
collected with the same instrument in both 2004 and 2005. The $70 \mathrm{kHz}$ Simrad fishery echosounder used in 2005 was mounted in the transducer moon-pool well of the ship and ran continuously. The companion $38 \mathrm{kHz}$ fishery echosounder was lowered into the water over the side of the ship on a lever arm. Because of load strain on the arm, the ship was usually limited to speeds below 4 knots when that echosounder was deployed. In general, the $38 \mathrm{kHz}$ fishery echosounder was only operated when the ship was moving slowly around groups of whales.

Continuous ADCP records were primarily made during the night. Because the $38 \mathrm{kHz}$ fishery echosounder was able to record more accurately deeper layers of scattering around and below the main DSL, it was primarily used during the day when visual observations of whales were easiest and tagging operations were underway. These instances totaled $24 \%$ of the cruise, or about half the available daytime survey effort. Conversely, the ADCP was used during any survey effort when speeds exceeded 4 knots, and during efforts to follow cruising whales overnight. Because the $38 \mathrm{kHz}$ fishery echosounder was not used at night, the ADCP recorded mostly nighttime acoustic data. However, there are five instances where the ADCP was left on for multiple days in succession recording both day and night information in summer 2005 .

Fisheries echosounders, like the Simrad, are designed to locate organisms in the water column using the reflections of a transmitted signal back from individual organisms. While the ADCP's primary design purpose is to measure ocean currents, it can also measure the reflection of sound off particles in the water to measure relative acoustic backscatter. To avoid interference, the $38 \mathrm{kHz}$ ADCP and the $38 \mathrm{kHz}$ Simrad 
echosounder were not operated at the same time. Therefore, only the $70 \mathrm{kHz}$ data could be compared with the ADCP data collected during the 2005 field season (see Chapter V). A comparison of longitude and latitude positions and time and date allowed the comparison of the concurrent ADCP and Simrad data. A combination of remote sensing from space and measurements from ships were used to define the spatial boundaries of the divergence zone. The depth of the $15^{\circ} \mathrm{C}$ isotherm (found using XBT temperature profiles) is a useful proxy for defining upwelling regions subsurface $\left(15^{\circ} \mathrm{C}<180 \mathrm{~m}\right)$ and for the opposite, warm core eddy condition $\left(15^{\circ} \mathrm{C}>250 \mathrm{~m}\right)$. A complete list of instrumentation used in this thesis can be found in Table 1.

TABLE 1 . Summary of instrumentation used in thesis.

\begin{tabular}{|l|l|l|}
\hline Name & Use & Details \\
\hline $\begin{array}{l}\text { Surveyor Manufacturer's } \\
\text { prototype, s/n } 0000\end{array}$ & $\begin{array}{l}\text { Record relative acoustic } \\
\text { backscatter intensity }\end{array}$ & $\begin{array}{l}\text { 3-second ping interval, } \\
16 \text { meters depth bins, } \\
\text { starting 33m below the } \\
\text { surface } \\
\text { Short term average: 5 } \\
\text { minute intervals }\end{array}$ \\
\hline $\begin{array}{l}\text { Simrad 70 kHz and } \\
38 \mathrm{kHz} \text { fishery echosounders }\end{array}$ & $\begin{array}{l}\text { Record echo amplitude } \\
\text { backscatter }\end{array}$ & $\begin{array}{l}\text { Processed into 1 meter } \\
\text { bins beginning at 33 } \\
\text { meters }\end{array}$ \\
\hline $\begin{array}{l}\text { Expendable Bathythermograph } \\
\text { (XBT) }\end{array}$ & $\begin{array}{l}\text { Subsurface temperature } \\
\text { profiles }\end{array}$ & $\begin{array}{l}\text { Deployed along track at } \\
\text { about 10 nautical mile } \\
\text { intervals } \\
82 \text { XBT deployed 2005 }\end{array}$ \\
\hline $\begin{array}{l}\text { Recordings made by towed } \\
\text { passive hydrophone array system }\end{array}$ & $\begin{array}{l}\text { Record sperm whale } \\
\text { vocalizations }\end{array}$ & $\begin{array}{l}\text { Recording constantly } \\
\text { while deployed. } \\
574 \text { hours over 26.5 days } \\
\text { 27 unique acoustic } \\
\text { contacts in 2005 }\end{array}$ \\
\hline
\end{tabular}


The last set of data collected are the acoustic records of sperm whale clicks recorded during both field seasons. These data were used to create the dive depth profiles, which were compared between locations for analysis of dive depths. I also examined the relationship between sperm whale dive depth and bottom depth. I investigated whether whale dive depths are independent of bottom depths, or if there appears to be a standard dive distance from the bottom that exists independent of overall depth. This potential relationship might help explain the foraging behavior and preference of feeding grounds.

\section{Methods}

The analysis and processing of the ADCP backscatter data required several computer programs and data proxies. WinADCP (a manufacturer supplied software package) was used to convert the raw data files into short-term average (STA) files consisting of 5minute averages of the raw data, partitioned into 16-meter vertical depth bins.

In order to compare day and night characteristics, I developed a proxy for isolating night and day data. Because data were collected over 24 hour periods, it was important that all potential vertical migration was complete during the times sampled so the layer would be representative of the isolated DSL. Color plots of the echo amplitude backscatter were examined at $2 \mathrm{AM}$ (to represent night) and $2 \mathrm{PM}$ (to represent day), making sure that the vertical migration of organisms was complete and that the main deep scattering layer was completely separated from the shallow surface scattering layer.

To account for sound attenuation in the water column, I applied a least-squares correction method. Sound attenuation occurs as sound spreads out from the source and is absorbed or scattered as it travels through the water. More specifically, a transmitted sound pulse 
or 'ping' is emitted from a transducer, like the ADCP, and travels through the water column. This 'ping' reflects or scatters off particles in the water. Because of sound attenuation (a combination of scattering, spherical spreading and sound absorption), a particle $100 \mathrm{~m}$ away will have a stronger return than the same particle $500 \mathrm{~m}$ away. This is due to the loss of energy as the pulse moves through the water. To correct for this loss in energy, I calculated the exponential decay constant, which is indicative of how much the initial transmitted signal decreases over distance. To correct the data set for sound attenuation, I used the equation:

$$
\mathrm{A}=\mathrm{A}_{\mathrm{o}} \mathrm{e}^{-\mathrm{kz}}
$$

where $\mathrm{A}$ is the corrected intensity return of the scatterer, $\mathrm{A}_{\mathrm{o}}$ is the observed uncorrected intensity of the pulse, $\mathrm{k}$ is the decay constant, and $\mathrm{z}$ is the depth (distance) at which the observed intensity was recorded.

By correcting the data set for this attenuation, the same size particle should give approximately the same RABI return regardless of distance from the ADCP instrument. This correction procedure allows the comparison of individual depth bins across time and space and also the averaging of intensities over multiple depth bins.

I investigated three specific characteristics of the deep scattering layer: 1) the average depth of occurrence, 2) the average vertical thickness of the layer, and 3) the average relative backscatter intensity (in counts) of the layer (Figure 6). SPSS statistical software was used to perform Student's t-tests to determine statistical differences in the data sets (i.e. between night and day). I also performed a correlation analysis to determine whether night and day scattering intensities were correlated. 
Figure 6 shows examples of the three characteristics of the deep scattering layer that I analyzed. The colored vertical lines extending from the surface to the bottom are times when there was very low signal to high noise recorded by the ADCP. This is due to increases in ship speed, which reduces the resolution of the ADCP creating the observed lines of poor data. The majority of the low signal-to-noise occurrences were due to increases in speed for survey efforts during the cruise to locate whales. At these times, the boat would increase speed to 4-8 knots for 20-30 minutes and then slow down to between 2 and 3 knots for 5-10 minutes to listen for indications of whales. The heavy red line that starts at the surface to the left of the graph and increases in depth to about $1000 \mathrm{~m}$ toward the middle of the graph is the bottom reflection recorded by the ADCP.

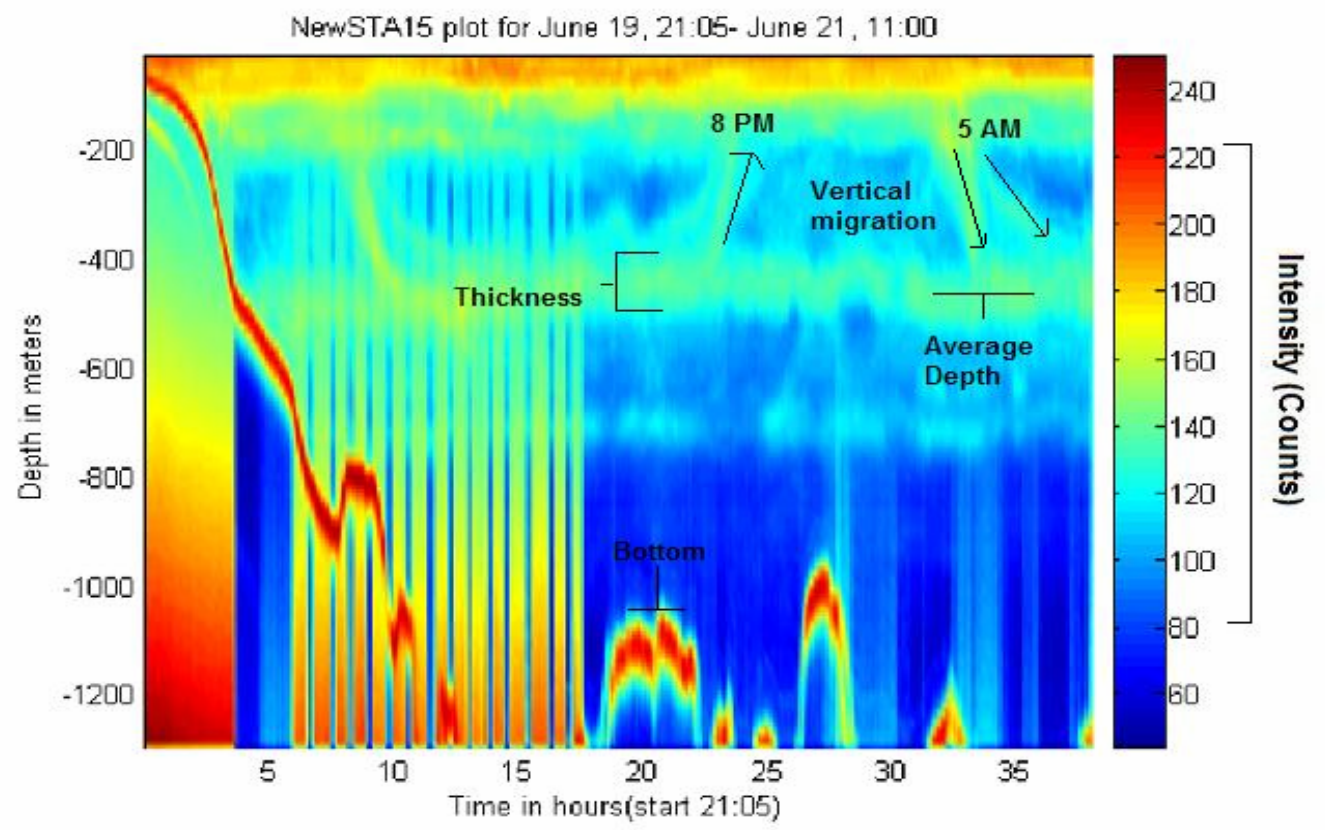

FIG.6. Demonstration of the three scattering layer characteristics to be tested, average depth, vertical thickness, and average intensity in counts. Vertical lines are times of low signal to high noise. Vertical migrations at 8 PM and 5 AM are labeled. The heavy red line is the bottom reflection. 
In order to compare data from different locations, I used subsurface depth measurements of the $15^{\circ} \mathrm{C}$ isotherm to separate the backscatter data into two location classes: divergent or non-divergent. Divergent data are categorized as those XBT launches where the $15^{\circ} \mathrm{C}$ depth is 185 meters or less, and for XBTs that fall between latitude of $26.5^{\circ} \mathrm{N}$ and $27.5^{\circ}$ $\mathrm{N}$ and a longitude of $95^{\circ} \mathrm{W}$ and $96^{\circ} \mathrm{W}$ and have $15^{\circ} \mathrm{C}$ depths of approximately $200 \mathrm{~m}$. I chose this location based on the MODIS satellite surface chlorophyll image that showed the location of the cyclonic eddy (Figure 3) and used the $15^{\circ} \mathrm{C}$ isotherm at $200 \mathrm{~m}$ depth to include variability of the environment. Because there is a frontal area between the divergent and non-divergent areas where the waters are mixing, it is important to try to include temperature variations that may be due to the motion of water between areas near the surface. All other data points outside the divergent area were included in the nondivergent class, when the $15^{\circ} \mathrm{C}$ depth was greater than $220 \mathrm{~m}$.

Night and day ADCP data for the three measured characteristics were included in the XBT data set to ensure sufficient data points for statistical analysis. The ADCP data samples from $2 \mathrm{AM}$ and $2 \mathrm{PM}$ were included into the XBT data set only during times where the same conditions, either divergent or non-divergent, existed before and after the ADCP sample.

To account for night/day migration, the XBT data set was divided into four classifications: Day/divergent, Night/divergent, Day/non-divergent and Night/nondivergent. In addition to t-tests to compare data sets for significant differences, I used ANOVA statistical analysis to examine cross variable effects on the data sets and correlation analysis to look for trends. I attempted to further divide the data set to look at 
divergent, non-divergent and frontal areas. The data were divided based on spatial parameters and global positioning system (GPS) ship track location to isolate areas of the track that crossed continuously from divergent to non-divergent. Not enough frontal data were collected to separate frontal regions for individual analysis. I then used ADCP data to isolate scattering layer samples that characterize divergent and non-divergent areas, and applied the same statistical analysis to look for differences between scattering layer characteristics based on location.

The same general analyses were done on the 2004 ADCP data as the 2005 data. Because the main deep scattering layer in 2004 was often not distinctly separated from the surface scattering layer, it was not possible to evaluate the data set based on the same statistical tests done on the 2005 data. Instead, the goal was to define the vertical range of the overall scattering layer and document the depth to the bottom of the scattering layer for comparison to the 2005 data. While some examples of a discrete main deep scattering layer were isolated from the 2004 data, there were not enough realizations for a meaningful day-night statistical comparison. 


\section{CHAPTER III}

\section{ANALYSIS OF 38 KHZ ADCP BACKSCATTER DATA IN THE WESTERN GULF OF MEXICO COLLECTED DURING SUMMER 2005}

\section{Introduction}

From GulfCet I and II ship and aerial surveys done in the Gulf of Mexico (Baumgartner et al., 2001; Wormuth et al., 2000; Davis et al., 2002), connections between locations of sperm whale sightings and their proximity to large-scale circulation features were observed. In general, the majority of sightings occurred in or along the boundaries of cold-core, cyclonic eddies (Davis et al., 2002). Baumgartner et al. (2001) compared the $15^{\circ} \mathrm{C}$ isotherm depth and locations of sperm whale sightings. They found that where the $15^{\circ} \mathrm{C}$ isotherm depth was greater than $200 \mathrm{~m}$, the sperm whale sighting rate was one quarter that of areas where the isotherm depth was shallower than $200 \mathrm{~m}$. This indicates a preference for whales to occupy areas of upwelling associated with cyclonic systems.

In order to further explore this trend in sightings, Wormuth et al. (2000) performed net trawls in several eddy locations as they monitored the upper 300 meters using a $153 \mathrm{kHz}$ ADCP. They reported greater zooplankton biomass samples in net tow samples taken in cyclonic areas, as well as higher numbers of cephalopod paralarvae in these areas.

Although these are not the size organisms that sperm whale prey on, they are indicators of a productive system containing juvenile prey items. These juveniles also provide food for larger organisms, some of which could be found at depths where they would be sperm whale prey items. These findings may help explain why sperm whales appear to prefer certain locations based on physical processes. 
In order to offer a more complete answer to why whales prefer certain features, it is necessary to explore more than just the upper layers of the water column. Sperm whales, traditionally, are believed to feed on large, deep living squid (Clarke, 1996). While net trawls are able to sample these depths, larger, faster organisms have the ability to avoid nets. As a result, net trawls often do not collect a representative sample of the organisms present at a given depth (John Wormuth, communication). Kaltenberg (2004) showed that a ship mounted $38 \mathrm{kHz}$ ADCP is capable of observing scattering intensities to the depth of approximately $800 \mathrm{~m}$ when the ship speed is less than 3 knots, and that it is possible to isolate strong scattering layers deep in the water column. She speculated the anomalies might represent aggregations of large squid or large fish that the whales may be hunting at depth. While an ADCP instrument is not capable of isolating a scattering profile for individual organisms, it is capable of representing the volume scattering layer at depth. By analyzing characteristics of the main deep scattering layer among locations representing cyclonic eddies and non-cyclonic areas, it may be possible to distinguish specific characteristics to help explain why sperm whales show preference to these areas of upwelling over other areas.

\section{Results}

The focus for the analysis of the 2005 data set is to quantify differences in the main deep scattering layer between the cyclonic eddy and the two anti-cyclones on either side. These differences are based on characteristics of depth and strength of the main deep scattering layer. 
As an initial test for differences in hypothesized areas of divergence and non-divergence, I used temperature data from the XBT profiles to compare average temperature of the main scattering layer from points within the divergent area and points within the nondivergent area. The comparison revealed significantly lower temperatures within the divergent area. Temperatures at the center of the main DSL averaged $8^{\circ} \mathrm{C}$ while temperatures in the feature in the non-divergent area were $10^{\circ} \mathrm{C}$. This confirmed that shoaling of the $15^{\circ} \mathrm{C}$ isotherm in cyclones extended to the $400-600 \mathrm{~m}$ depths of the main DSL, which I hypothesize, has an effect on characteristics of the scattering layer.

The first analysis of ADCP data tested whether there was a change in main deep scattering layer characteristics between night and day. Three characteristics were assessed; the average depth of the scattering layer, the average vertical thickness of the layer, and the average scattering intensity of the layer. The initial test was a KolmogorovSmirnov test for normality, which showed all three characteristics, both night and day, to be normally distributed $(\mathrm{P}<0.05)$ shown in Table 2 . The ADCP data were divided into two data sets, night and day with 16 ADCP profiles per data set.

TABLE 2. Results of the Kolmogorov-Smirnov parametric test of normal distribution for the ADCP data sets. Data are considered to have a normal distribution if $\mathrm{P}>0.05$.

\begin{tabular}{|l|c|c|c|c|c|c|}
\hline & $\begin{array}{c}\text { Night } \\
\text { intensity }\end{array}$ & $\begin{array}{c}\text { Night } \\
\text { depth }\end{array}$ & $\begin{array}{c}\text { Night } \\
\text { thickness }\end{array}$ & $\begin{array}{c}\text { Day } \\
\text { intensity }\end{array}$ & $\begin{array}{c}\text { Day } \\
\text { depth }\end{array}$ & $\begin{array}{c}\text { Day } \\
\text { thickness }\end{array}$ \\
\hline $\mathrm{N}$ & 16 & 16 & 16 & 16 & 16 & 16 \\
\hline $\begin{array}{l}\text { Kolmogorov- } \\
\text { Smirnov P }\end{array}$ & .64 & .65 & .80 & .59 & .99 & .77 \\
\hline
\end{tabular}


The next test assessed whether these characteristics were significantly different depending on the time of day (significance at the $\mathrm{P}<0.05$ ).

I based the analysis on both the $\mathrm{P}$ value for significance, but, also on the range of the $95 \%$ confidence intervals. I specifically looked for a complete separation of confidence intervals for night and day data sets. The complete separation provided confidence that the data sets were truly statistically different and no false assumptions were made. The extra caution in analysis was especially important given the small sample size of the data sets being analyzed. Results of the t-test showed that there was no significant difference between night and day average scattering layer depths (Figure 7), although the mean nighttime depth of the DSL showed more variability. This is most likely attributable to the vertical migration of some scatterers to shallower depths while others remained at depth (Davis et al., 2002). The mean daytime DSL depth was generally identical to that of the night DSL (see Table 3).

TABLE 3. T-test results of the night/day comparison of main deep scattering layer depth.

\begin{tabular}{|l|c|c|c|c|}
\hline & $\mathrm{N}$ & Mean & $\begin{array}{c}\text { Std. } \\
\text { Deviation }\end{array}$ & $\begin{array}{c}\text { Std. Error } \\
\text { Mean }\end{array}$ \\
\hline $\begin{array}{l}\text { Night } \\
\text { Depth }\end{array}$ & 16 & 487.0 & 21.8 & 5.4 \\
\hline $\begin{array}{l}\text { Day } \\
\text { Depth }\end{array}$ & 16 & 488.5 & 15.6 & 3.9 \\
\hline
\end{tabular}




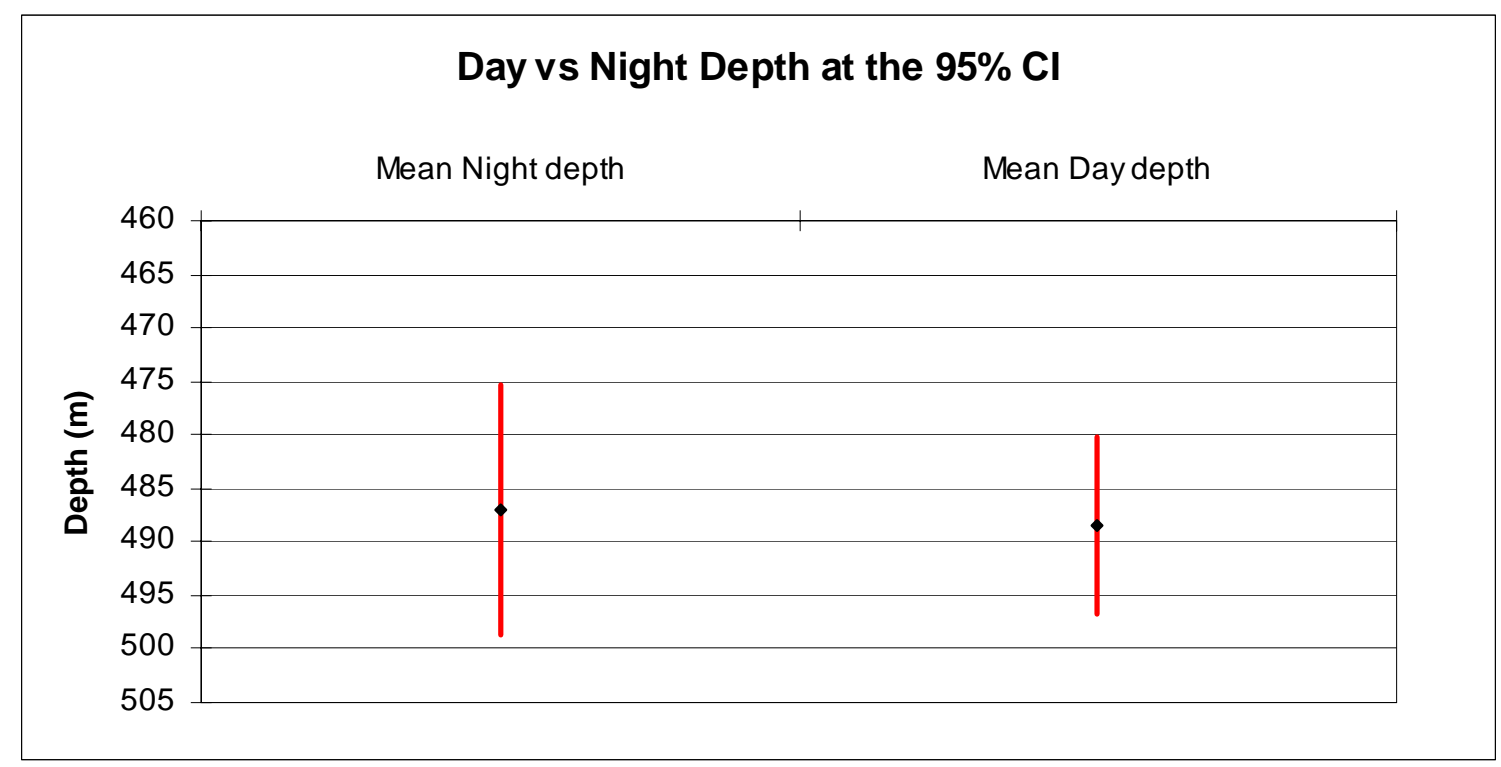

FIG.7. Graphical representation of the t-test results for main deep scattering layer mean depth shown in Table 3. Red lines indicated 95\% confidence interval. Black diamonds indicate mean.

Analysis of results of the T-tests for main DSL thickness and main DSL intensity, shown in Tables 4 and 5, show a significant difference between night and day. Figures 8 and 9 show a separation of $95 \%$ confidence intervals where both thickness and intensity increase during the day and decrease at night. The red lines on the graph represent the range of the $95 \%$ confidence interval as indicated on the graph and the black diamonds represent the mean of the data set. Results are most likely explained by day/night vertical migration of the organisms living in the DSL (see Chapter III discussion). 
TABLE 4. T-test results of night and day comparison for main deep scattering layer thickness.

\begin{tabular}{|l|c|c|c|c|}
\hline & $\mathrm{N}$ & Mean & $\begin{array}{c}\text { Std. } \\
\text { Deviation }\end{array}$ & $\begin{array}{c}\text { Std. Error } \\
\text { Mean }\end{array}$ \\
\hline $\begin{array}{l}\text { Night } \\
\text { Thickness }\end{array}$ & 16 & 76.0 & 21.5 & 5.4 \\
\hline $\begin{array}{l}\text { Day } \\
\text { Thickness }\end{array}$ & 16 & 100.8 & 28.0 & 7.0 \\
\hline
\end{tabular}

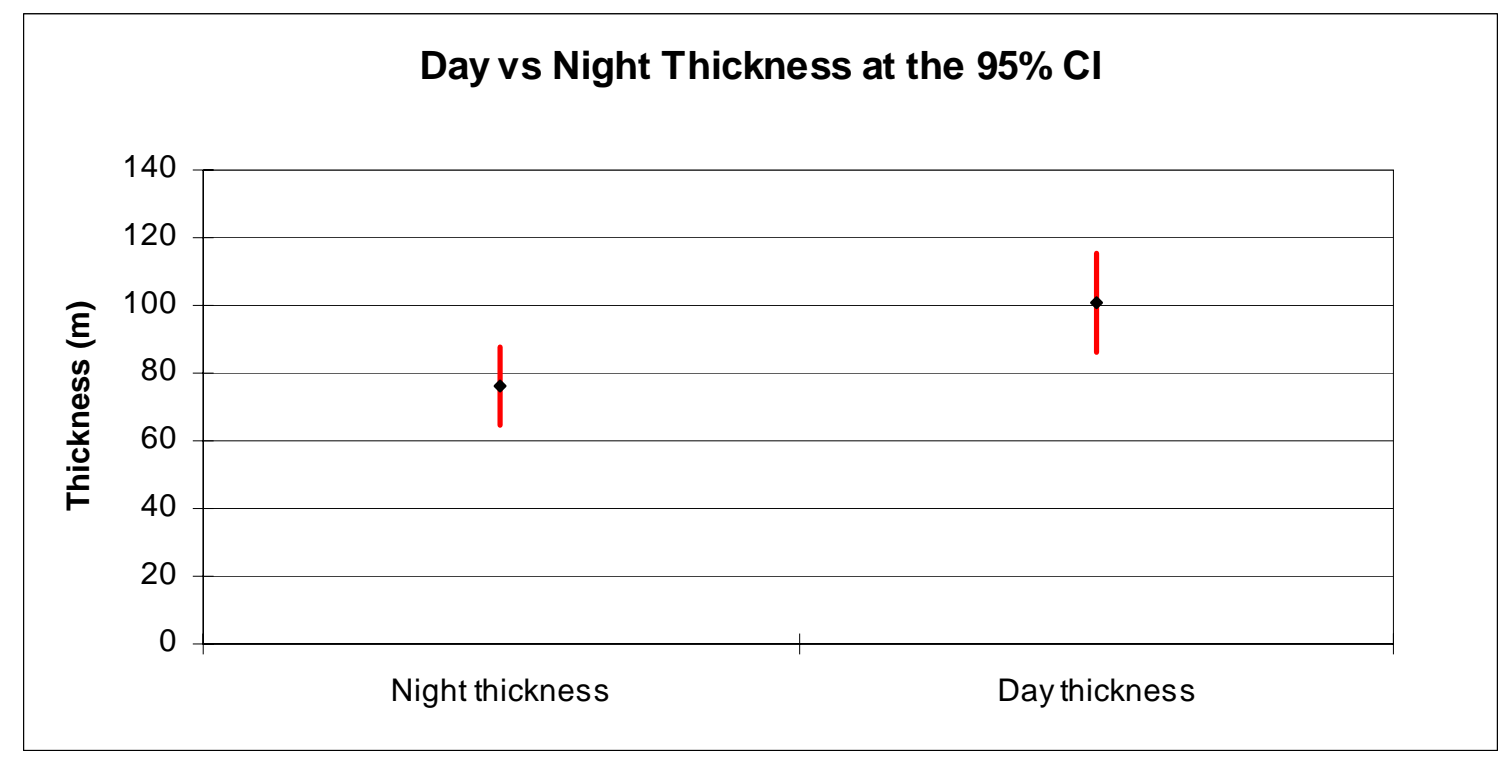

FIG.8. Graphical representation of the t-test results for main deep scattering layer thickness shown in Table 4. Red lines indicated 95\% confidence interval. Black diamonds indicate mean.

TABLE 5. T-test results of night and day comparison for main deep scattering layer intensity.

\begin{tabular}{|l|c|c|c|c|}
\hline & $\mathrm{N}$ & Mean & $\begin{array}{c}\text { Std. } \\
\text { Deviation }\end{array}$ & $\begin{array}{c}\text { Std. Error } \\
\text { Mean }\end{array}$ \\
\hline $\begin{array}{l}\text { Night } \\
\text { Intensity }\end{array}$ & 16 & 133.0 & 2.0 & 0.49 \\
\hline $\begin{array}{l}\text { Day } \\
\text { Intensity }\end{array}$ & 16 & 136.2 & 2.8 & 0.66 \\
\hline
\end{tabular}




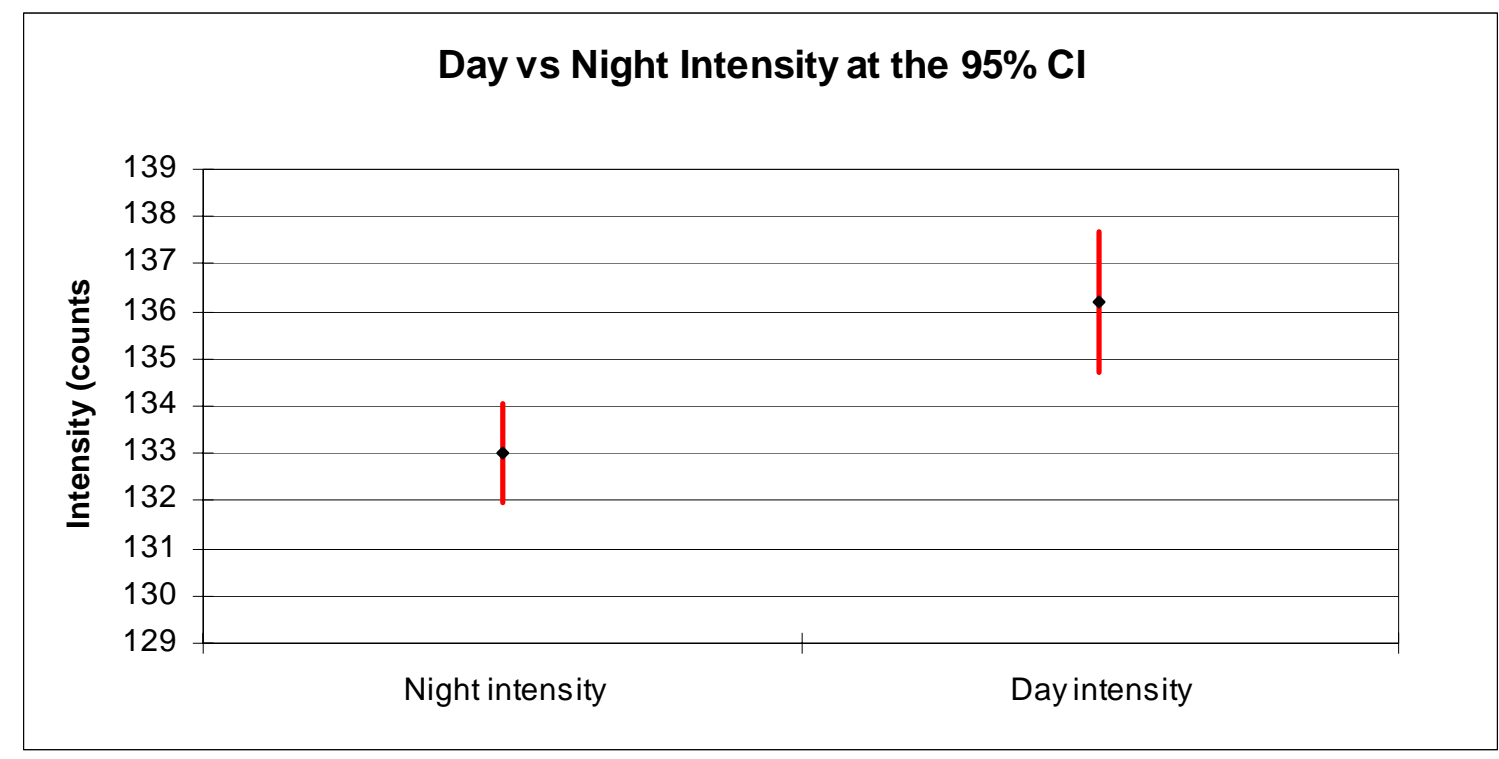

FIG.9. Graphical representation of t-test results for main deep scattering layer intensity shown in Table 5. Red lines indicated 95\% confidence interval. Black diamonds indicate mean.

The results of the t-tests for the three characteristics showed that while mean depth remained constant during night and day observations, mean thickness and mean intensity of the main deep scattering layer were both greater during the day than at night.

The correlation analysis for comparison of characteristics of the main DSL indicated a positive correlation between mean nighttime intensity and average depth (Pearson correlation $=0.518, \mathrm{p}=0.04)$ and between mean nighttime intensity and average thickness (Pearson correlation $=0.532, \mathrm{p}=0.03$ ). Correlation is significant at the $\mathrm{P}<0.05$ level. These results indicate that the mean nighttime intensity varies with the average thickness of the nighttime deep scattering layer. This variance can be partially explained by the thinner layer of scatterers remaining at night after some organisms have migrated upward in the water column. There is no correlation between characteristics during the day, 
indicating that daytime characteristics of the deep scattering layer vary independently of each other.

The next portion of the analysis examined whether location, either inside or outside the cyclonic eddy, had any effect on the main deep scattering layer characteristics. Because time of day had a significant effect on two out of three DSL characteristics, the data were further subdivided into four parts for analysis; Day Divergent (DD), Night Divergent (ND), Day Non-divergent (DN) and Night Non-divergent (NN).

Each of the three DSL characteristics was then tested using a one-sample t-test to see if there were differences between locations inside the cyclonic eddy and locations outside the cyclonic eddy. Due to the small sample size because of residual noise present in the data set, the $90 \%$ confidence interval and a significant $\mathrm{P}$ value of 0.1 were used to account for biological variability and opportunistic data collection.

TABLE 6. T-test results for divergent/non-divergent main deep scattering layer depth comparison.

\begin{tabular}{|l|c|c|c|c|}
\hline & $\mathrm{N}$ & Mean & $\begin{array}{c}\text { Std. } \\
\text { Deviation }\end{array}$ & $\begin{array}{c}\text { Std. Error } \\
\text { Mean }\end{array}$ \\
\hline $\begin{array}{l}\text { Day Div } \\
\text { Depth }\end{array}$ & 14 & 487.3 & 16.4 & 4.4 \\
\hline $\begin{array}{l}\text { Night Div } \\
\text { Depth }\end{array}$ & 15 & 490.6 & 21.2 & 5.5 \\
\hline $\begin{array}{l}\text { Day Non } \\
\text { Depth }\end{array}$ & 11 & 484.6 & 30.6 & 9.6 \\
\hline $\begin{array}{l}\text { Night Non } \\
\text { Depth }\end{array}$ & 13 & 477.3 & 17.5 & 4.8 \\
\hline
\end{tabular}




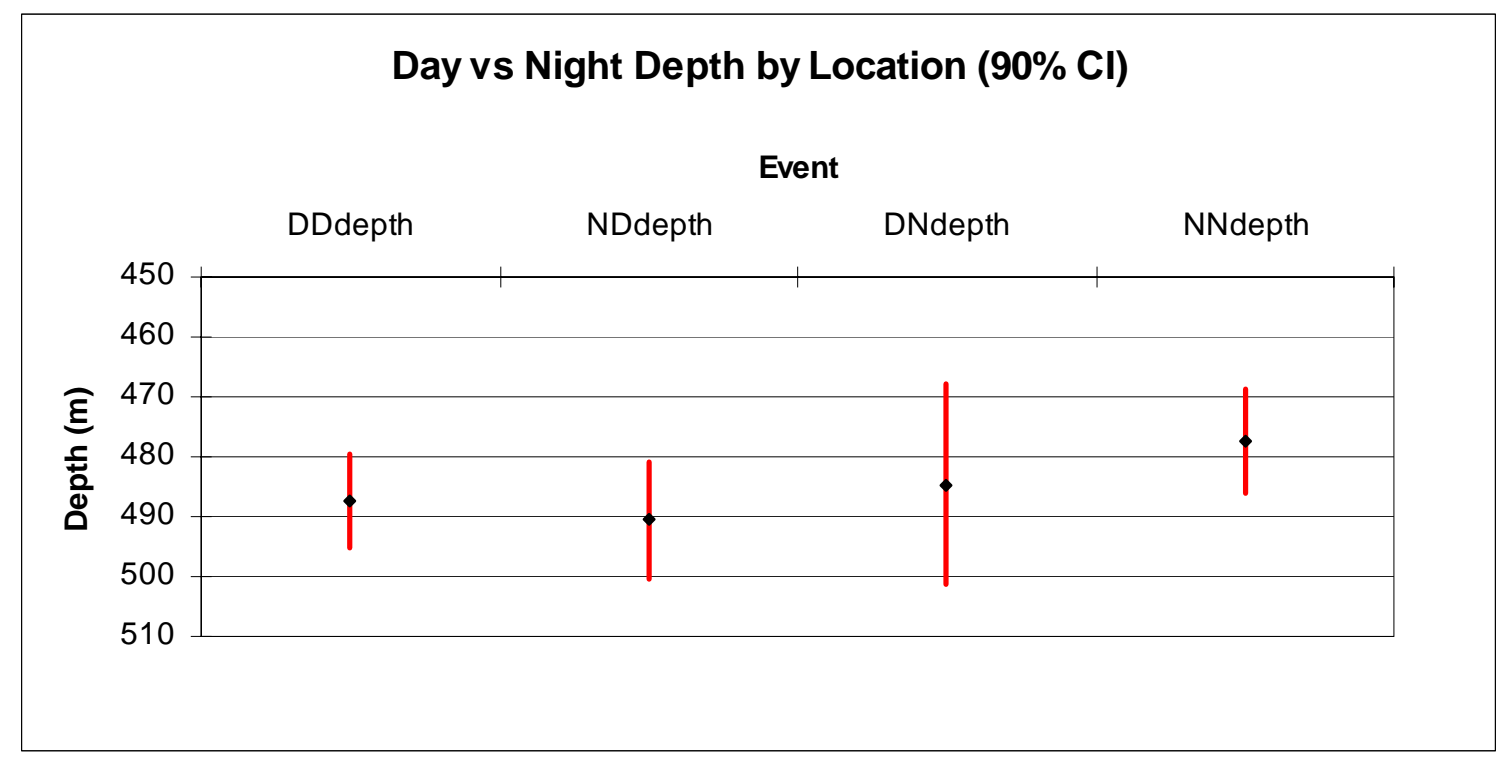

FIG.10. Graphical representation of the $90 \%$ confidence interval for t-test results of the main deep scattering layer depth comparison by location shown in Table 6. Red lines indicated $90 \%$ confidence interval. Black diamonds indicate mean.

Results of the comparison for average depth of the mean deep scattering layer showed that there was no significant difference between night and day, as seen in the previous section, and that there was no significant difference in mean depth of the main DSL based on location (Table 6, Figure 10).

The t-tests for mean intensity and mean thickness concurred with the t-test results shown in Tables 4-5 for significant difference between night and day. Mean intensity and mean thickness both increased during the day. There was no significant difference in either mean intensity or mean thickness of the main DSL based on differences in location (see Tables $7 \& 8$ and Figures $11 \& 12$ ). 
TABLE 7. T-test results for divergent/non-divergent main deep scattering layer intensity comparison.

\begin{tabular}{|l|c|c|c|c|}
\hline & $\mathrm{N}$ & Mean & $\begin{array}{c}\text { Std. } \\
\text { Deviation }\end{array}$ & $\begin{array}{c}\text { Std. Error } \\
\text { Mean }\end{array}$ \\
\hline $\begin{array}{l}\text { Day Div } \\
\text { intensity }\end{array}$ & 14 & 136.2 & 2.2 & 0.6 \\
\hline $\begin{array}{l}\text { Night Div } \\
\text { intensity }\end{array}$ & 15 & 133.1 & 2.1 & 0.5 \\
\hline $\begin{array}{l}\text { Day Non } \\
\text { intensity }\end{array}$ & 11 & 136.4 & 3.7 & 1.16 \\
\hline $\begin{array}{l}\text { Night Non } \\
\text { intensity }\end{array}$ & 13 & 131.6 & 2.5 & 0.7 \\
\hline
\end{tabular}

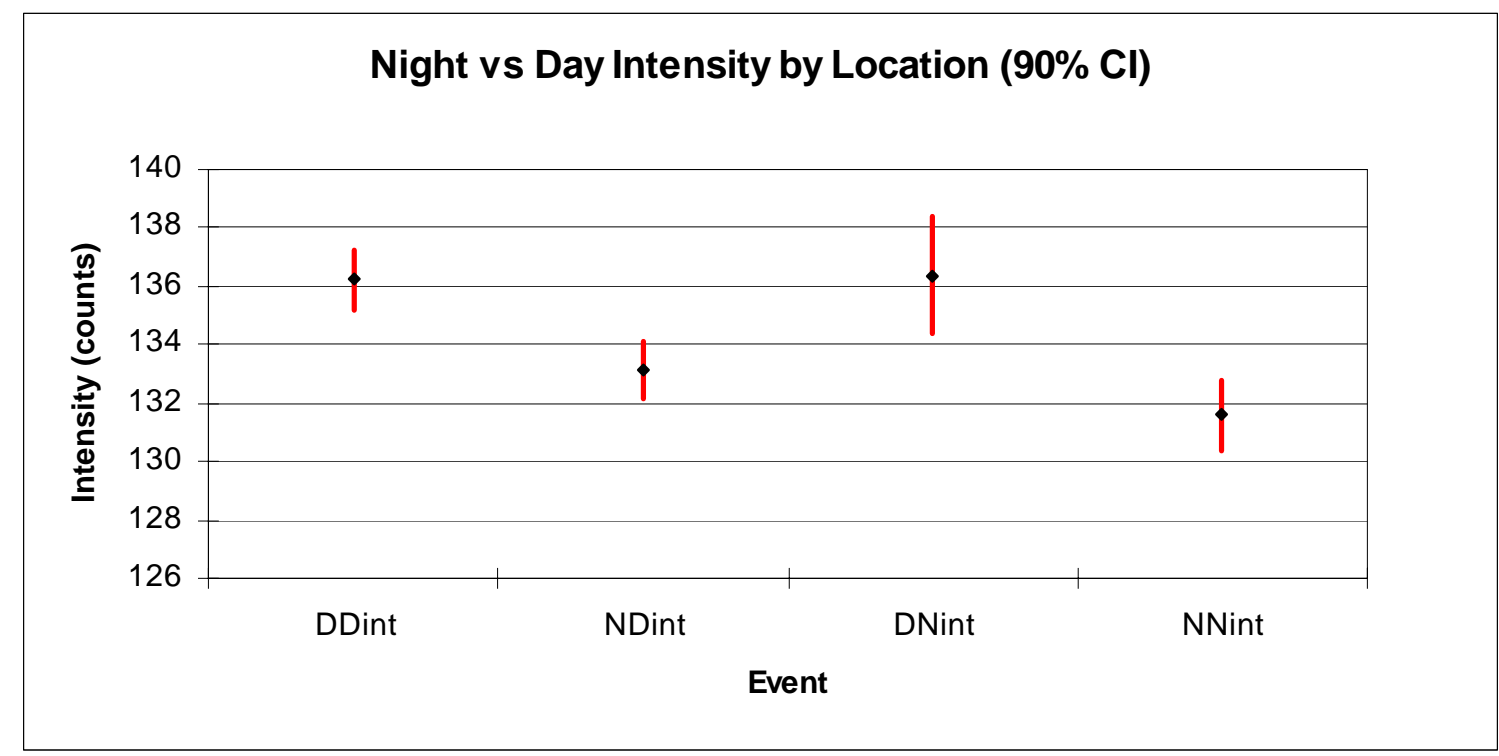

FIG.11. Graphical representation of the $90 \%$ confidence interval for t-test results of the main deep scattering layer intensity comparison by location shown in Table 7 . Red lines indicated $90 \%$ confidence interval. Black diamonds indicate mean. 
TABLE 8. T-test results for divergent/non-divergent main deep scattering layer thickness comparisons.

\begin{tabular}{|l|c|c|c|c|}
\hline & $\mathrm{N}$ & Mean & $\begin{array}{c}\text { Std. } \\
\text { Deviation }\end{array}$ & $\begin{array}{c}\text { Std. Error } \\
\text { Mean }\end{array}$ \\
\hline $\begin{array}{l}\text { Day Div } \\
\text { thickness }\end{array}$ & 14 & 115.2 & 36.3 & 9.7 \\
\hline $\begin{array}{l}\text { Night Div } \\
\text { thickness }\end{array}$ & 15 & 83.2 & 25.1 & 6.5 \\
\hline $\begin{array}{l}\text { Day Non } \\
\text { thickness }\end{array}$ & 11 & 114.9 & 42.2 & 12.7 \\
\hline $\begin{array}{l}\text { Night Non } \\
\text { thickness }\end{array}$ & 13 & 71.4 & 26.6 & 7.4 \\
\hline
\end{tabular}

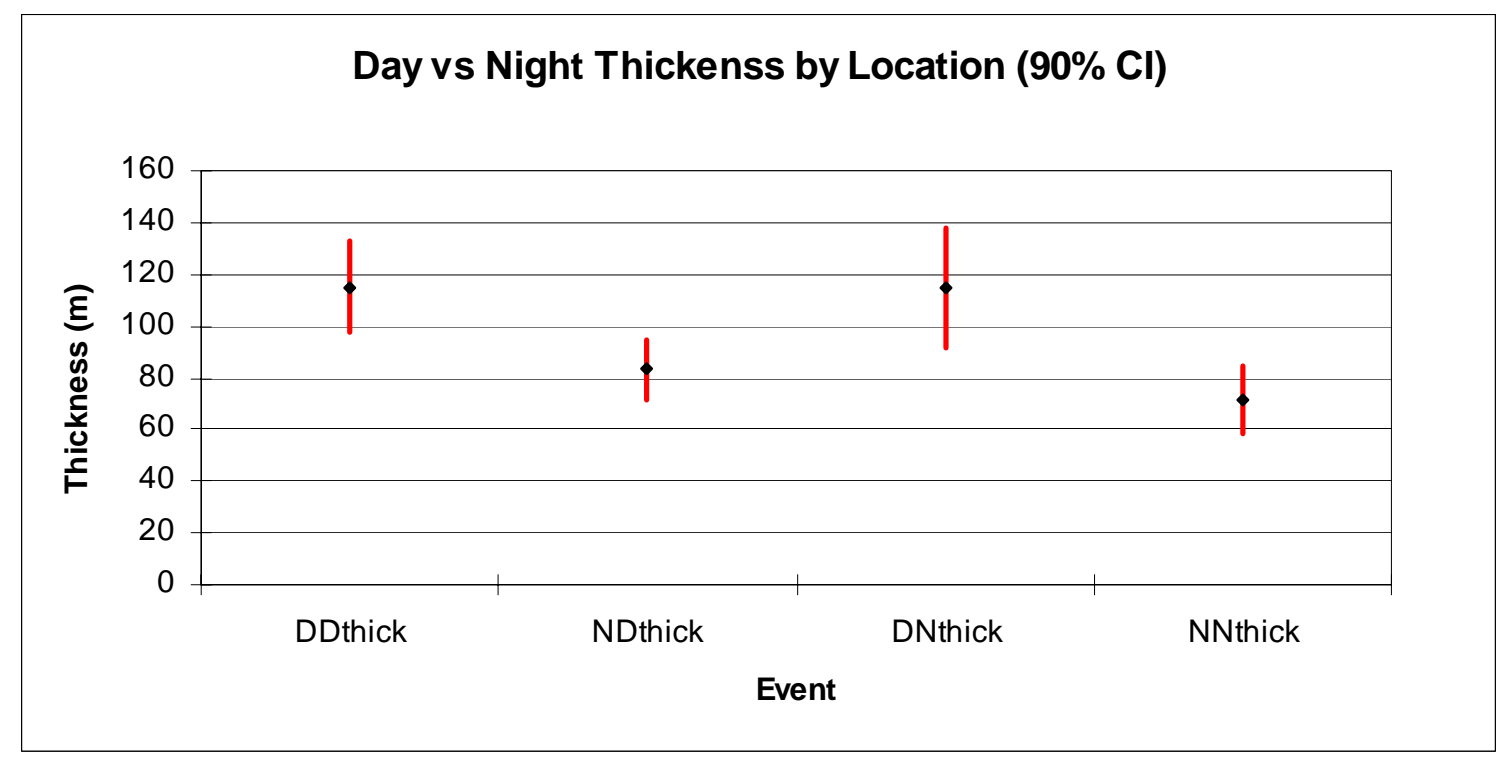

FIG.12. Graphical representation of the $90 \%$ confidence interval for t-test results of the main deep scattering layer thickness comparison by location shown in Table 8. Red lines indicated $90 \%$ confidence interval. Black diamonds indicate mean.

The ANOVA test for factor effects of time of day and location on main deep scattering layer characteristics showed that time of day had a significant effect, but failed to show any significance for combined effects of time and location. The ANOVA also showed 
that there was no independent effect of location on the characteristics of the main deep scattering layer. In further support that location has no significant affect on main DSL characteristics, the Pearson's Correlation analysis showed no correlation between any characteristics during the day. It did, however, show significant correlations between night divergence and night non-divergence characteristics. Night non-divergent intensity was negatively correlated with Night divergent thickness (Pearson correlation $=-0.68, \mathrm{P}$ $=0.01)$ and positively correlated with Night non-divergent thickness (Pearson correlation $=0.57, \mathrm{P}=0.041)$. Night divergent thickness was also negatively correlated with Night non-divergent thickness (Pearson correlation $=-0.60, \mathrm{P}=0.03$ ). The positive correlation between Night non-divergent intensity and Night non-divergent thickness indicates that the nighttime intensity varies with nighttime thickness in non-divergent locations.

\section{Discussion}

Analysis from ship and aerial surveys has shown cold-core eddies are usually associated with increased acoustic backscatter, increased zooplankton and micronekton biomass in trawls, and with cetacean sightings (Zimmerman and Biggs, 1999; Wormuth et al., 2000; Baumgartner et al., 2001; Ressler, 2001; Davis et al., 2002; Ressler and Jochens, 2003; Tynan et al., 2004). This association has been attributed to the doming of cold mid-water and the associated influx of deep nutrient rich water into the more oligotrophic surface waters in the Gulf of Mexico (Zimmerman and Biggs, 1999; Davis et al., 2002). There are also data to document that a strong daily migration occurs between the main daytime deep scattering layer and the surface, which can be seen with the $38 \mathrm{kHz}$ ADCP (Kaltenberg, 2004), as well as a diel migration of a shallower, epipelagic scattering layer 
at approximately $200 \mathrm{~m}$ (Duvall and Christiansen, 1946; Franceschini et al., 1970; Hays et al., 2001) which has been observed with higher frequency ADCPs and with smokypaper records from non-digital echosounders.

The null hypothesis for no change in DSL metrics between night and day was accepted for some, but not all DSL characteristics. Although the average depth of the layer did not change between night and day, the nighttime DSL clearly extends over a greater range of vertical depth bins than that of the daytime. Both mean intensity and mean thickness of the main DSL increased during the day, supporting the hypothesis that organisms are migrating to the surface at night, potentially to feed (Hays et al., 2001), and then down during the day to avoid larger visual predators. Figure 6 shows this daily migration. The deep scattering layer is connected to the surface by migrating organisms twice a day, which can be seen by the green line extending from the deep scattering layer to the surface at approximately 8 PM and 5 AM.

Kaltenberg (2004) noted deeper secondary deep scattering layers more frequently in cyclonic than anticyclonic circulation events. Visual comparison of ADCP echo amplitude plots (not shown) showed that 9 of out of 16 plots from 2005 contained secondary scattering layers either directly below the main DSL or at depths of approximately $800 \mathrm{~m}$. Unlike Kaltenberg (2004), these secondary layers were equally apparent in both cyclonic and anticyclonic plots. The layers were also continuous across several days that transitioned from cyclonic to anticyclonic conditions or vice versa. While these secondary layers are apparent and may have an effect on where sperm 
whales are diving, they do not seem to be any more common in cyclones than in adjacent areas of the continental margin.

Limited research has been done in the far western Gulf of Mexico on scattering layers, particularly the main deep scattering layer. The 2005 cruise was the first time a $38 \mathrm{kHz}$ ADCP has been used to look at acoustic volume backscatter in the northwestern Gulf. In summers of 2002 and 2003, the survey focus was on the central and eastern parts of the northern Gulf of Mexico (Kaltenberg 2004). As a consequence, there is little with which to compare current western results. There have, however, been multiple studies comparing the productivity and upper scattering layer biomass densities among different cyclonic events. Most applicable are the comparisons between productivity in cold-core upwelling eddies and frontal boundaries and warm-core or loop current eddies (Zimmerman and Biggs, 1999; Wormuth et al., 2000; Baumgartner et al., 2001; Davis et al., 2002; Ressler and Jochens 2003; Tynan et al., 2004). Biggs and Ressler (2001) nicknamed these upwelling locations as 'oases' or 'hot spots' of production. The results for the comparison between divergent and non-divergent locations did not reveal a strong separation between locations as was seen in previous studies. However, the comparison in 2005 was done on the deep scattering layer, not in the upper $200 \mathrm{~m}$, which may, generally, show less variability between locations.

Investigation of vertical ADCP current plots shows that currents created by the interactions of the cyclonic and anti-cyclonic eddies reached below surface depths and in some cases down to the depths of the man DSL. However, currents within the cyclonic and anti-cyclonic eddies did not penetrate down to the depths of the deep scattering layer 
which may explain why there were no significant differences between scattering layer characteristics as a result of location either within or outside of the cyclonic eddy.

Figure 13 shows the currents along the ship track between $96^{\circ} \mathrm{W}$ and $94^{\circ} \mathrm{W}$ (see Figure 4 for surface current plot). The top box shows the ship track. The middle box shows the vertical section of current speed from the surface to $900 \mathrm{~m}$ depth. The colors represent the speed of the water currents during that time. Warmer (red) colors indicate higher current speed and cooler (blue) colors indicate lower current speed. This is shown in the color bar in the third box at the bottom of the figure. The increased currents at the surface near the left and right edge of the plot are from areas where the cyclone and anti-cyclone were located. The depth penetration of the currents shows the vertical range of these eddies. These regions are thought to be areas of higher upwelling and could ultimately be what attracts sperm whales to areas along the peripheries of cyclonic eddies. 

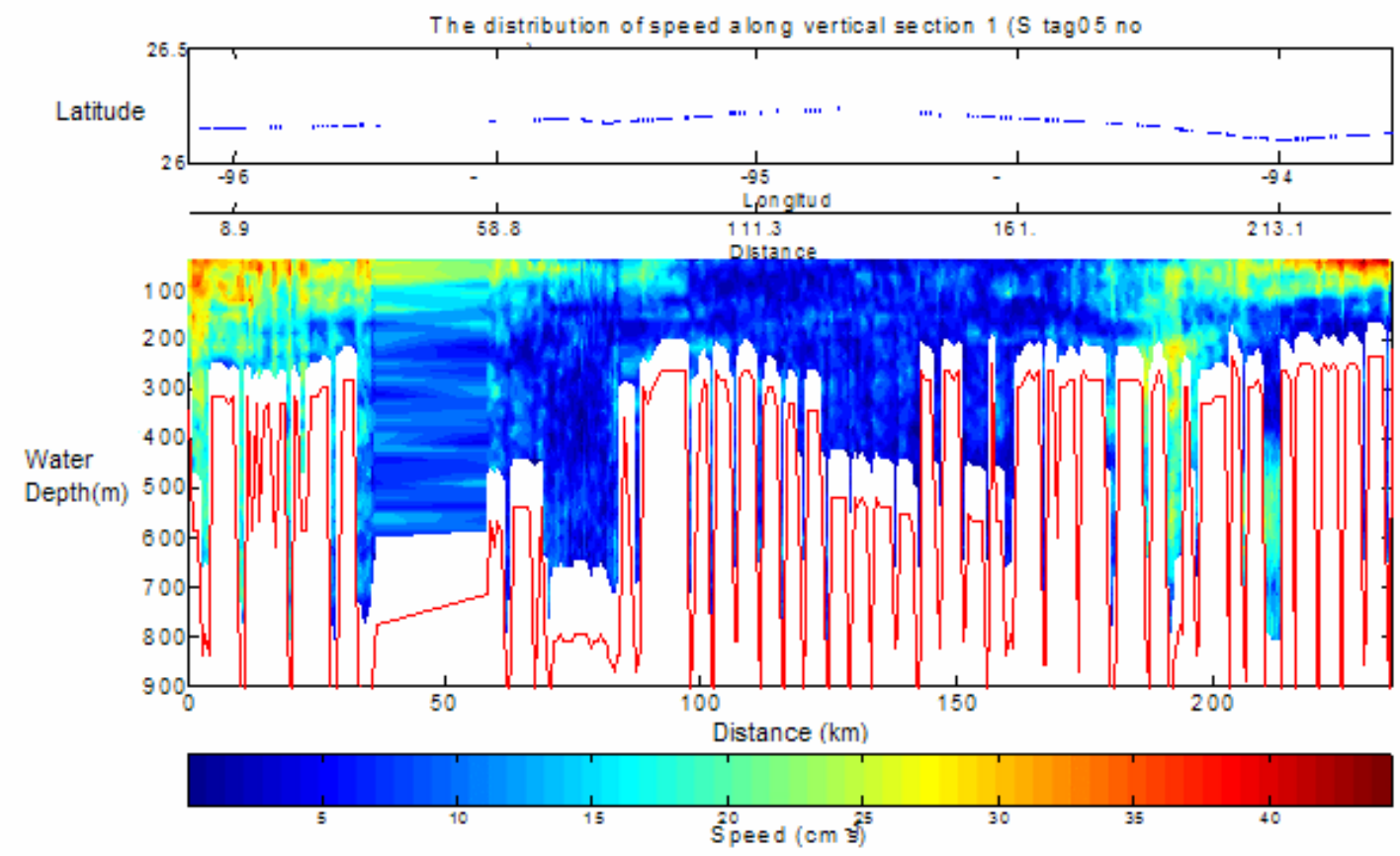

FIG.13. ADCP current plot of the recorded data from the horizontal ship track from $96^{\circ}$ $\mathrm{W}$ to $94^{\circ} \mathrm{W}$. The top box shows the ship track. The middle box shows the vertical section of water from the surface to $900 \mathrm{~m}$ depth. The colors represent the speed of the water currents. Areas of white are times or depths when no good data were recorded. The thin red line is the bottom. (Plot provided by X. Zhang, TAMU).

Multiple studies including GulfCet I and II, have shown that sperm whales and other cetaceans are often observed in frontal zones or areas where two systems converge (Jochens et al., 2006; Jochens and Biggs, 2006b). Quantifying the differences between these productive cold-cores eddies and their frontal boundaries produce a strong link between preferred feeding grounds of whales and of their preferred prey items as discussed in studies by Wormuth et al. (2000). The comparison of deep scattering layer characteristics between the divergent area and the frontal zone showed no differences. Because the primary goal of the 2005 SWSS cruise was to tag sperm whales in the western Gulf, multiple transects across the frontal zone were not done. While there were sets of data containing frontal crossings, visual examination of plots showed no 
noticeable change from divergent to non-divergent areas. Characterization of preferential locations for sperm whale aggregation is an important area of investigation for understanding the foraging behavior of sperm whales and for characterizing areas of high abundance of prey, which attract sperm whales to the area. This is an area that needs to be more fully sampled and explored in conjunction with continued studies of deep scattering layer characteristics and variability. 


\section{CHAPTER IV \\ COMPARISON OF BACKSCATTER DATA \\ BETWEEN 2004 AND 2005}

\section{Introduction}

In this chapter, I analyze the acoustic backscatter data collected during the 2004 northeast and central Gulf survey and compare the scattering characteristics at different geographical locations (Figure 14). During the 2002-2004 SWSS seasons, R/V Gyre cruises searched for sperm whales along the 1000-meter isobath in the central and northeast Gulf of Mexico. To better understand why there were local aggregations of whales at different locations, I compare backscattering from both summers for areas where whales were encountered. The summer 2004 cruise collected relative acoustic backscatter intensity using a $38 \mathrm{kHz}$ ADCP and also collected CTD, XBT, and underway temperature, salinity, and chlorophyll fluorescence data. Analyzing both the visual representations of the scattering layer and performing statistical tests looked for trends in similarities and differences between locations and between years for significance.

The most important physical difference affecting this study between locations is the difference in water depth of the areas surveyed. In 2004, while the ship track follows the continental margin, the majority of the ADCP data were collected from an average bottom depth of $800 \mathrm{~m}$. The 2005 data, in contrast, were collected from an average depth of $1000 \mathrm{~m}$ or greater. Another major difference between locations is the physical processes occurring where the majority of sightings were recorded. In 2004, most local aggregations of sperm whales were found seaward of the Mississippi River Delta area, in 
the Mississippi Canyon. The sea surface height plots of this area for 2004 show it was an area of higher sea surface height than the region that whales were found in 2005 .

However, the summer 2004 cruise also transited into the eastern area of the Gulf to explore DeSoto Canyon, a location where large numbers of sperm whales had been spotted in previous years. The DeSoto Canyon area was also the only area surveyed in 2004 in which the water depth often exceeded $800 \mathrm{~m}$ for extended periods of time and had similar bathymetry to the 2005 cruise data. In summer 2004, this area was the location of a strong cyclonic eddy, which created a divergent area similar in size to the 2005 cyclone in the western Gulf where animals were found. However, in summer 2004 sperm whales were rare in the eastern Gulf cyclone.

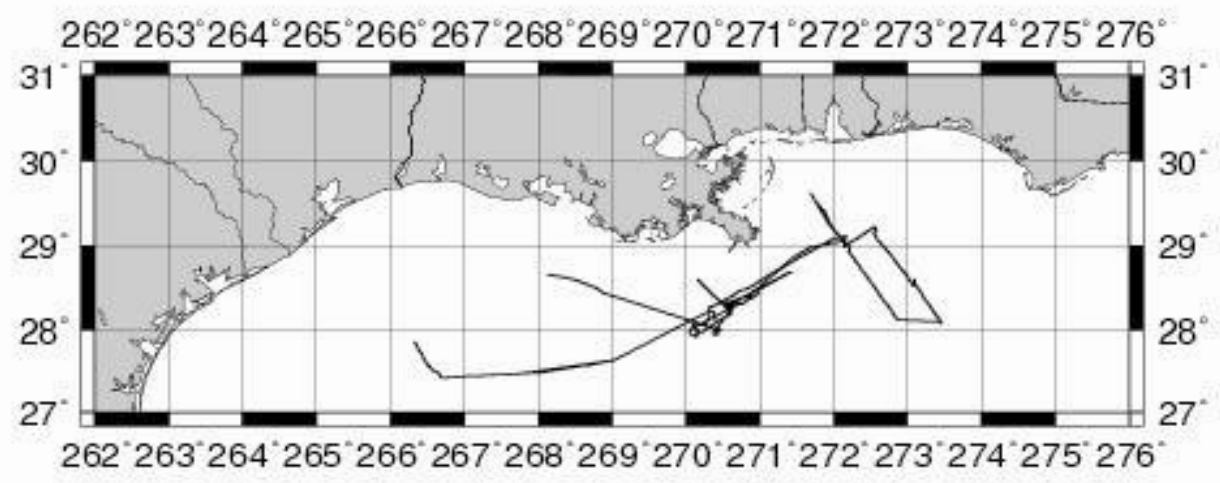

FIG.14. SWSS cruise 2004 ship track in the northeastern Gulf of Mexico.

\section{Results}

The hypotheses tested in this section compare characteristics of the deep scattering layer between SWSS cruise locations in 2004 and 2005. Because the 2005 data showed 
significant differences between some night and day main DSL characteristics, the data from 2004 were also divided into night and day. The data were then tested for normal distribution using a K-S test. The data for day/night comparison of scattering layer depth are all normally distributed $(\mathrm{P}>0.05)$, as is evident in Table 9 .

TABLE 9. Results of One-Sample Kolmogorov -Smirnov test for normal distribution of night/day scattering layer depth data from 2004 and 2005. Normality for this test is defined at $\mathrm{P}>0.05$.

\begin{tabular}{|l|c|c|c|c|}
\hline & 2005 Night & 2005 Day & 2004 Night & 2004 Day \\
\hline $\mathrm{N}$ & 16 & 16 & 14 & 17 \\
\hline Kolmogorov-Smirnov P & 0.77 & 0.93 & 0.68 & 1.01 \\
\hline
\end{tabular}

I performed t-tests to compare whether the average depth of the main DSL was different between night and day. The results are shown in Tables 10 and 11. I used a significance level of $\mathrm{P}<0.1$ rather than $\mathrm{P}<0.05$ because of the small sample size $(\mathrm{n}=14$ to 17 compared to generally accepted 30 or more) and because I recognize there were likely temporal and spatial variability between years. Based on the results of the t-tests, there was no significant difference in mean depth of the bottom of the main DSL between night and day in 2005 or in 2004. In both years the bottom of the main DSL averaged about $540 \mathrm{~m}$ below the surface. Figures 15 and 16 show this graphically. 
TABLE 10. Results of t-test comparing Night and Day mean depth to the bottom of the main DSL in 2005.

\begin{tabular}{|l|c|c|c|c|}
\hline & $\mathrm{N}$ & Mean & $\begin{array}{c}\text { Std. } \\
\text { Deviation }\end{array}$ & $\begin{array}{c}\text { Std. Error } \\
\text { Mean }\end{array}$ \\
\hline Night 2005 & 16 & 525.0 & 28.9 & 7.2 \\
\hline Day 2005 & 16 & 539.0 & 22.5 & 5.6 \\
\hline
\end{tabular}

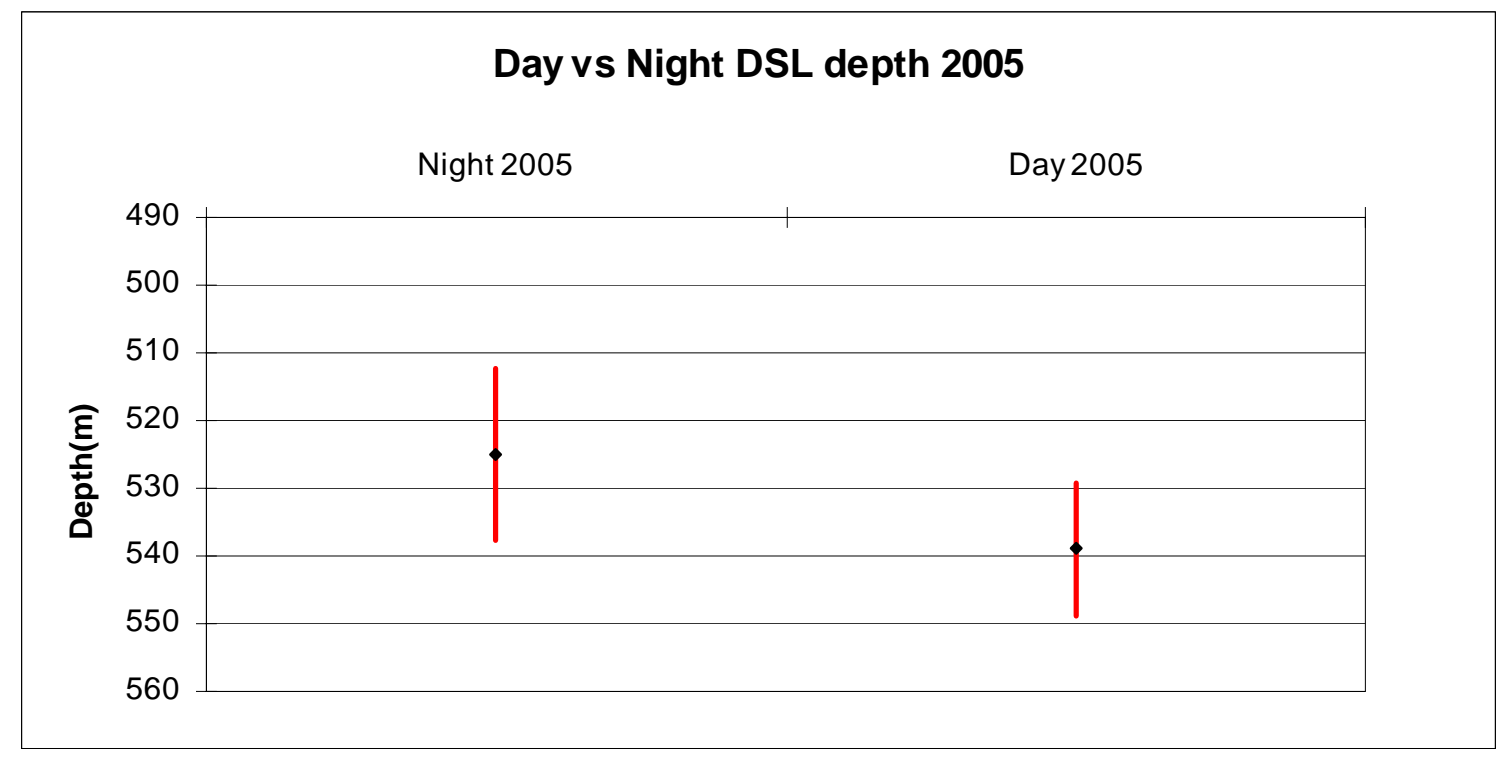

FIG.15. Graphical representation of t-test results for Day/Night comparison of main DSL depth in 2005 shown in Table 10. Red lines indicated 90\% confidence interval. Black diamonds indicate mean.

TABLE 11. Results of t-test comparing Night and Day mean depth to the bottom of the main DSL for 2004.

\begin{tabular}{|l|c|c|c|c|}
\hline & $\mathrm{N}$ & Mean & $\begin{array}{c}\text { Std. } \\
\text { Deviation }\end{array}$ & $\begin{array}{c}\text { Std. Error } \\
\text { Mean }\end{array}$ \\
\hline Night 2004 & 14 & 532.4 & 47.0 & 12.6 \\
\hline Day 2004 & 17 & 554.4 & 72.2 & 17.5 \\
\hline
\end{tabular}




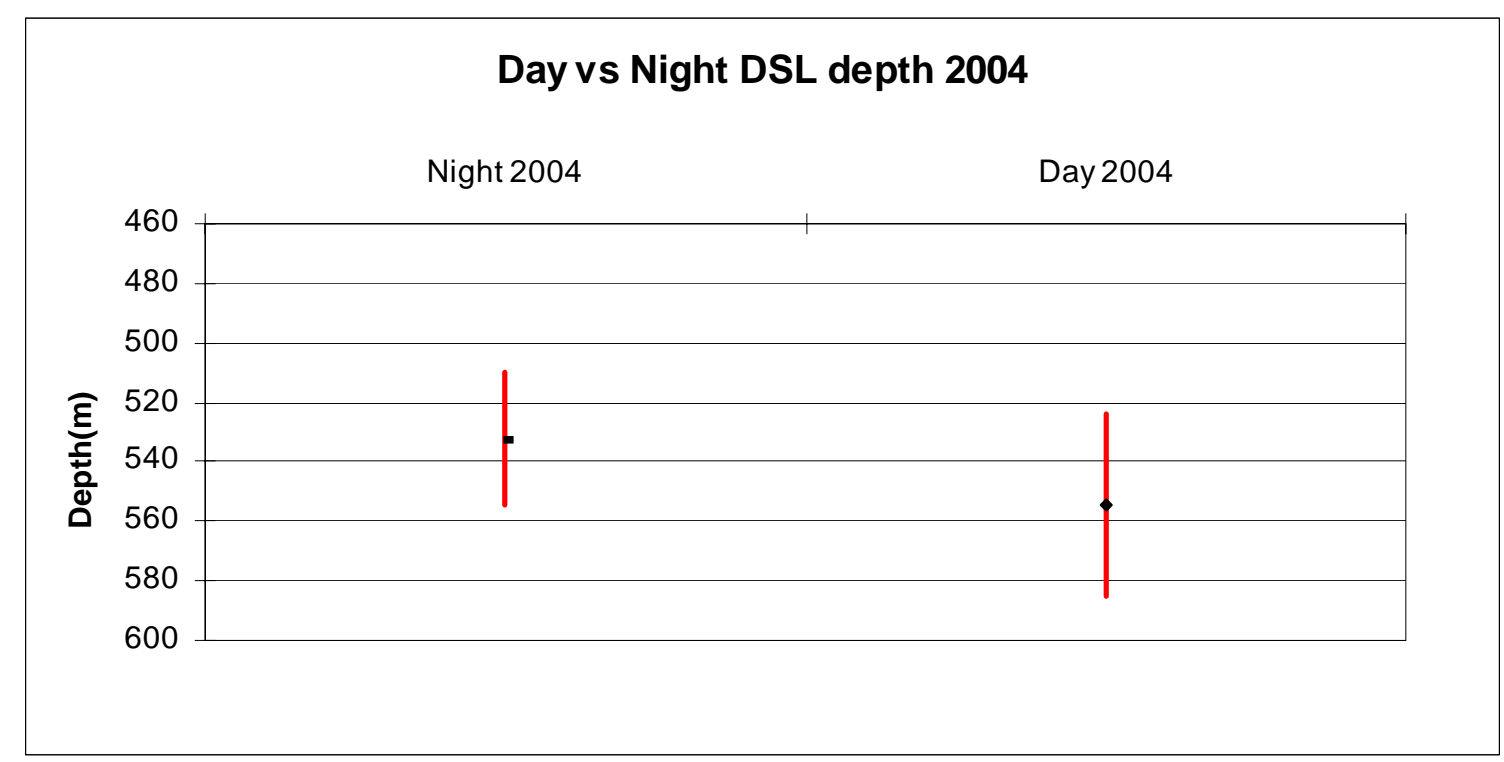

FIG.16. Graphical representation of t-test results for Day/Night comparison of main DSL depth in 2004 shown in Table 11. Red lines indicated 90\% confidence interval. Black diamonds indicate mean.

The next test for differences between locations compared night and day data between years. Both the night and day comparison of main DSL bottom depths showed a complete overlap of confidence intervals at the 0.1 level, indicating that there was no significant difference between the depth of the layer based on location (Figures 17\&18). 


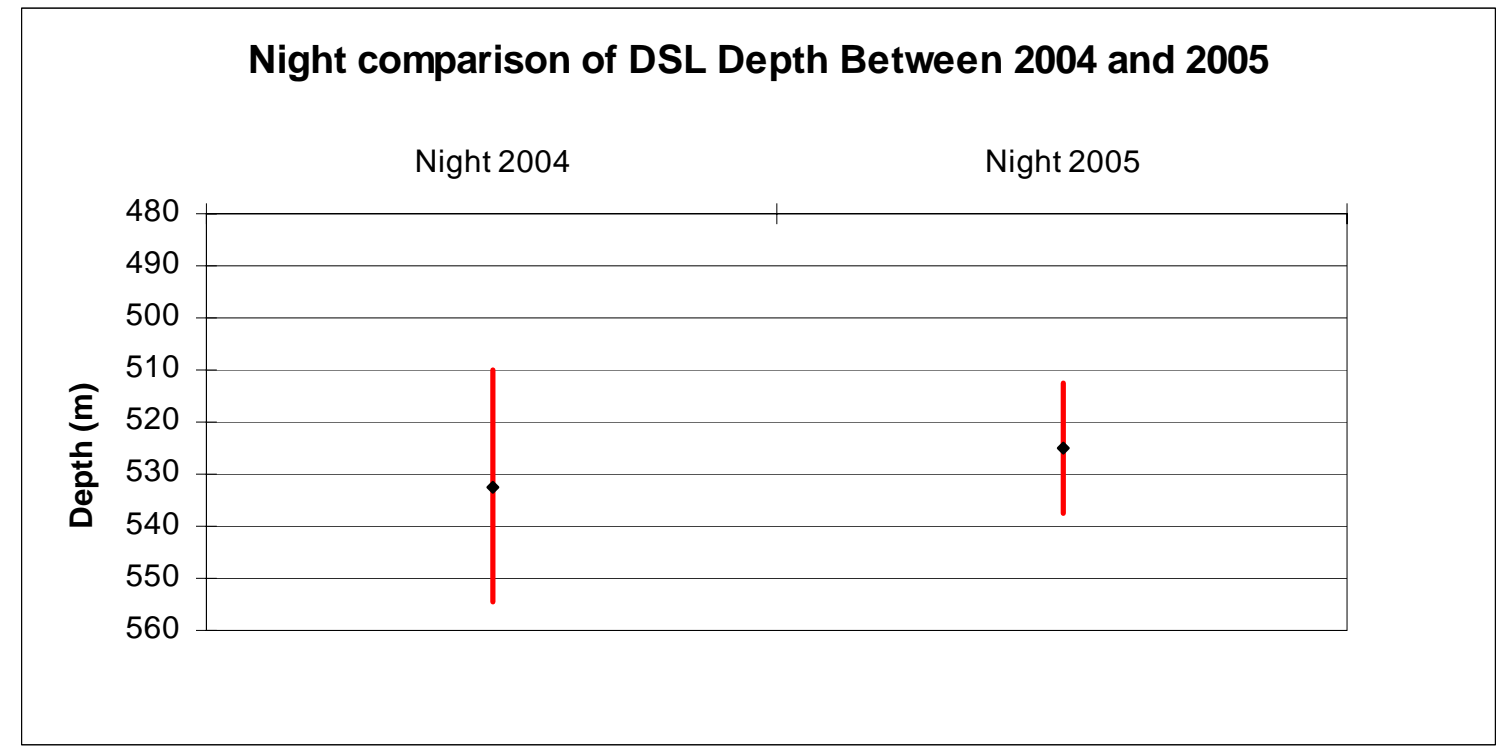

FIG.17. Graphical representation of t-test results for Night comparison of main DSL depth between 2004 and 2005. Red lines indicated 90\% confidence interval. Black diamonds indicate mean.

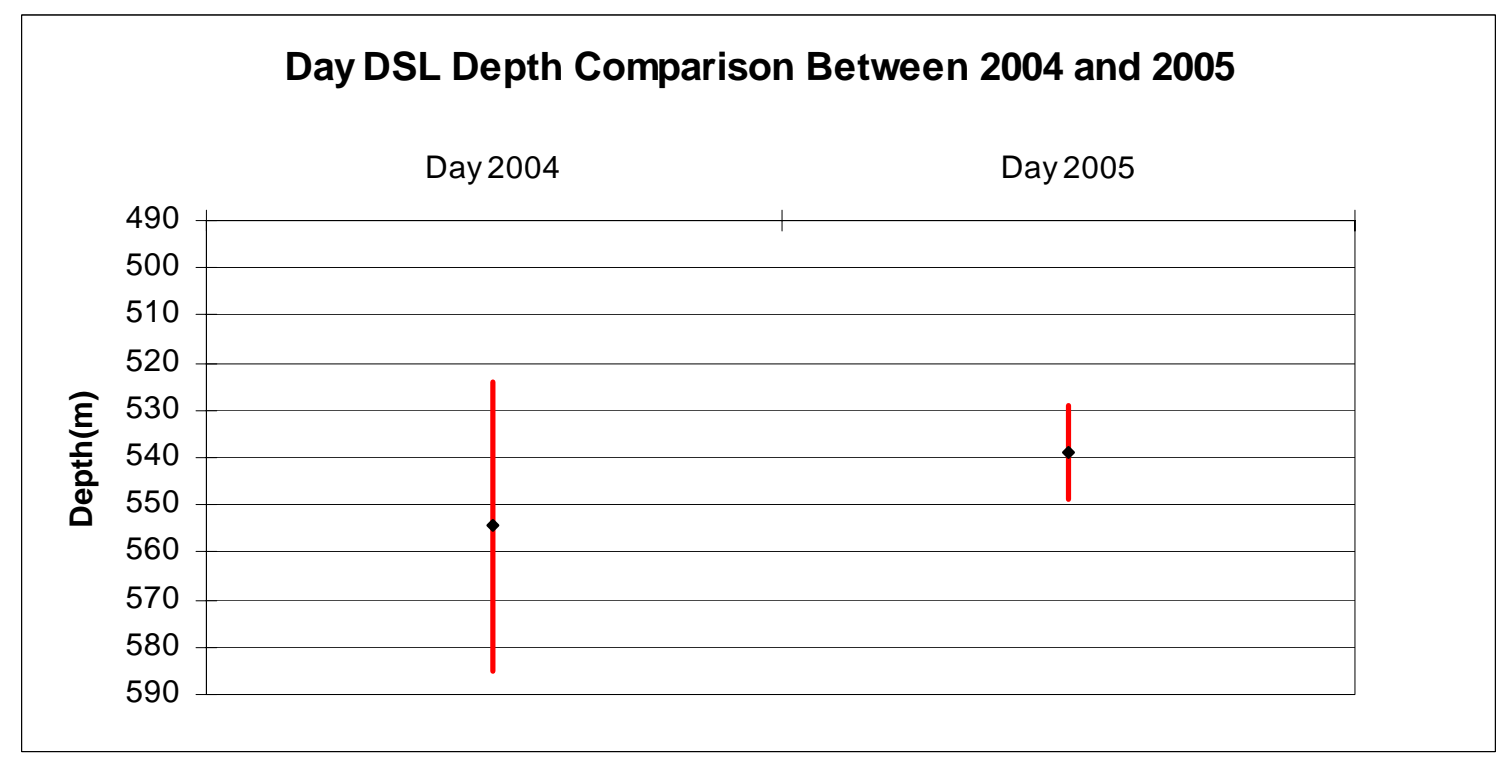

FIG.18. Graphical representation of t-test results for Day comparison of main DSL depth between 2004 and 2005. Red lines indicated 90\% confidence interval. Black diamonds indicate mean. 
A vertical integration of the total scattering intensity from $\sim 50$ meters to the average depth of the bottom of the scattering layers in 2004 and 2005 showed that the total backscatter in the water column was greater during 2004 (Table 12). This increase may be a factor explaining the less defined main deep scattering layer in 2004. The total nighttime backscatter was lower than the daytime backscatter which is likely due to the vertical migration of organisms to depths shallower than $\sim 50$ meters at night (and out of the integrated volume). The increase of scattering in 2004 in the northeastern Gulf may result from more water column biomass higher on the slope (water depth of $800 \mathrm{~m}$ ), and/or from proximity to the Mississippi River Delta.

TABLE 12. Comparison of day and night integrated intensity values for 2004 and 2005.

\begin{tabular}{|c|l|c|}
\hline Date & \multicolumn{1}{|c|}{ Time } & Total Counts \\
\hline 21-Jun-05 & Midnight - 4 AM & 240744 \\
\hline 9-Jun-05 & Noon - 4 PM & 271322 \\
\hline 28-May-04 & Midnight - 4 AM & 270102 \\
\hline 6-Jun-04 & Noon - 4 PM & 284990 \\
\hline
\end{tabular}

The overall higher average in backscatter in 2004 is evident (Figure 19) as an increase in scattering from surface to bottom depths of the main DSL. This figure is a plot of the backscatter data from the afternoon of 28 May through noon on the 29 May. The location of the data is from southwest of the Mississippi River Delta in the Mississippi Canyon (Figure 20). This location was an area where multiple sperm whales were sighted in 2004. 
In addition to statistical evaluation, it is also possible to qualitatively assess visual representations of the data. By visually analyzing color plots of the 2004 data, it is possible to hypothesize reasons for the lack of separation of the main deep scattering layer.

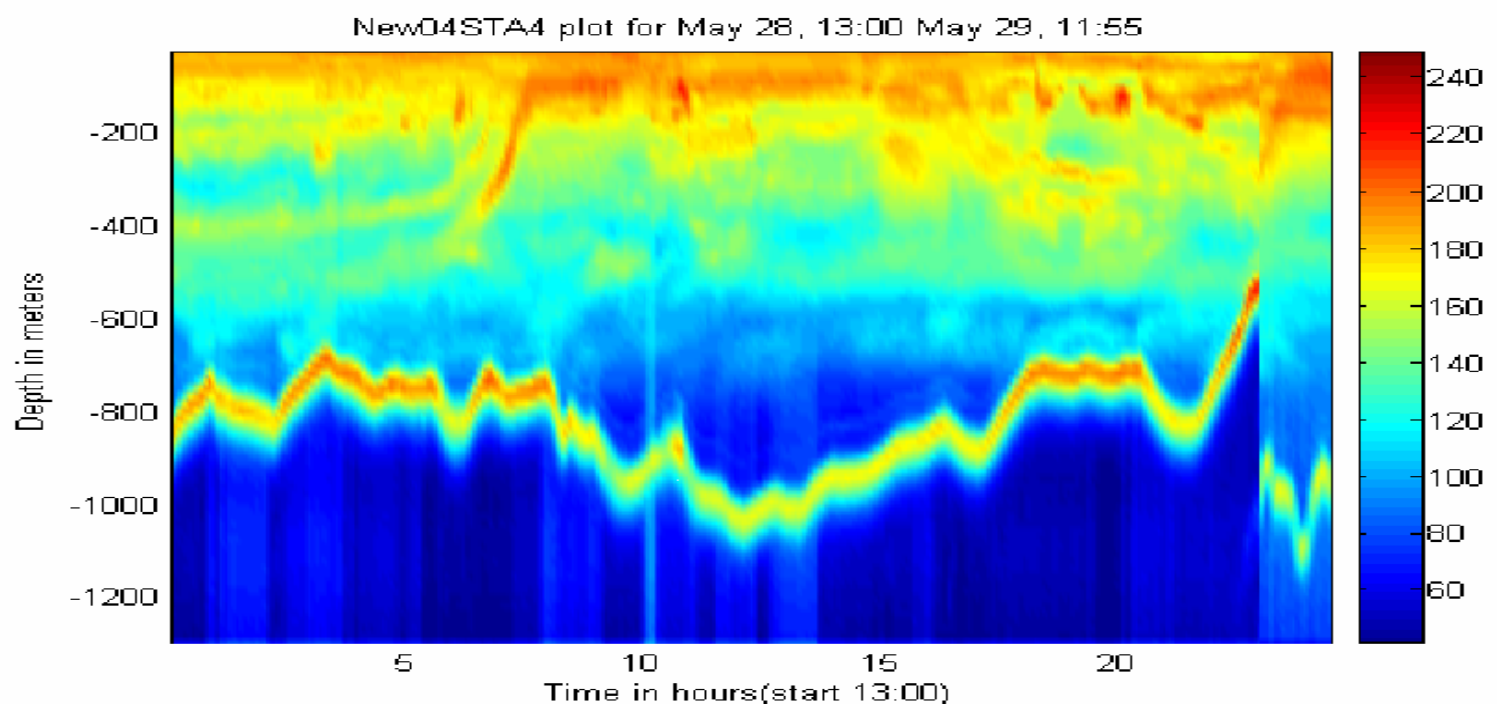

FIG.19. Vertical section of SWSS ADCP acoustic amplitude backscatter data from the Mississippi Canyon on 28-29 May 2004.

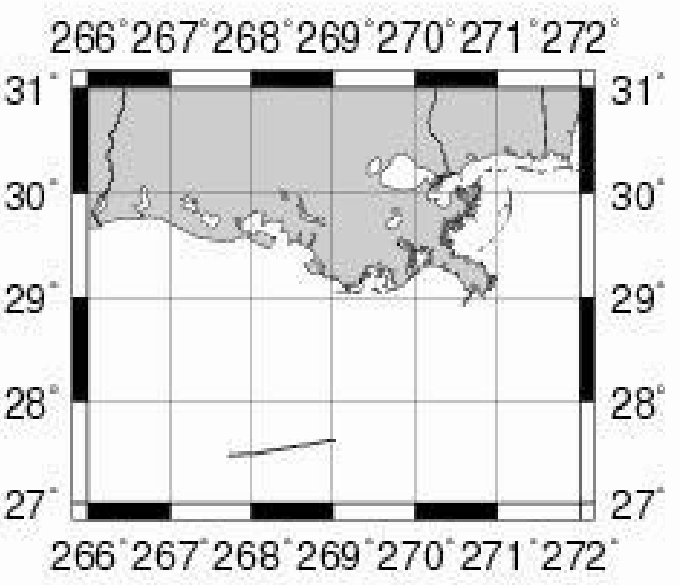

A
Historical SSH and C-phyll Concentration - May 292004

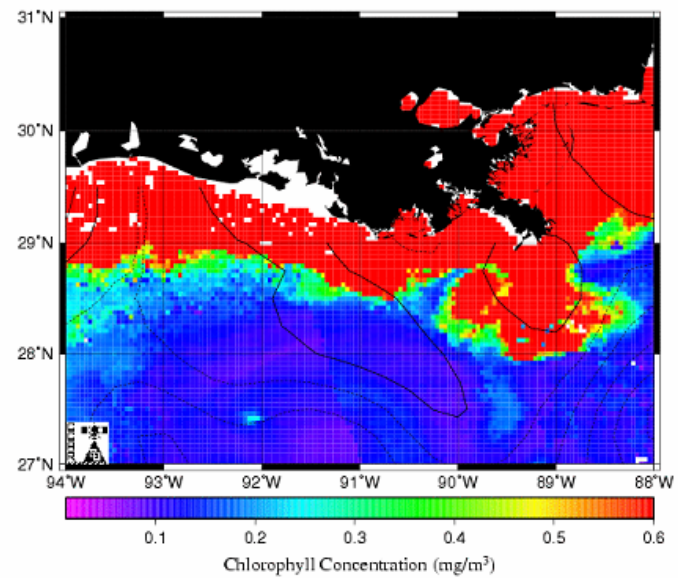

B

FIG.20. (A) Ship track from the 28-29 of May 2004. (B) Sea surface color and height plot five day composite from 29 May 2004 (CCAR, 2004) 


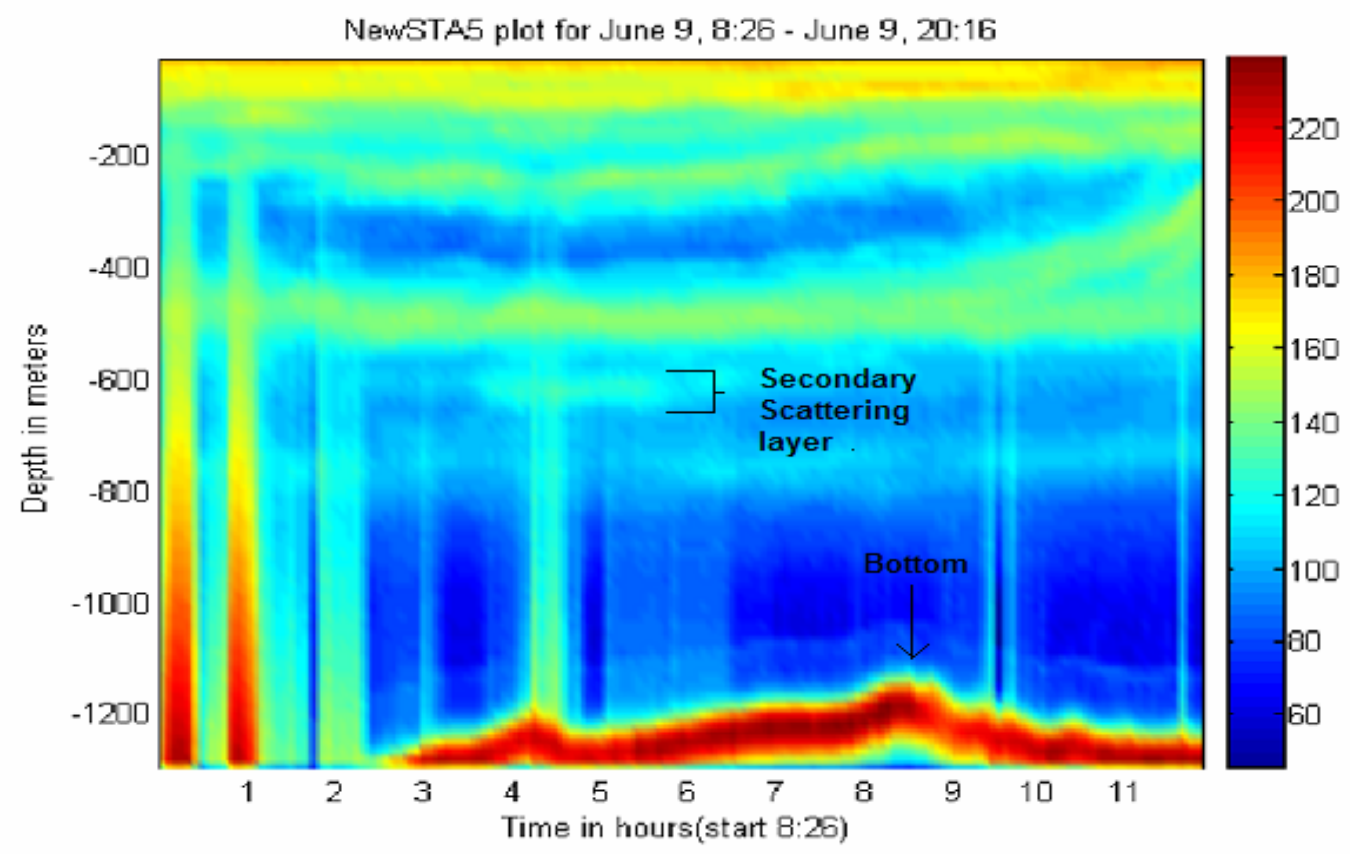

FIG.21. Vertical section of SWSS ADCP acoustic amplitude backscatter data from the western Gulf of Mexico on 9 June 2005.

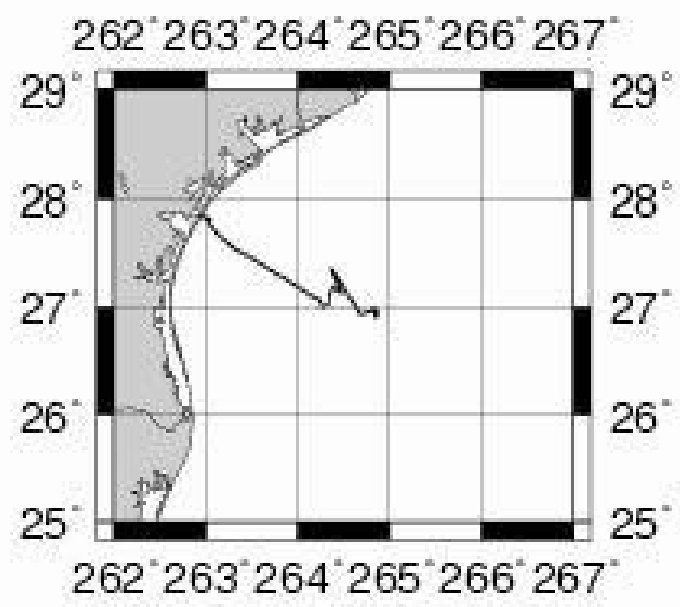

A
Hind-Cast SSH and C-phyll Concentration - Jun 152005

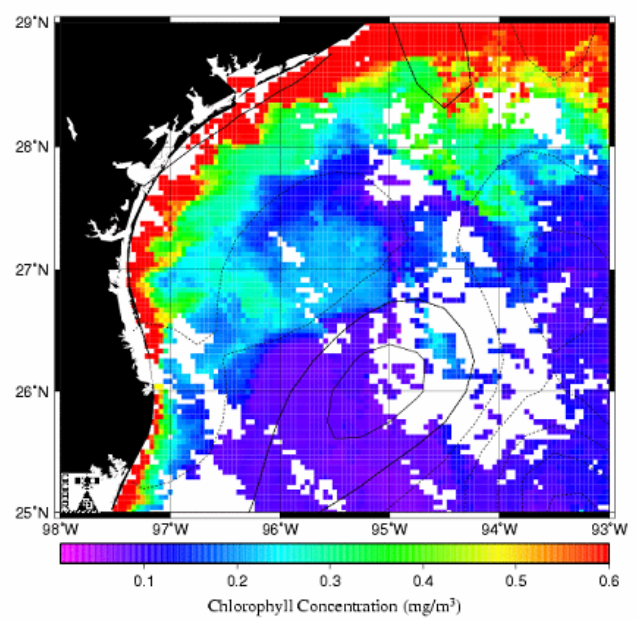

B

FIG.22. (A) Ship track from 9 June 2005. (B) Sea surface color and height plot five day composite from 15 June 2005 (CCAR, 2005). 
The main DSL in 2004 (Figure 19) was not as defined as the main DSL in 2005 (Figure 21). It is possible that the shallower water depth may have affected the establishment of the DSL in 2004. When the bottom depth was about $800 \mathrm{~m}$, the main DSL was not always distinct and in some instances the high scattering was continuous from the surface to depth. However, when the water depth increased to approximately $1000 \mathrm{~m}$, it was usually possible to compute distinct scattering layer metrics. It is also possible to see that Figures 19 and 21 differ in bottom depth and in ocean color. The tail end of the 2005 track moved into blue water after spending the majority of time in green water. The ship track from 2004 in Figure 20, when compared to the sea surface color, shows that the ship is moving through an area of low surface chlorophyll, as indicated by the blue surface color. The ship track from the 2005 plot, shown in Figure 22, is in predominantly in green water, and it is possible to see how the rotation of the cyclonic eddy has entrained higher chlorophyll surface water from the coast. This may be another factor beside water depth to explain differences in main deep scattering layer definition.

In 2005 there was a distinct main deep scattering layer between 400 and $600 \mathrm{~m}$, which can be seen in Figure 21. A weak/patchy secondary scattering layer was often located below the main DSL depth. Bottom depths in the area sampled in the western Gulf of Mexico were deeper than in the northeast, approximately $1000 \mathrm{~m}$ on average. Also apparent in the color plots is the daily vertical migration of zooplankton from the main deep scattering layer to the surface. In the 2005 plot, the vertical migration upwards in the late afternoon appears as one larger migration with only limited distinction between early migrating groups and later migrations. Inspection of the 2004 vertical section from Figure 19, however, reveals a much different migratory pattern including at least three 
separate groups migrating at different times to different depths and with differing acoustic intensities. This may also account for the lack of a larger defined main deep scattering layer and could be correlated with the shallower depths of the ocean bottom. There also appears to be a deeper secondary layer of scatterers in 2004. However, their appearance is much weaker and less clearly defined than the 2005 layer.

Part of the 2004 cruise surveyed the DeSoto Canyon area of the northeastern Gulf of Mexico (Figure 1). While sperm whales were historically located in that area, during the 2004 cruise there were only 4 whales encountered during the 3-day survey of the area. The backscatter plot (Figure 25), however, was much more similar to the 2005 western Gulf than to the majority of 2004 backscatter plots. Figure 23 shows how the scattering layer becomes more defined with increasing water depth, showing a linkage between the main deep scattering layer and total depth. However, the next day the cruise entered into a strong divergent eddy, similar to, but stronger than the divergent eddy sampled in 2005 . The increased separation of the main deep scattering layer from surface scattering, and the increased similarity to the 2005 plot of the divergent eddy in the western Gulf area is shown in Figure 25. The similarities connect not only increasing bottom depth with definition of the main deep scattering layer but also cyclonic features with main deep scattering layer definition. 


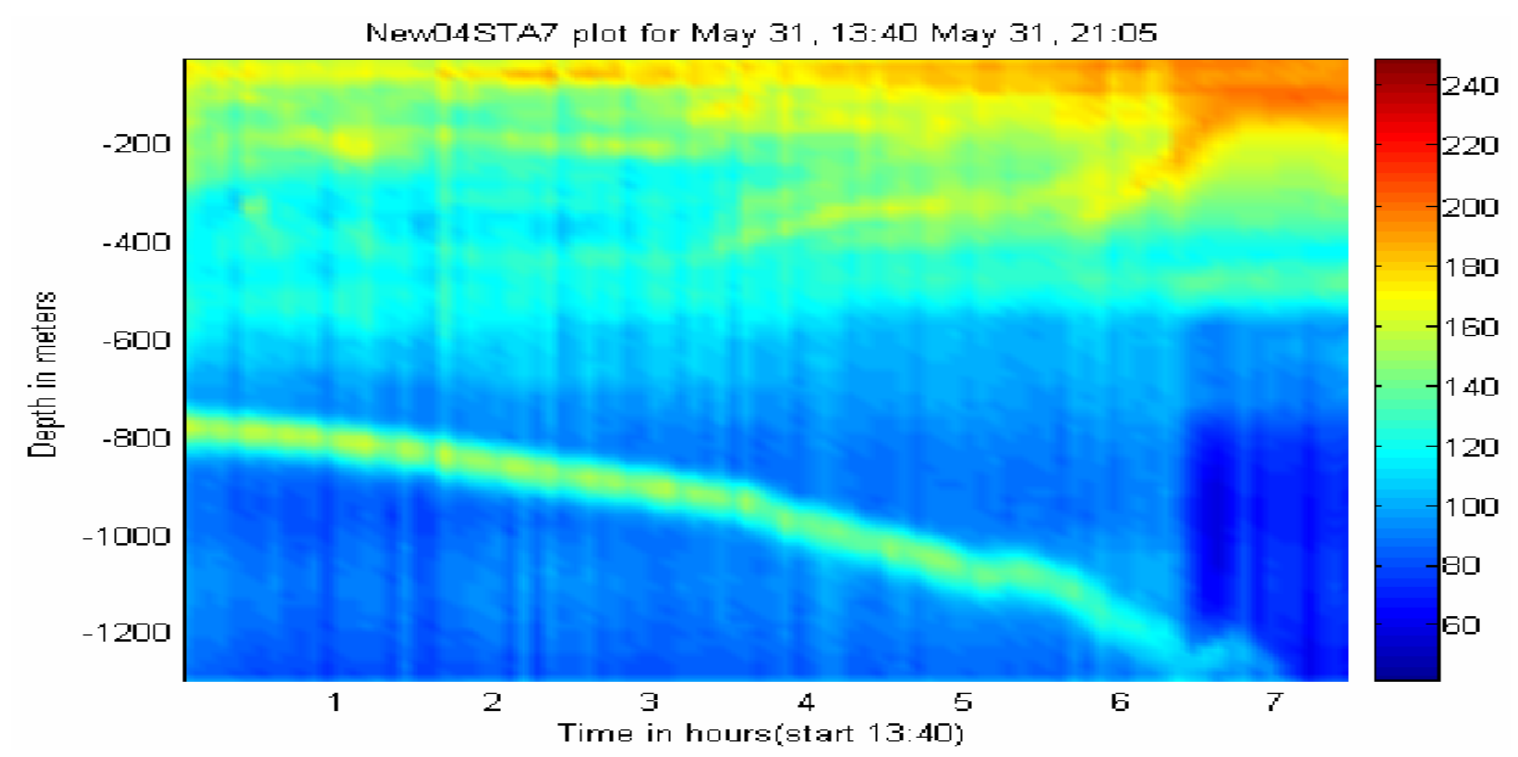

FIG.23. Vertical section of acoustic backscatter during 2004 in the northeast Gulf of Mexico entering into Desoto Canyon. The bottom in this figure is indicated by a heavy green line.

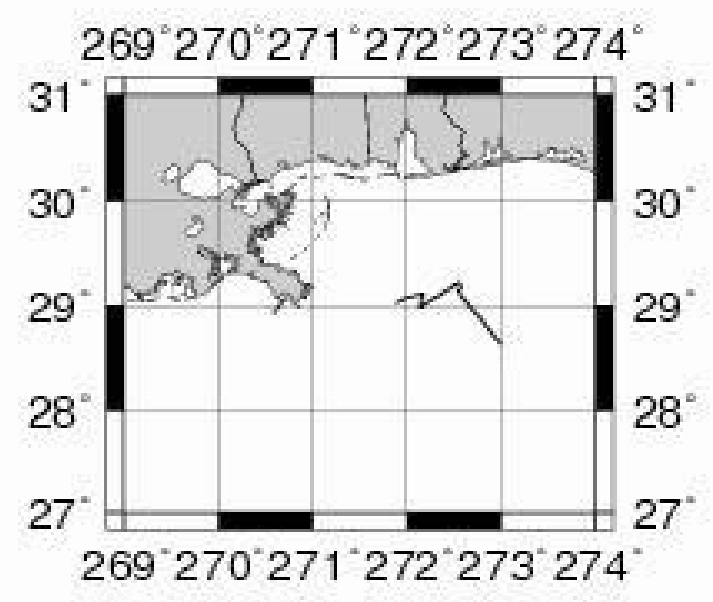

A
Historical SSH and C-phyll Concentration - May 292004

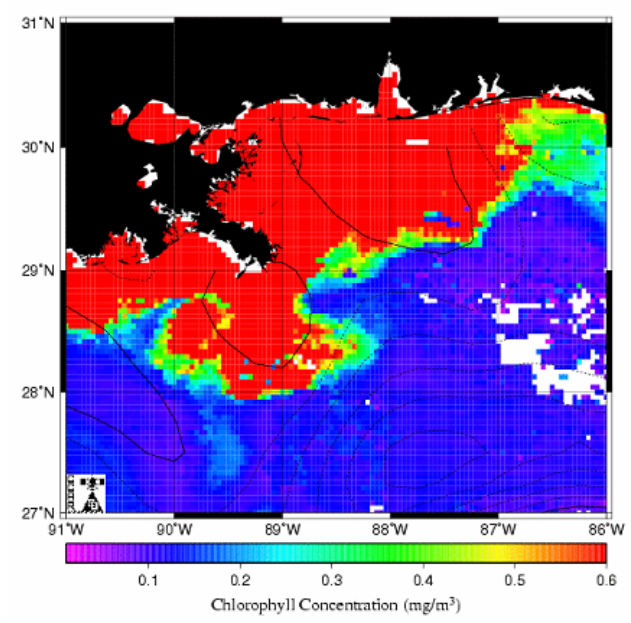

B

FIG.24. (A) Ship track entering Desoto Canyon 31 May 2004. (B) Sea surface color and height plot five day composite from 29 May 2004 (CCAR, 2004). 


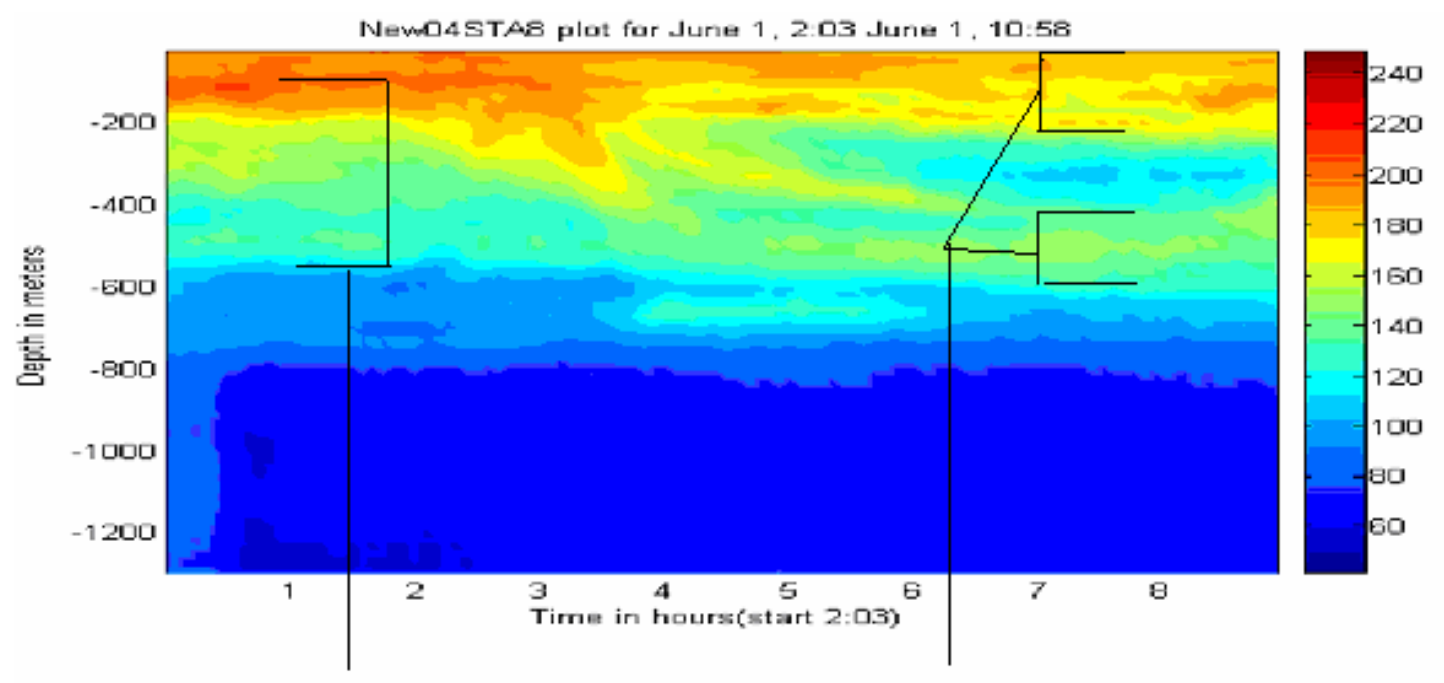

\section{Continuous}

Distinct

FIG.25. Vertical section of acoustic backscatter during 2004 in the northeast Gulf of Mexico, Desoto Canyon.

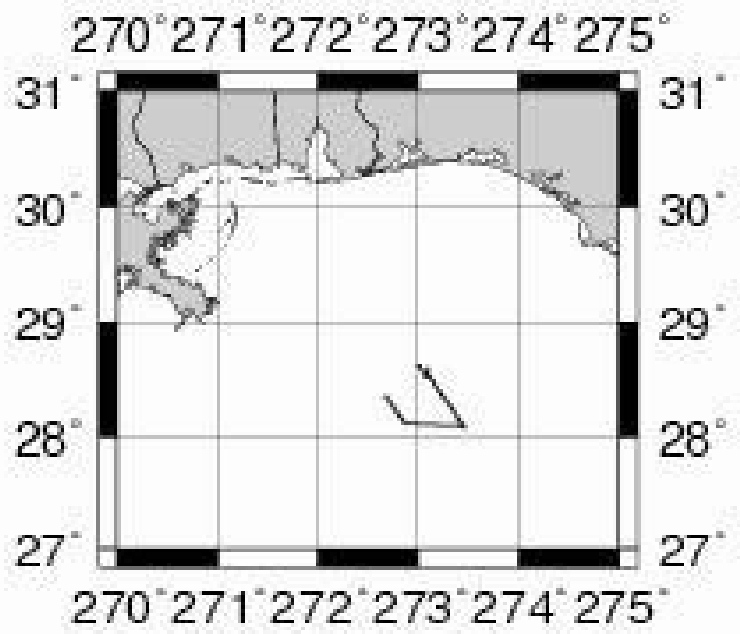

A

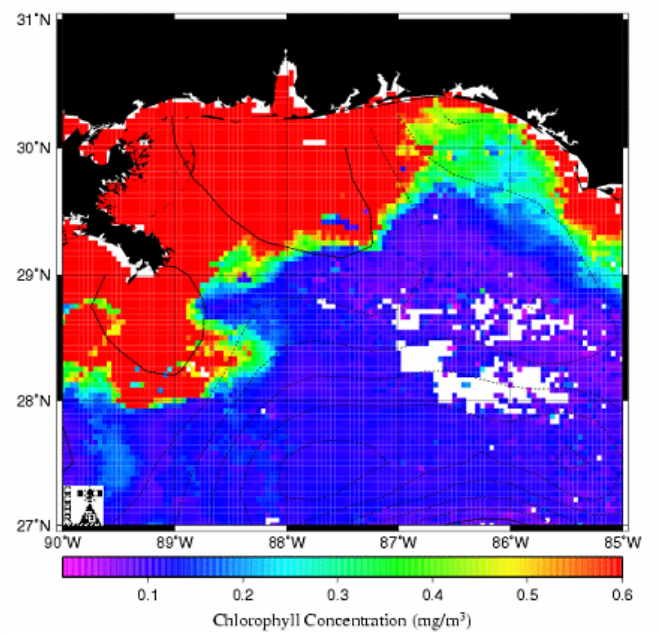

B

FIG.26. (A) Ship track surveying Desoto Canyon 1 June 2004. (B) Sea surface color and height plot five day composite from 29 May 2004 (CCAR, 2004). 
There is a change from a more continuous scattering layer on the left side of Figure 25 into two distinct scattering layers towards the right, a shallow scattering layer and the main deep scattering layer. The distinct layers are defined by a specific separation between the bottom of the shallow scattering layer and the top of the main deep scattering layer. This separation can be distinguished on the right hand side of the figure by the blue colored area between the bottom of the shallow scattering layer and the top of the main deep scattering layer. Based on the surface chlorophyll images and the companion ship track, Figure 24 shows the ship moving off shelf from higher surface chlorophyll levels, as denoted by the red and green color, to areas of lower chlorophyll, indicated by the blue color in Figure 26. Figure 25 is almost identical to the plot of the scattering data from 2005. It shows a clearly defined main deep scattering layer both at night and during the day. The downward vertical migration of organisms still shows the characteristic separation, however, it is closer in time to the 2005 vertical migration. The migration also forms a much more distinct deep layer with complete separation from the surface layer once the migration is complete. Additionally, there is the appearance of a very distinct secondary layer below the main deep scattering layer at $650 \mathrm{~m}$ similar to the grouping below the layer seen in the 2005 plot.

\section{Discussion}

Research on plankton in the Gulf of Mexico has been reviewed and revised (MullerKarger et al., 1991; Zimmerman and Biggs, 1999; Baumgartner et al., 2001; Wormuth et al., 2000; Biggs and Ressler, 2001; Ressler, 2002; Davis et al., 2002; Ressler and Jochens, 2003; Qian et al., 2003; Sindlinger, 2003; Kaltenberg, 2004). Several studies 
have focused on the northern and northeastern Gulf of Mexico, both shelf and deep-water areas (Muller-Karger et al., 1991; Zimmerman and Biggs, 1999; Baumgartner et al., 2001; Wormuth et al., 2000; Biggs and Ressler, 2001; Davis et al., 2002; Ressler, 2002; Qian et al., 2003; Ressler and Jochens, 2003; Sindlinger, 2003; Kaltenberg, 2004). However, few studies have been done in the Western Gulf. The 2005 SWSS cruise was the only tag and survey cruise to the western Gulf and the only SWSS survey cruise done in the western Gulf using a $38 \mathrm{kHz}$ ADCP instrument to record backscatter. Both the 2004 and 2005 cruises were successful in locating and tagging whales, which makes the comparison of the locations of the cruise important in understanding where sperm whales are feeding and the food web characteristics of those areas.

Since sperm whales were observed feeding both years in both locations it suggests a links between the food webs present at each location. If sperm whales are diving to depths at or below the main DSL, the possibility of their preying on the same types of organisms is high since the assumption can be made that the prey items feed on organisms found in scattering layers with characteristics similar to those described in this research. The next step is to image the main DSL using the Simrad fishery echosounder systems, which have the ability to resolve thin strong scattering layers and the ability to identify specific groups of high backscatter intensity. To compliment the echosounder data and ground truth the echosounder findings, it will be necessary to sample this deep scattering layer with multiple open and closing net and environmental sensing system (MOCNESS) trawls or similar equipment. 
Based on the data collected between years it was possible to test the null hypothesis that there was no difference in main deep scattering layer characteristics based on geographic location. A test of bottom depths between divergent and non-divergent locations in 2005 revealed no significant difference between bottoms depths. The non-divergent locations had greater variability in the bottom depth of the layer, but the range of the divergent data is completely within the $95 \%$ confidence interval of the non-divergent. The overall comparison between 2004 and 2005 showed that there was no significant difference between the bottom depths of the scattering layer affirming the null hypothesis. 


\section{CHAPTER V}

\section{COMPARISON OF BACKSCATTER DATA FROM 38 KHZ ADCP AND 70 KHZ SIMRAD FISHERY ECHOSOUNDER}

\section{Introduction}

Calibration of the $38 \mathrm{kHz}$ ADCP instrument has proven to be a difficult challenge. Few studies have investigated the relationship between ADCP backscatter data and fisheries echosounder equipment (Griffiths and Diaz, 1996; Brierley et al., 1998). Calibration of the instrument would allow analysis of absolute scattering intensities of layers with the ADCP instead of relative acoustic backscatter intensity. One of the goals from the SWSS 2005 cruise was to compare data from the Simrad fisheries echosounders and the ADCP to validate that $38 \mathrm{kHz}$ ADCP backscatter comes primarily from biological, rather than from other sources of scattering. The comparison reported here is between the $70 \mathrm{kHz}$ Simrad and the $38 \mathrm{kHz}$ ADCP because the two instruments ran concurrently.

\section{Methods}

One-hour sections of quality controlled, processed ADCP data were compared to the natural $\log$ transform of the Area Scattering $\left(\mathrm{S}_{\mathrm{A}}, \text { units }-\mathrm{m}^{2} / \mathrm{n} \cdot \mathrm{mi}^{2}\right)^{1}$ backscatter measurements for the Simrad data. The natural log was used because the ADCP data were corrected for sound attenuation using a natural $\log$ transform and decay constant. The $70 \mathrm{kHz}, 7^{\circ}$ conical split beam echosounder (Simrad EK60) used a $128 \mu$ s long pulse and collected 4 pulses per second. The Simrad system was calibrated using an indirect procedure incorporating a $38.1 \mathrm{~mm}$ diameter tungsten carbide reference sphere as

\footnotetext{
${ }^{1} \mathrm{http} / / /$ www.sonardata.com/WEBHELP/Reference/Algorithms/Analysis_variables/ABC_and_NASC.htm
} 
prescribed by Foote et al. (1987). Area Scattering was calculated in SonarData's

Echoview software for $1 \mathrm{~m}$ vertical intervals (Kelly Benoit -Bird, communication). $\mathrm{S}_{\mathrm{A}}$ (NASC is identical to $\mathrm{S}_{\mathrm{A}}$ as used by Simrad) is calculated as:

where

$$
\begin{aligned}
\text { NASC } & =4 \pi \times 1852^{2} \times 10^{\mathrm{Sv} / 10} \times T \\
& =4 \pi \times 1852^{2} \times 10^{\mathrm{Sv} \_ \text {mean } / 10} \times \text { Thickness_mean } \\
& =4 \pi \times 1852^{2} \times \text { ABC, }
\end{aligned}
$$

$4 \pi=$ Steradians in a sphere - converting "backscattering" cross-section to "scattering" cross-section.

$1852=$ meters per nautical mile ( $\mathrm{m} / \mathrm{n} \cdot \mathrm{mi}$.).

$S_{\mathrm{v}}=$ mean volume backscattering strength of the domain being integrated (dB re $1 \mathrm{~m}^{2} / \mathrm{m}^{3}$ ).

$T=$ mean thickness of the domain being integrated.

$\mathrm{ABC}=$ Area Backscattering Coefficient $\left(\mathrm{m}^{2} / \mathrm{m}^{2}\right.$, manufacturers stated units).

The calibrated, one-meter bin data from the $70 \mathrm{kHz}$ Simrad echosounder provided by Dr. Kelly Benoit-Bird (OSU) were averaged over the 16-meter intervals corresponding to the same 16-meter depth bins the ADCP uses, putting the averaged value at the midpoint of the bin. The counts from the ADCP were then plotted versus the $\mathrm{S}_{\mathrm{A}} \log$ transform values. Several data sets were analyzed to compare $\mathrm{R}^{2}$ values and regressive line slopes to determine whether the correlation was constant across data sets, time of day and spatial and temporal variables. Two nighttime and four daytime data sets were used for the comparison. Despite only six sets of comparison, several trends and characteristics have emerged. They are discussed in the next section.

\section{Results}

The ADCP backscatter (counts) data were compared with the $\mathrm{S}_{\mathrm{A}}$ data collected concurrently by the $70 \mathrm{kHz}$ fishery echosounder on R/V Gyre cruise 05G09 in June 2005. There is a strong correlation between the two instruments near the surface, where both 
instruments recorded high acoustic backscatter. From depths of $49 \mathrm{~m}$ to depths between 208 and $304 \mathrm{~m}, \mathrm{R}^{2}$ correlation coefficients ranged from 0.76 to 0.90 (Table 13). Data for comparison were selected between depths $\mathrm{z}=49 \mathrm{~m}$, the depth of the top of the second shallowest usable vertical bin of ADCP data and the depth where ADCP counts data dropped below 120 (low signal to noise), typically at depths between 208 and $304 \mathrm{~m}$. The depth of ADCP scattering greater than 120 counts was correlated with variability in the thickness of the upper scattering layer, which was, in turn, dependent on the time of day and location. From $300-400 \mathrm{~m}$, the ADCP counts were usually less than 120 . Deeper than $400 \mathrm{~m}$, ADCP backscatter counts generally increased to greater than 120 , and in practice counts greater than 120 at depth were used to mark the top (and bottom) of the daytime main DSL in the ADCP backscatter data.

TABLE 13. Summary of correlation coefficients and slope of the ADCP counts versus $\mathrm{S}_{A}$ regression by data set beginning at either noon or midnight local time and extending for a period of one hour. The $\mathrm{R}^{2}$ and slope values for the complete data sets and the data sets with counts greater than 120 are also included in the table. All correlations are significant at the $95 \%$ level based on the effective degrees of freedom of the data sets.

\begin{tabular}{|c|l|c|c|c|c|}
\hline Data Set & Time & $\mathrm{R}^{2}$ & Slope & $\mathrm{R}^{2}$ (Counts $\left.>120\right)$ & Slope (Counts $>120)$ \\
\hline 9-Jun & Noon & 0.77 & 15.40 & 0.77 & 14.57 \\
\hline 11-Jun & Noon & 0.78 & 13.30 & 0.74 & 12.79 \\
\hline 12-Jun & Noon & 0.77 & 14.92 & 0.76 & 14.52 \\
\hline 28-Jun & Noon & 0.79 & 14.87 & 0.78 & 14.83 \\
\hline 21-Jun & Midnight & 0.91 & 16.32 & 0.95 & 14.63 \\
\hline 22-Jun & Midnight & 0.83 & 16.42 & 0.90 & 15.76 \\
\hline
\end{tabular}




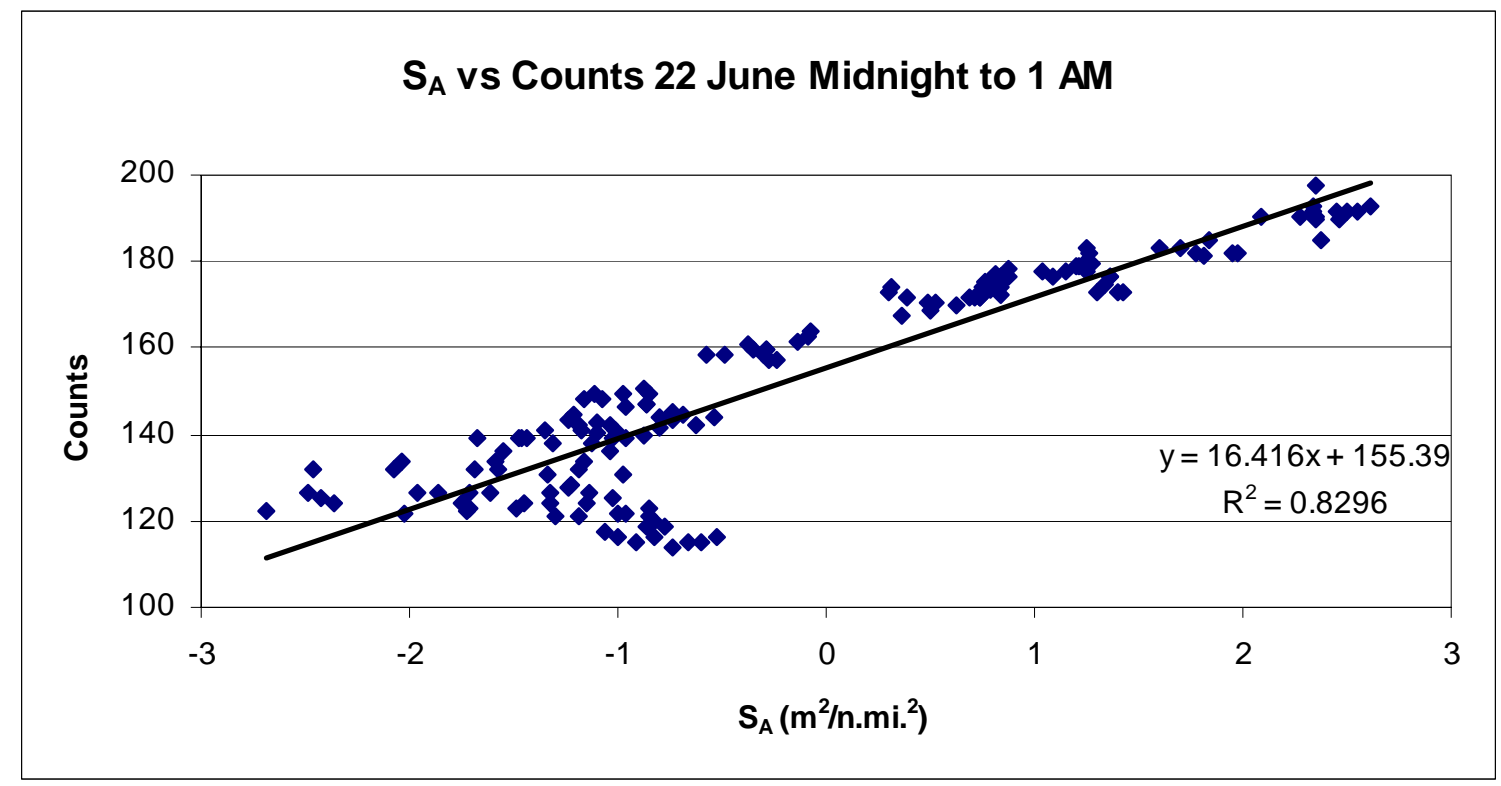

FIG.27. Plot of the 22 June 2005 nighttime comparison for the period of Midnight to 1 AM (12, five-minute samples). The distinct ' $C$ ' shaped curve at the base of the graph indicates the breakdown in correlation when the ADCP counts drop below 120.

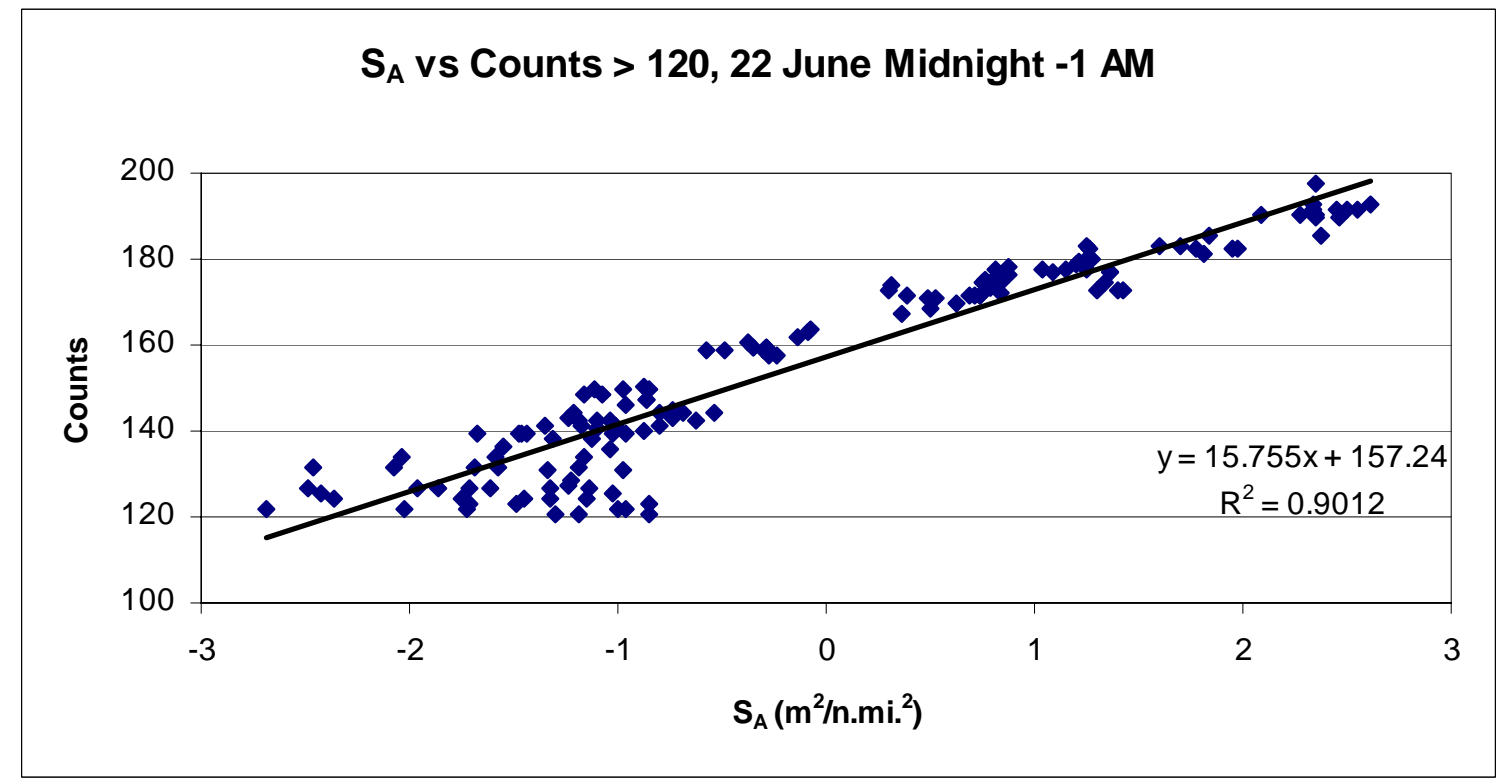

FIG.28. Modified plot of the 22 June 2005 nighttime comparison for the period of Midnight to 1 AM (12, five-minute samples). The distinct ' $C$ ' shaped curve at the base of the graph in Figure 27 is less apparent now that ADCP count values below 120 are removed. 


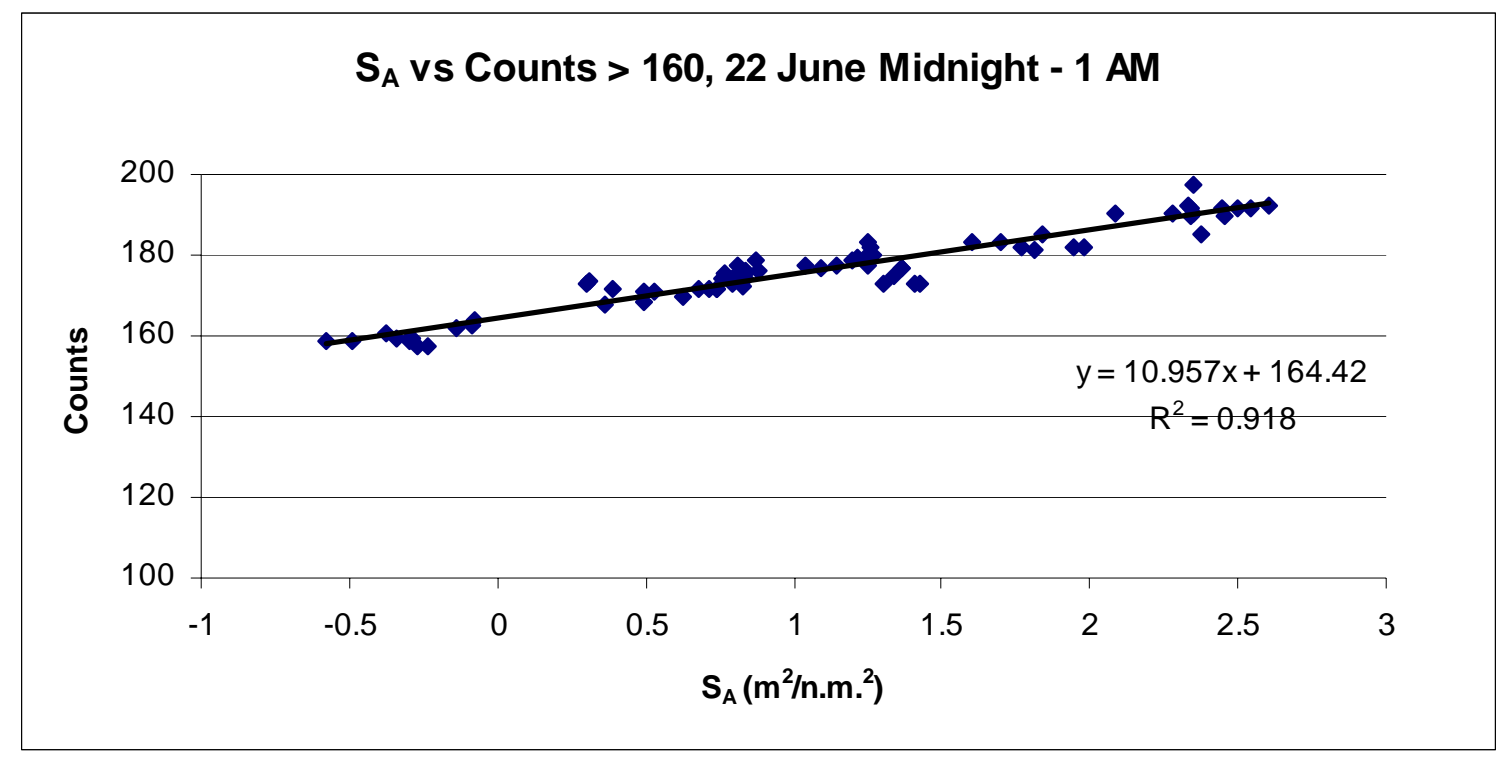

FIG.29. Modified plot of the 22 June 2005 nighttime comparison from Midnight to 1 AM (12, five-minute samples) showing the relationship between $\mathrm{S}_{\mathrm{A}}$ values and counts above 160 .

Figures 27 and 28 show evidence of the decorrelation of the Simrad and ADCP data when the backscatter from the ADCP has a value less than 120 counts. The correlation increases from 0.83 to 0.90 (Table 13) indicating an improvement in the relationship when counts less than 120 are removed. The further restriction of counts to 160 and above increases the correlation value to 0.92 , indicating a stronger correlation between the Simrad and ADCP systems when the backscatter intensity is greater (Figure 29). The relationship also varies non-linearly with depth. Below approximately $200 \mathrm{~m}$, ADCP counts generally drop below 120 until the main daytime scattering layer is reached at 400-600 $\mathrm{m}$. The ADCP instrument is unable to resolve thin but intense scattering layers that are sometimes present in the fishery echosounder data at depths below $200 \mathrm{~m}$ (Kelly Benoit-Bird, communication). Shallower scattering layers are more evenly distributed enabling the ADCP to record their presence. Because these thinner, more intense 
scattering layers are averaged over $16 \mathrm{~m}$ by the ADCP, the large surrounding volume of low scattering masks their acoustic signature when depths are greater than $200 \mathrm{~m}$. However, shallow nighttime scattering recorded by the ADCP within the upper $200 \mathrm{~m}$ is highly correlated with nighttime scattering values recorded by the Simrad echosounder.

The relationship between the two instruments is better at night than during day. Based on the correlation values found in Table 13, the daytime data sets averaged 0.78 . Unlike the nighttime analysis this correlation did not greatly improve with the removal of counts below 120 and in some cases decreased when values below 120 were removed. This could be due to the deepening of the surface scattering layer during the day as organisms move out of the upper water column. Removal of strong, accurate signals deeper in the water column would decrease the correlation because only the weaker signals from higher in the water column were being compared.

The ' $\mathrm{C}$ ' shape seen at depth in Figure 27 on the 22 of June at night, when ADCP counts drop below 120, is not apparent in a graph of the 9 June ADCP data from Noon to 1 PM (Figure 30). Instead, there is an aggregation of points apparent at approximately $\left(\mathrm{S}_{\mathrm{A}} 0\right.$, Counts 175). This may be caused by the discrepancies in ADCP counts and $\mathrm{S}_{\mathrm{A}}$ found between 49 and $100 \mathrm{~m}$ during the day. Figure 31 plots the $\mathrm{S}_{\mathrm{A}}$ data from 9 June as a function of depth. $\mathrm{S}_{\mathrm{A}}$ near the surface was close to zero with values increasing to a maximum at $100 \mathrm{~m}$. This was not true for ADCP data, which reached its maximum at 50 $\mathrm{m}$ then decreased with depth similar to $\mathrm{S}_{\mathrm{A}}$ values after $100 \mathrm{~m}$ (Figure 32). This is most likely explained by the vertical daily migration of more or larger scatterers out of the upper $50 \mathrm{~m}$ of the water column resulting in a particularly intense shallow scattering layer 
at around $100 \mathrm{~m}$, which the echosounder picks out specifically. The ADCP instrument is less sensitive to thin high intensity layers and thus distributes the intense scattering from $50 \mathrm{~m}$ to $100 \mathrm{~m}$. This distribution results in the uniform decrease in counts from $50 \mathrm{~m}$ to depth while the echosounder shows a rapid jump in scattering intensity from $50 \mathrm{~m}$ to 100 $\mathrm{m}$ followed by a more uniform decrease. Although both data sets are averaged over 16 meter bins, the averaging of higher returns from the Simrad system leads to the overall higher intensity return from the 16-meter bin. A determination of the actual difference in backscatter return would involve the direct comparison of one-meter bins of both Simrad and ADCP data. This comparison was not possible with these data sets so it is only possible to hypothesize reasons for the difference in backscatter intensity over the same vertical bins.

The results of this discrepancy of backscatter intensity with depth appear in Figures 30 and 33 as an aggregation of points where $S_{\mathrm{A}}$ is zero and Counts are between 170 and 180 . With the exception of these outlying aggregations, the correlation is high indicating that, like the nighttime comparison, counts and $\mathrm{S}_{\mathrm{A}}$ also have positive functional relationship supporting the hypothesis that the ADCP is receiving backscatter readings from biological organisms in the water column. 


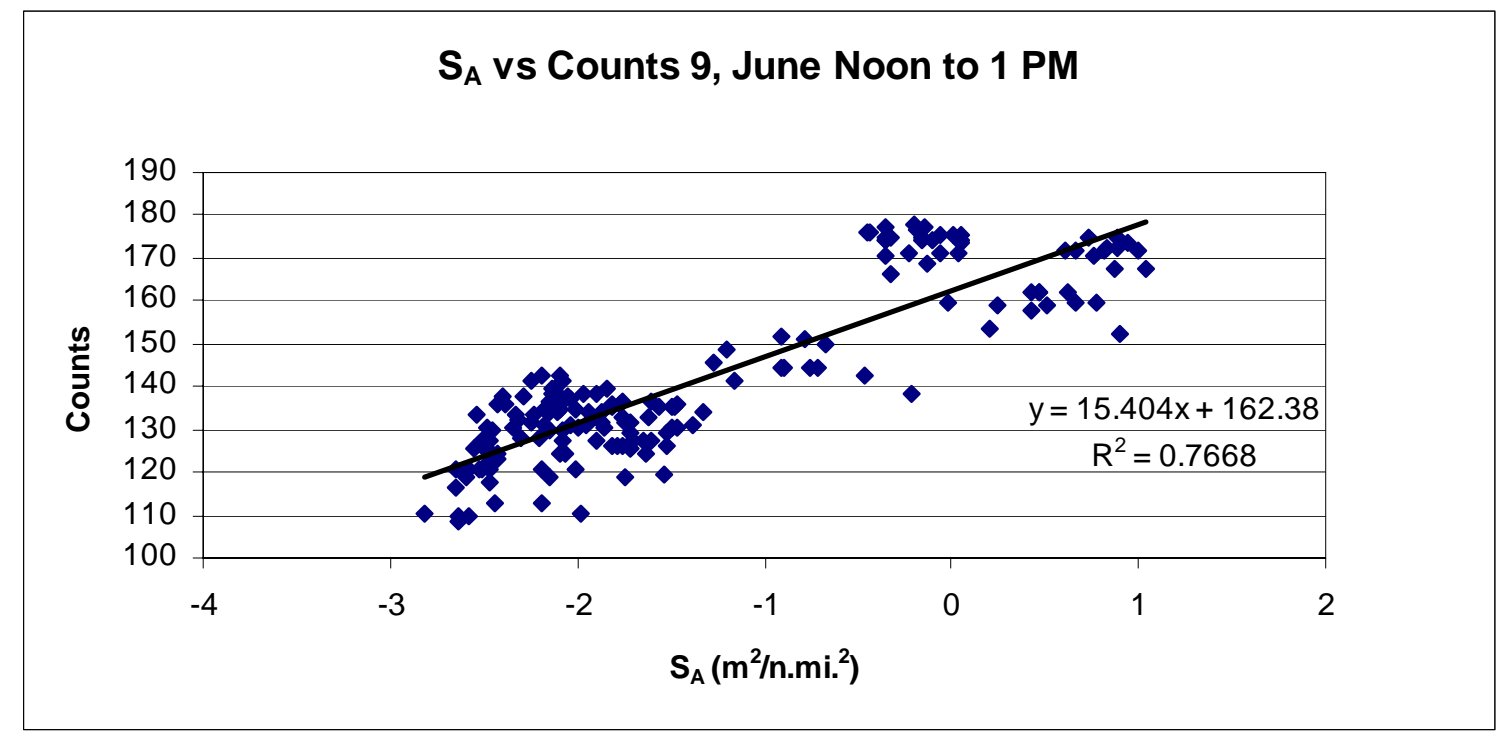

FIG.30. Plot showing 9 June 2005 data comparison between the ADCP and Simrad data sets from Noon to 1 PM (12, five-minute samples). The aggregation of points at approximately $(0,170)$ indicates that depth may play a more important role in the correlation.

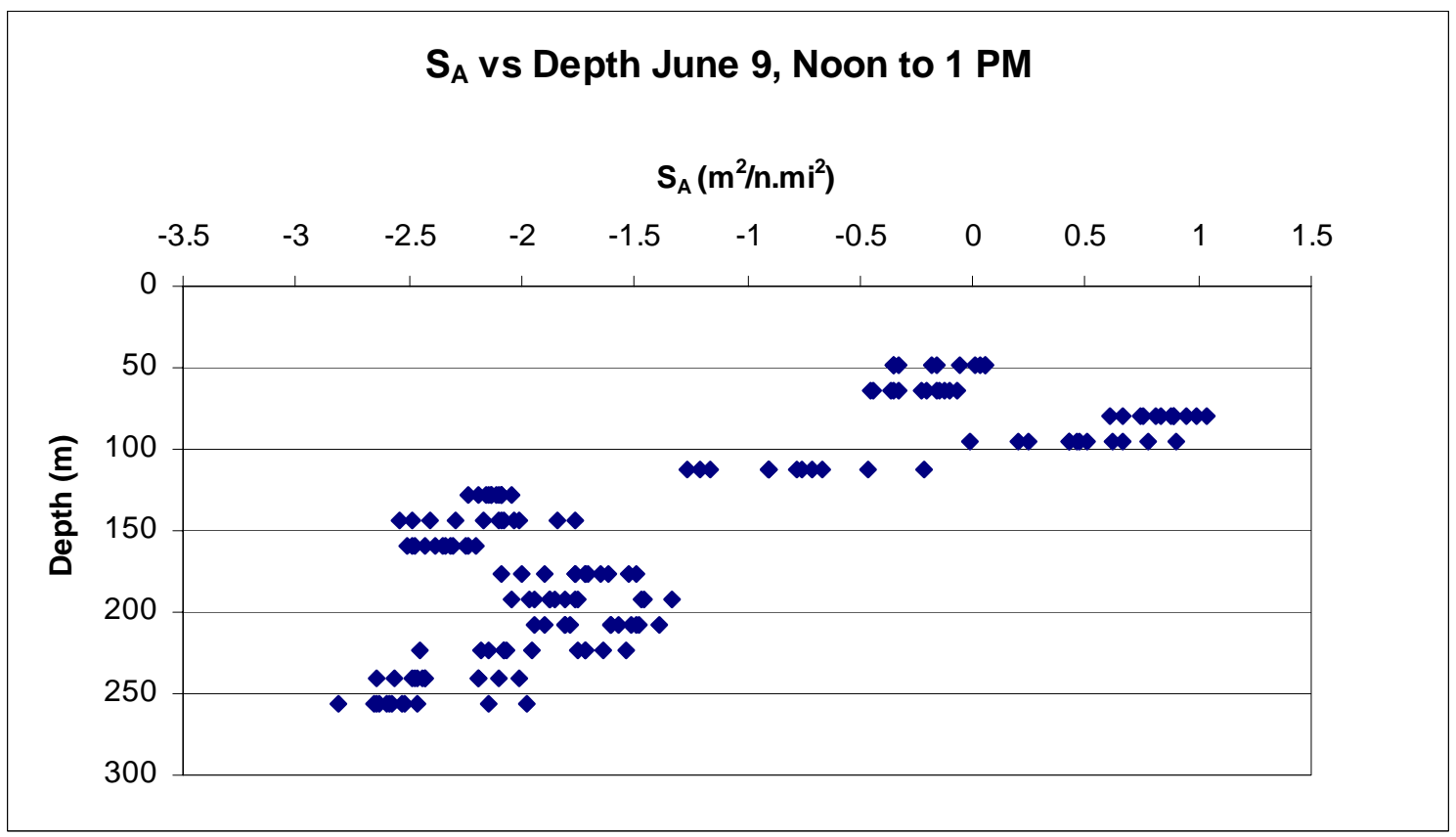

FIG.31. Plot of fishery echosounder $S_{A}$ values vs. Depth, Noon to1 PM June $9^{\text {th }}(12$, fiveminute samples). Log transformed $\mathrm{S}_{\mathrm{A}}$ values at 50 meters ranged just 0.0 to -0.5 , where as many of those at $100 \mathrm{~m}$ ranged as high as +1.0 . While the averages are almost the same, the ADCP appears most sensitive to the high end of the $\mathrm{S}_{\mathrm{A}}$ dynamic range. 


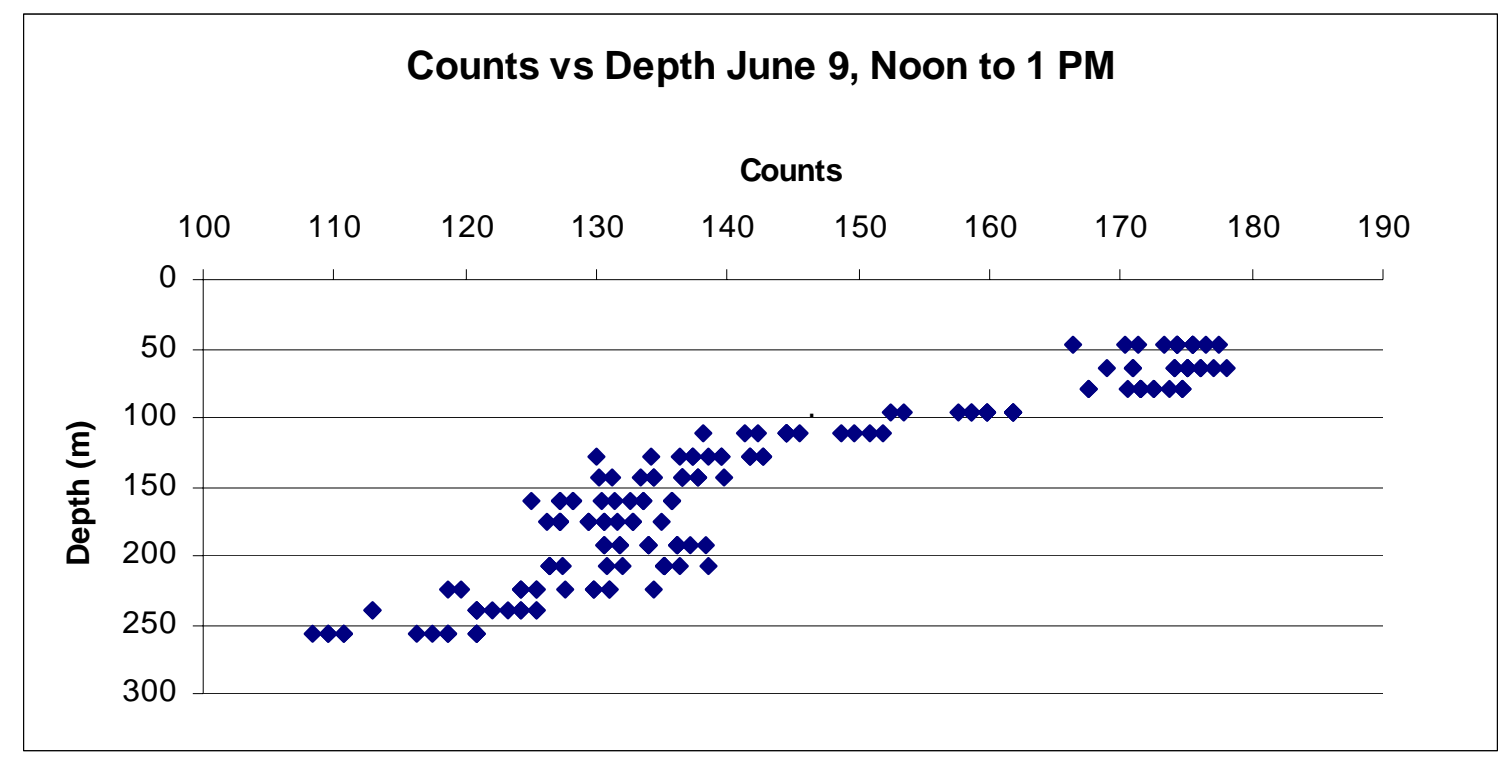

FIG.32. Plot of Counts vs. Depth at Noon on June $9^{\text {th }}$ (12, five-minute samples). Unlike the $\mathrm{S}_{\mathrm{A}}$ data, counts values are fairly constant from 50 to $100 \mathrm{~m}$. This difference is due to the lower sensitivity of the ADCP to detect small changes in scattering intensity. The discrepancy in sensitivity may account for the lower correlation values of $\mathrm{S}_{\mathrm{A}}$ and Counts during the day.

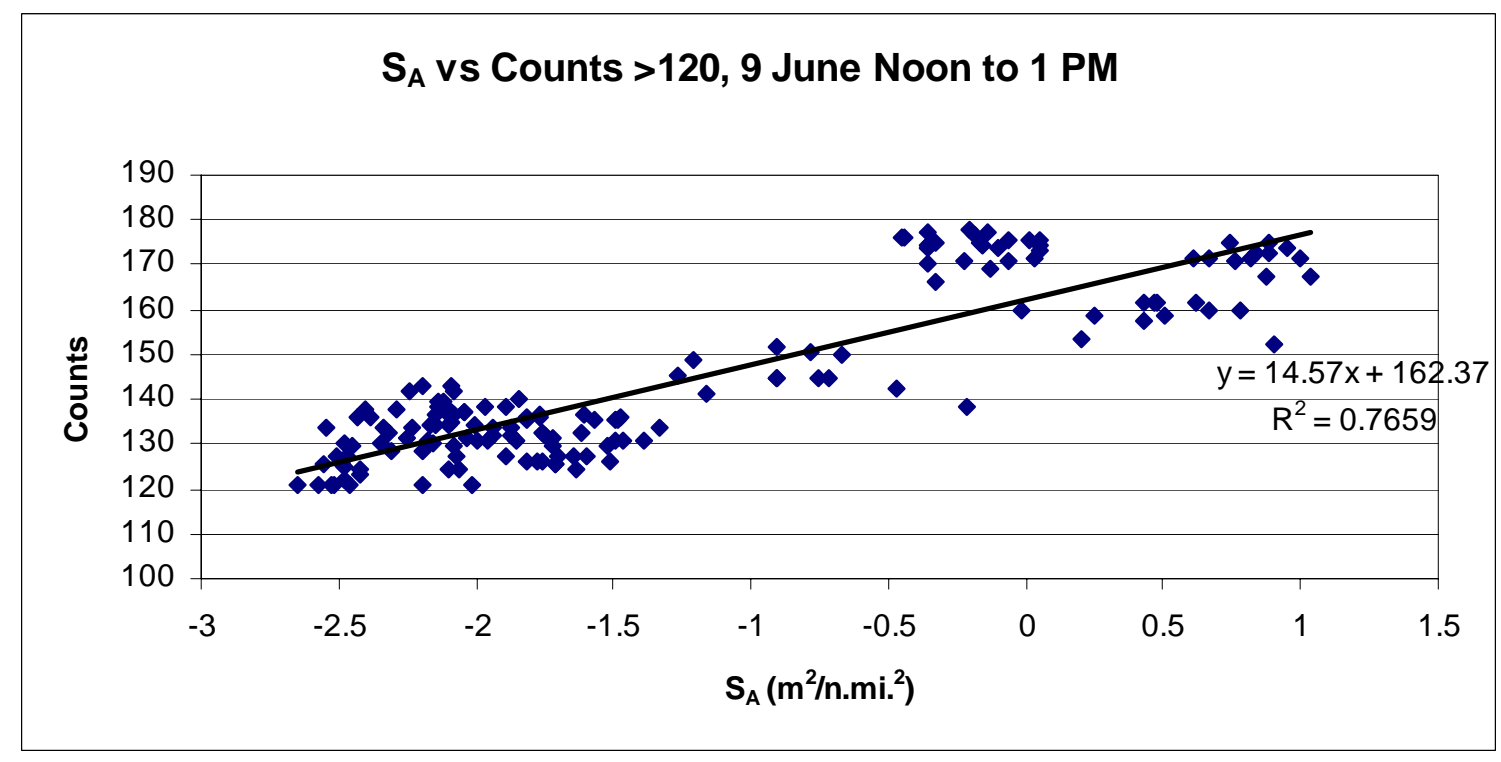

FIG.33. Plot of ADCP counts $>$ than 120 versus $\mathrm{S}_{\mathrm{A}}$ for 9 June 2005 (12, five-minute samples). The removal of counts $<120$ has little effect on the correlation coefficient. The aggregation of points at $(0,170)$ is still present and appears to reduce the $\mathrm{R}^{2}$ correlation more than counts below 120 . 
An important part of the analysis is the comparison between Counts and the volume backscatter intensity measured by the fishery echosounder in $\mathrm{S}_{\mathrm{v}}$. The correlation analysis (Figure 34) shows a positive functional relationship where Counts of 180 are approximately equal to $S_{v}$ values of $-70 \mathrm{~dB}$, and Counts values of 120 are approximately equal to $S_{v}$ values of $-85 \mathrm{~dB}$. The log-log slope value of 4.18 indicates that a change in ADCP counts of 4 is about equivalent to a change in $S_{v}$ of $1 \mathrm{~dB}$.

The relative comparison with Simrad echosounder acoustic volume backscatter is only possible between data sets collected from the same ADCP, preferably collected during the same field season. This is because the instrument is uncalibrated, meaning that the data is relative backscatter, and there is no way to account or correct for instrument drift over time. This drift would effect the numerical representation of backscatter intensity, causing objects that should have identical backscatter intensities to be recorded as having backscatter intensities that are not identical. There is also currently no reliable procedure to quantify absolute backscatter from a $38 \mathrm{kHz}$ ADCP. Therefore, numerical comparisons of counts between different data sets or data sets collected by different $38 \mathrm{kHz}$ instruments are impossible to validate. The ability to compare ADCP data across field seasons and locations is important for correlating studies of the same scattering layers. A wider dynamic range of comparison is necessary before a quantitative calibration can be realized, but the preliminary results presented in Figure 34 are encouraging. 


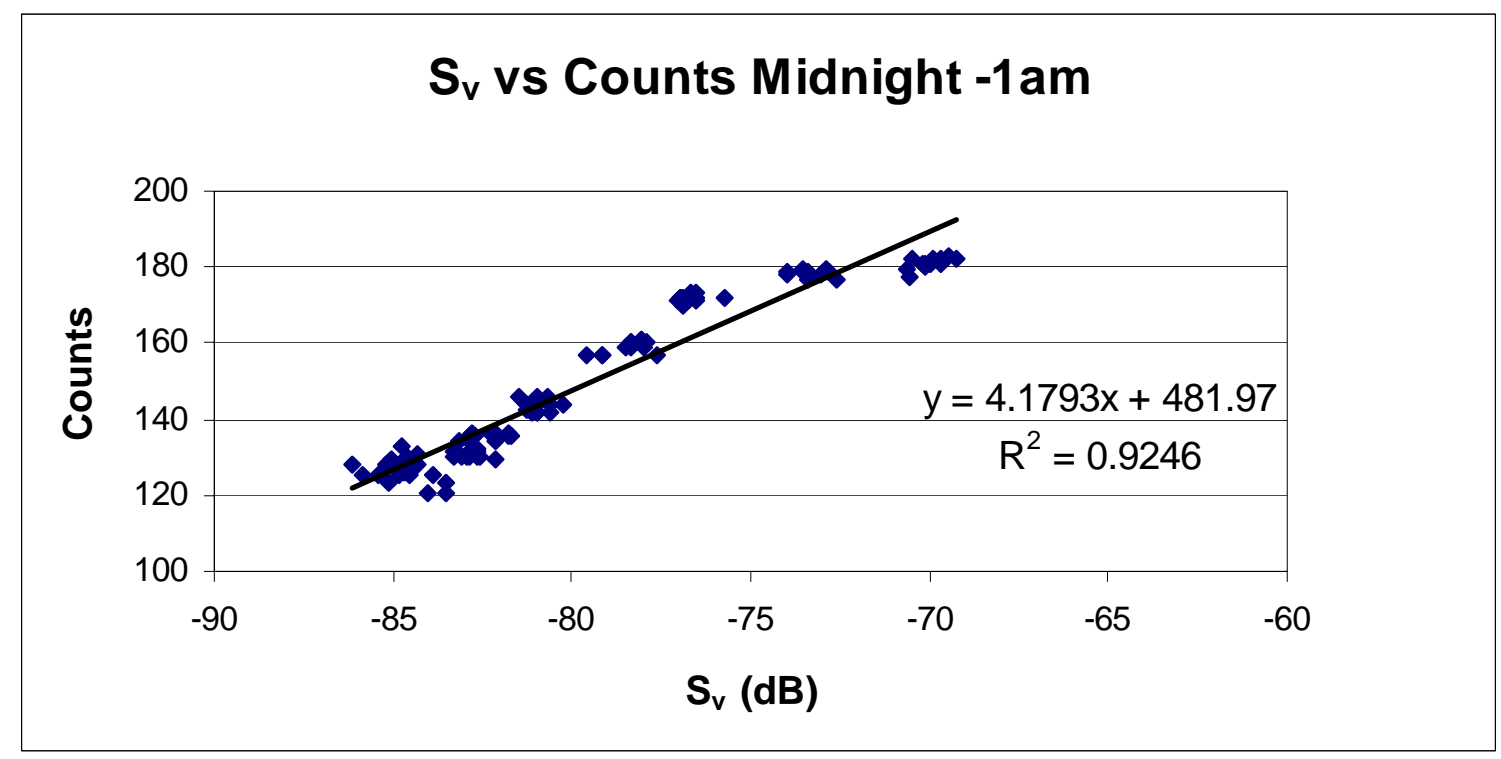

FIG.34. Plot of $\mathrm{S}_{\mathrm{v}}(\mathrm{dB})$ vs. Counts on June 21, for the time period of Midnight to $1 \mathrm{AM}$ (12, five-minute samples). The $\mathrm{R}^{2}$ value of 0.92 demonstrates the high correlation between the ADCP and the fishery echosounder when Counts values are limited to being greater than 120 .

\section{Discussion}

Discrepancies between echosounder and ADCP raw data reflect the instrumental limitations of the ADCP and the echosounder as well as the effects of comparisons between different operating frequencies. While the ADCP is able to resolve Raleigh, or volume, backscatter, it is not capable of resolving backscatter intensities from individual organisms, nor can it accurately represent backscatter from areas where there is little to no aggregation of scatterers. In contrast, the Simrad fisheries echosounder is designed to record individual scatterers as well as volume backscatter and it has a higher sensitivity. Frequently, in the depth range $200-400 \mathrm{~m}$ where the ADCP dropped to very low backscatter recorded levels (80-120 counts), the $70 \mathrm{kHz}$ Simrad recorded low intensity backscatter ( -85 to $-80 \mathrm{~dB}$ ) layers (Kelly Benoit-Bird, communication). This accounts for 
better nighttime correlation in the upper water column but progressively poorer correlation below $200 \mathrm{~m}$.

The lower correlation between $\mathrm{S}_{\mathrm{A}}$ and ADCP daytime data for 9 June at noon was likely caused by the vertical movement of organisms into the upper 100 meters of the water column. At night, more organisms move higher up in the water column and, as shown by the 21 June data, they aggregate more densely, forming a nearly continuous layer of high backscatter. During the day, most organisms migrate to deeper depths, as indicated by the increase in range of the scattering layer from 200-300 m. Because organisms are less tightly aggregated and the ADCP is less sensitive to fine scale changes, it does not recognize gradients in scattering layer density from 49-100 meters as precisely as the Simrad echosounder. Additionally, the higher frequency of the echosounder $(70 \mathrm{kHz})$ allows resolution of smaller sized organisms than is possible with the ADCP $(38 \mathrm{kHz})$. As a result, there is a discrepancy in the upper $50 \mathrm{~m}$, creating the aggregation seen in Figures 30 and 33 where Simrad $\mathrm{S}_{\mathrm{A}}$ values are lower compared to values below $100 \mathrm{~m}$. Despite these discrepancies, the overall positive functional relationship between backscatter measured by the two instruments confirms that the ADCP is a useful tool for evaluating the presence of dense biological scattering layers in the upper and lower water column.

In conclusion, the $70 \mathrm{kHz}$ echosounder has, intrinsically, a higher level of resolution, but the $\mathrm{ADCP}$ is able to resolve deeper because of its lower frequency, however, with reduced resolution. The $70 \mathrm{kHz}$ fishery echosounder can resolve scattering layers to at least a depth of $500 \mathrm{~m}$, but the signal-to-noise for the $70 \mathrm{kHz}$ instrument decreases well 
above this depth confining the comparison of instruments to the upper scattering layer. Based on the high correlation values of the comparisons of $\mathrm{S}_{\mathrm{A}}$ backscatter to ADCP backscatter the hypothesis that the ADCP is recording acoustic backscatter from biological organisms is validated. Some of the discrepancy between the locations of the most intense backscatter returns can be attributed not only to the different design purposes of the instruments but also to the different operating frequencies. The echosounder, because of its higher frequency, is able to record backscatter from smaller organisms where as the ADCP is able to resolve scatterers deeper in the water column but only of a larger size class or density. The comparison of Counts to $\mathrm{S}_{\mathrm{v}}$ is an encouraging start to finding a calibration for the ADCP instrument. 


\section{CHAPTER VI}

\section{ANALYSIS OF ACOUSTIC DATA AND INTERPRETATION OF SPERM WHALE DIVE PROFILES}

\section{Introduction}

During the SWSS fieldwork, towed hydrophone arrays were routinely used to passively detect and track sperm whales (Jochens and Biggs, 2006b). These hydrophone surveys tried to locate animals at night so that when tag boats were deployed the next day, they could be directed to the animals as early as possible. My use of the acoustic data is to examine vocalizations produced during diving. This chapter focuses on the analysis of 'usual' clicks as a means to determine the dive profile of the individual sperm whales during presumed foraging dives. Secondarily, the presence of creaks during dives was used as a proxy to indicate feeding attempts. Creaks, or buzzes are one of three major types of vocalizations and are indicated by a rapid increase in click frequency ending in a buzz or creak like sound akin to the method used by bats (Miller et al., 2004). These creaks are primarily heard during deep dives and are hypothesized to be indications of foraging attempts.

In past studies, researchers have used suction cup depth recorder tags, D-tags (datalogger tags), and radio tags outfitted with depth transducers to collect data on the diving and acoustic behavior of sperm whales (Whitehead, 2003; Miller et al., 2004; Watwood et al., 2006). The data from the 2005 SWSS cruise present long-term passive acoustic tracking of sperm whales and allow for multiple concurrent dive profiles of several animals. It is also the first time that dive profile data from sperm whales at depth in the Gulf of Mexico 
have been integrated with concurrent $38 \mathrm{kHz}$ backscatter data showing the relationship of dives with the subsurface location of the main and deeper scattering layers.

\section{Methods}

During the 2005 SWSS summer cruise a new and improved towed hydrophone array system was used to track sperm whales in the Gulf of Mexico. As explained by Thode (2005) and shown in Figure 35, the array system consisted of two pairs of calibrated hydrophones: the rear pair, located $600 \mathrm{~m}$ from the stern, and the forward array, located $400 \mathrm{~m}$ from the stern. Each array pair was equipped with a pressure sensor to record the depth of the array and autonomous inclinometer dataloggers to measure the dynamic geometry of the array (i.e. local tilt of the hydrophone pairs). The hydrophones had between $165-170 \mathrm{~dB}$ re $1 \mathrm{~V}$ sensitivity and recorded signals in the range of $30-45 \mathrm{kHz}$. The acoustic recordings were low-pass filtered using a Khron-hite model 3944 filter/amplifier and were recorded onto hard drive using an Alesis ADAT HD24XR digital recorder. The signal was high-pass filtered at $100 \mathrm{~Hz}$ to remove flow noise, ship noise and electrical noise (Aaron Thode, communication). Recordings were made whenever sperm whale clicks were detected. The start and stop times of these recordings were manually entered into a spreadsheet along with information regarding the type of vocalizations and the number of whales present. A secondary program, Whaletrack II, was used for documenting start and stop times of clicks and other vocalizations.

A detailed explanation of three-dimensional tracking methods using the towed array can be found in Thode et al. (2002) and in Thode (2005). The methods used to localize whales in 2005 consisted of three parts. The first method involves the pre-processing of 
acoustic recordings using an automated pulse detection program. This program recorded the arrival times and calculates the bearing of all acoustic pulses from the forward and rear arrays. This resulted in the creation of a so-called 'detection file'. Individual sperm whales were identified by either their bearing or time interval between the direct and surface reflected pulse arrivals (Thode, 2005). A custom Graphical User Interface (GUI) and associated scripts were developed in MATLAB by Thode.

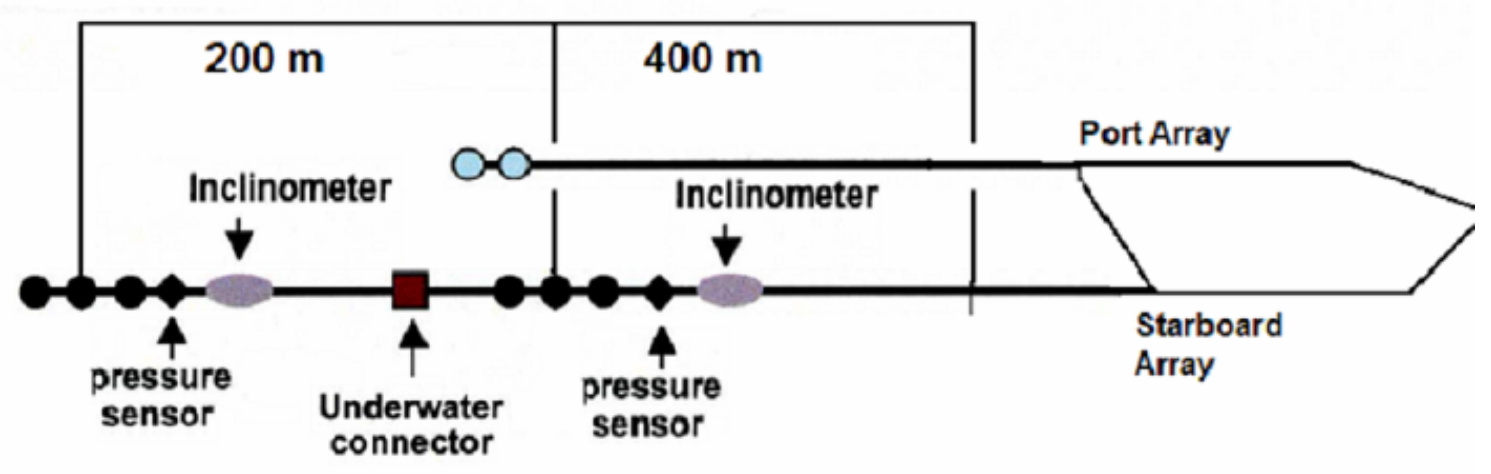

FIG.35. Diagram of passive acoustic hydrophone array setup. Starboard array was equipped with two hydrophone pairs. Each hydrophone pair was equipped with a pressure sensor and an inclinometer (Adopted from Thode (personal communication)).

The GUI works as follows: The estimation of dive profiles for individual sperm whales required the combination of several pieces of information including, click bearings, surface bounces, and the array tilt and depth (Figure 36). The acoustic bearings from clicks recorded with the rear array were used in combination with the surface reflections and acoustic arrival differences between the forward and rear arrays to triangulate the position of the whale click. The tilt and depth of the sub arrays are necessary for accurately calculating the position of the whale because this information is necessary to 
convert relative arrival times and acoustic bearings into range depth and azimuth.

Unfortunately, the tilt of the arrays were not continuously measured in 2005, and thus assumptions about the array shape had to be made in order to estimate each sub-array tilt from the measured array depths.

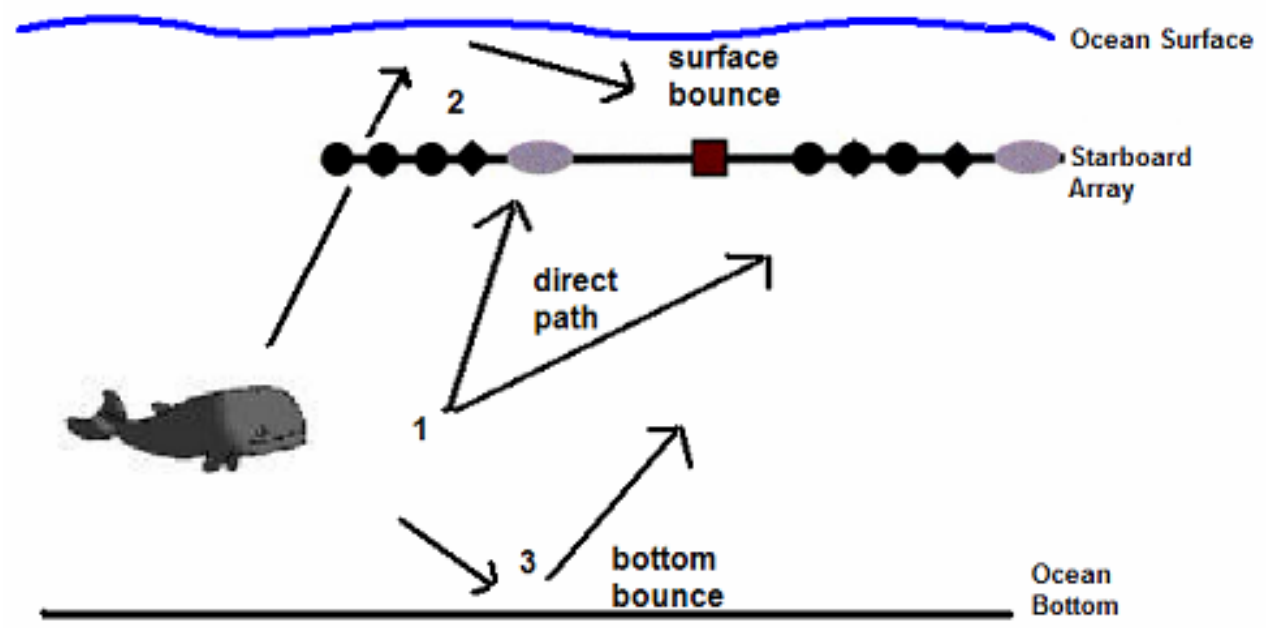

FIG.36. Diagram of acoustic signal arrival order. (1) Direct path (2) Surface bounce (3) Bottom bounce. The blue line at the top of the figure indicates the ocean surface. The representative set up as in Figure 35 depicts the hydrophone array. The black line at the bottom of the graph represents the ocean bottom.

Errors in localization are attributable to several factors. The first being relative and absolute changes in the underwater position of the array pairs. Changes in ship speed and heading can cause bending or sinking of the array, which may violate the assumptions made by the tracking algorithms including constant speed, heading, array depth, and tilt. 
The use of acoustic bottom bounces can help validate whale position by providing an extra localization parameter. Unfortunately, bottom bounces are not always available in the acoustic recordings, making validation of some dive profiles more difficult than others. However, surface echoes on the forward sub-array can be used to check the tracking results. Secondly, while the array can hear sperm whales at a distance of $6 \mathrm{~km}$, we are only able to localize sperm whale clicks at a slant distance of about $1 \mathrm{~km}$ or 20 ship-lengths because the animals are often diving to depths of 600-800 m, and are rarely located directly below the arrays. Animals at depth are close to the tracking range limit of the array, so small errors in measuring track parameters can translate into large positional errors.

I worked with Aaron Thode to derive accurate dive profiles of sperm whales using the GUI. The initial step was to identify click detection files that coincided with the times when good acoustic backscatter data were available. Individual whale tracks were then extracted from the detection files and checked for accuracy, completeness, and quality. This entailed verifying that there was no overlap of one whale profile with the profiles of other whales in the area. Impulsive ship noise could create false detections, so pulses arriving from bearings of less than 20 degrees with respect to the forward direction were rejected. Therefore, to separate simultaneously clicking animals, the processing relied on the bearings of clicks recorded by the rear array. The localization of the whales and the estimation of dive profiles were done by triangulating the acoustic signals. 
This process also allowed for manual corrections for array depth and tilt permitting the sensitivity of the location profiles to change in modeled array depth and tilt to be checked. The resulting localizations were checked for errors in depth and tilt assumptions by using the derived 3-D tracks to estimate the relative arrival time of a surface-reflected path on the forward sub-array, data that were not originally used to derive the tracking profile. Once an acceptable profile was created, it was saved as an independent track file and plotted using the MATLAB GUI (Figure 37). The top two plots in Figure 37 show the echo delay for the forward and rear arrays. The echo delay is the time between the arrival of the direct path and the surface reflection of the click. The second two plots show the ship heading and ship speed, respectively. When isolating dive profiles it is important that both the ship speed and ship heading are constant because the algorithms used to calculate the position of the whale make the assumption that both speed and heading are constant. 


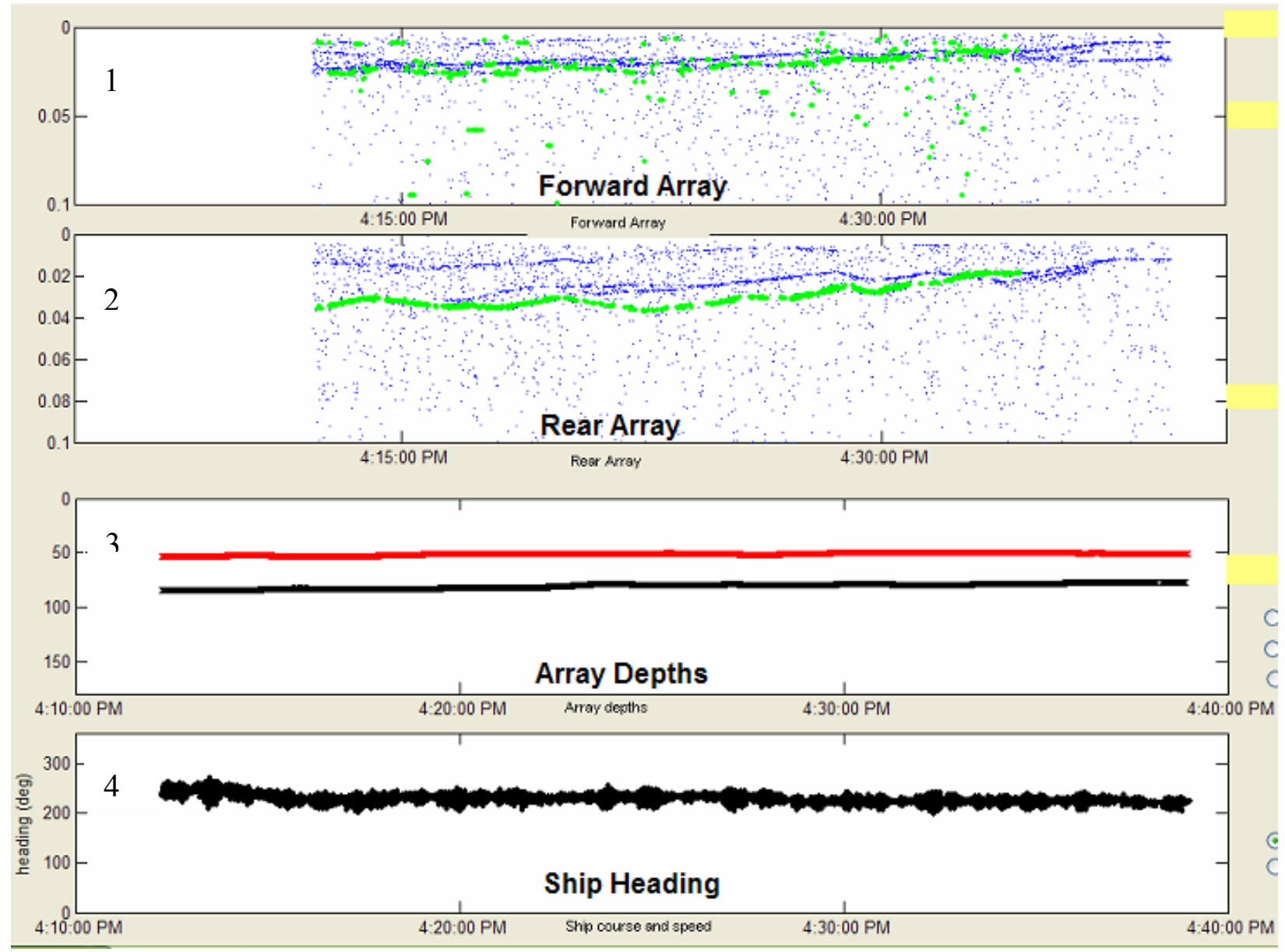

FIG.37. GUI Viewer window as it appears after one whale track has been selected. This is the track from 9 June 2005 4:10-4:40 PM as seen in Figure 46. (1) Echo delay for the sperm whale clicks recorded by the forward array. (2) Echo delay recorded by the rear array. The green line is the selected track. (3) Array depths, red is forward, black is rear array. (4) Ship heading.

When the initial track selection is completed, there are several secondary windows that appear which allow the user to check the accuracy of the track selected. Figure 38 is the corresponding window to the track selected in Figure 37. The three boxes show direct surface echo times from the forward and rear array followed by the difference in arrival time between the two sub arrays, respectively. 

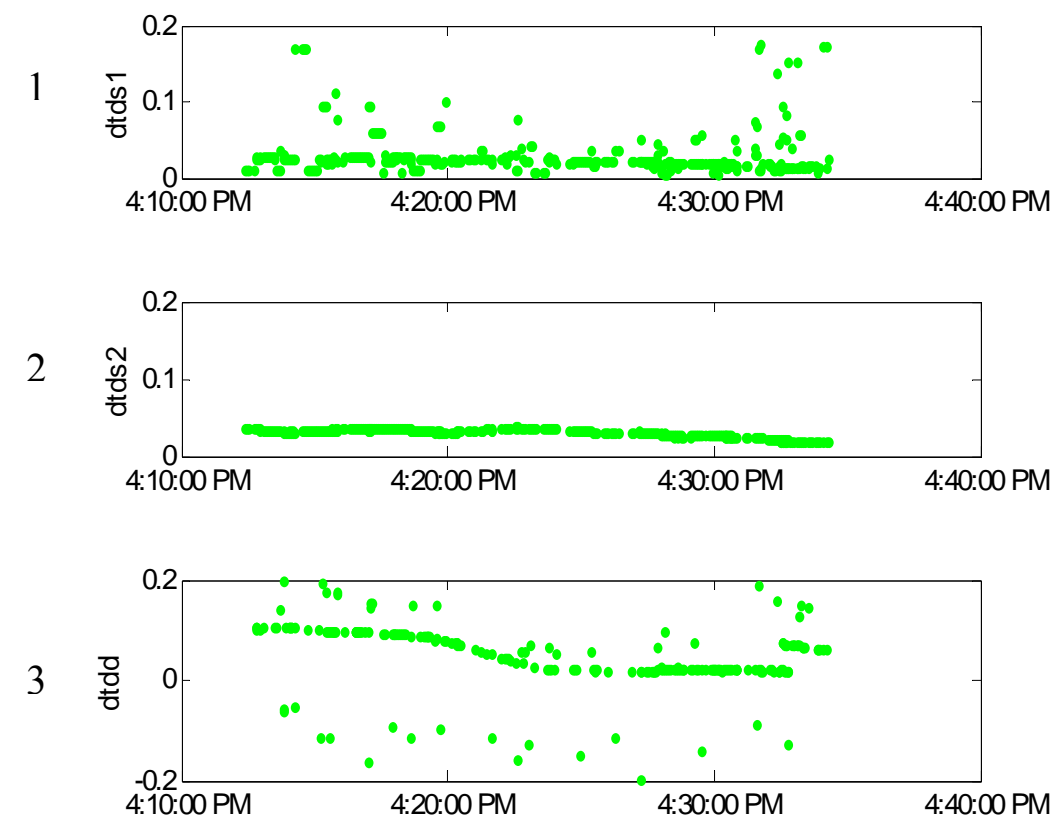

FIG.38. GUI Viewer plots of surface echo times for 9 June 2005. (1) Direct surface echo arrival time from forward array relative to direct path arrival. (2) Direct surface echo from rear array. (3) Difference in click arrival times between forward and rear array.

In order to verify that the track selected does not overlap with or include any other whale dive profiles, the GUI creates an additional plot shown in Figure 39. The top boxes show the bearings of the track in reference to what the rear array and forward array record. If the plots show one continuous trajectory, instead of discontinuous segments, this provides verification that only one animal is being represented by the localization. The track recorded by the forward array generally has more false detections than the rear array because of ship noise interference. Therefore, both a clean forward and clean rear array bearing plot are strong evidence for an accurate track selection. 

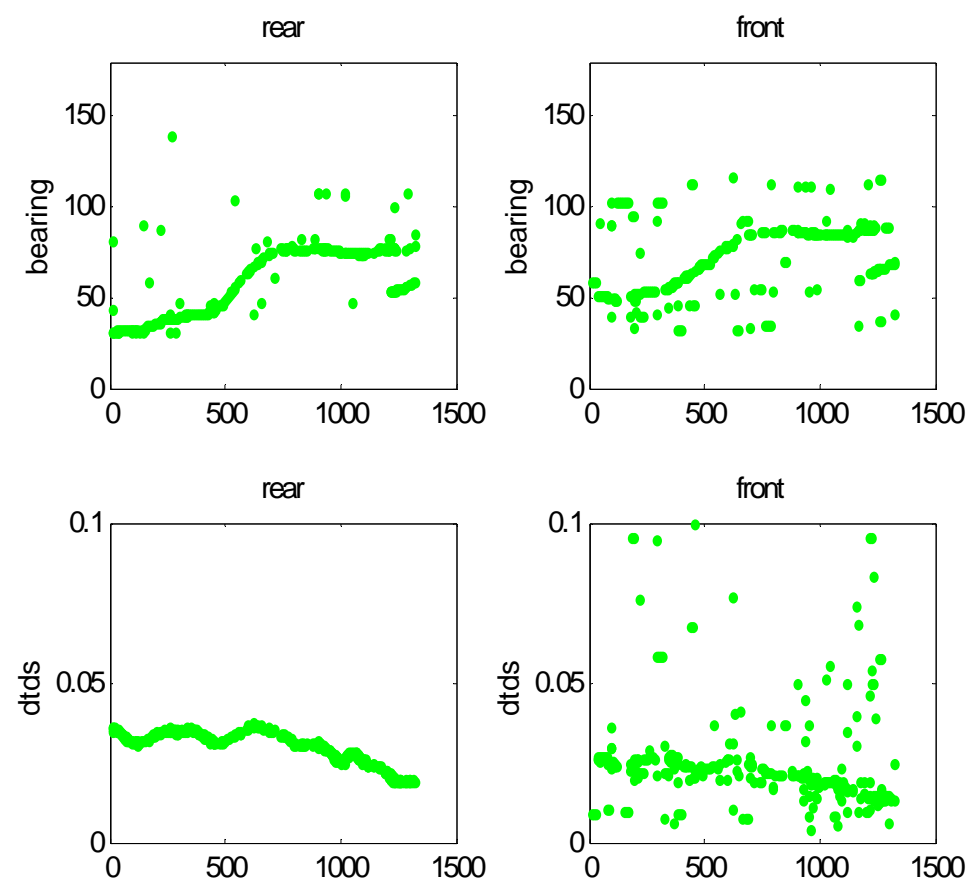

FIG.39. GUI Viewer plot of selected track bearings for 9 June 2005. Top pair shows forward and rear bearings for the selected track. Bottom pair shows echo times from forward and rear array.

Once the selected track has been checked for errors the dive profile can be localized. This is the point where corrections can be made to the assumed array depth, which affects the derived array tilt. The localization program can be run several times with the array depth adjusted differently until the profiles best match additional measurements of surface reflected paths on the forward array. For this analysis, the tilt correction recorded on the localization plot should be within two degrees. Figure 40 shows the raw output of the localization process. The three plots show the raw dive profile, range of the animal, and the animal's bearing (azimuth), respectively. 
:-fit local tilt: 6.61 degrees, global tilt: 9.19 , tilt correction: 2.00 array depth correction: [ 0.00

1
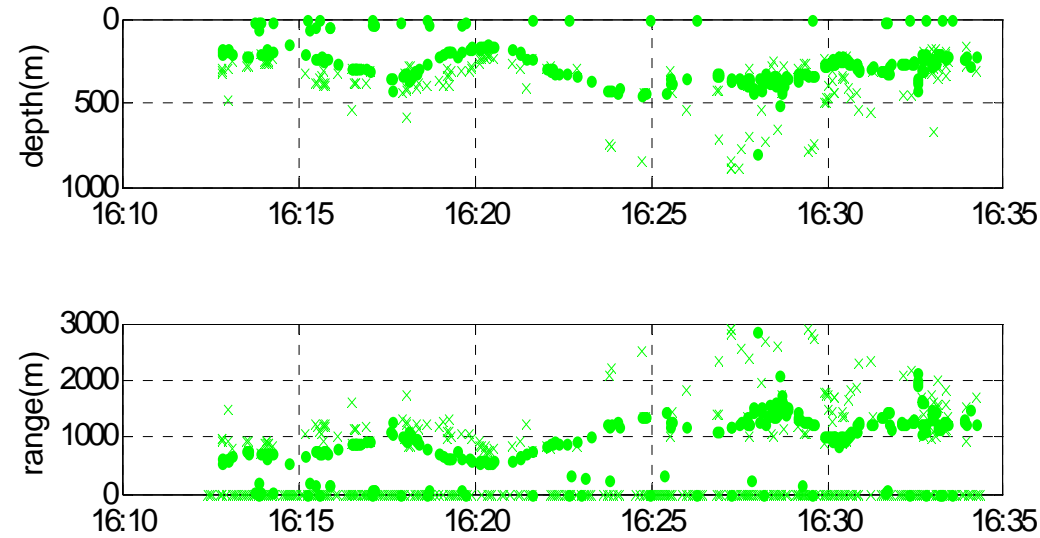

3

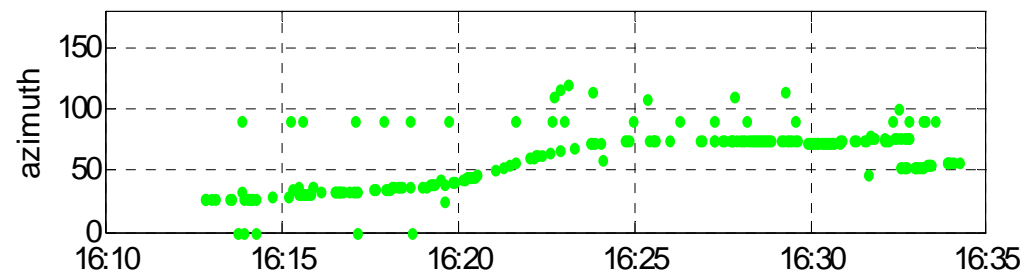

FIG.40. GUI Viewer plot of localized dive profile from 9 June 2005. (1) Localized dive profile. (2) Range of localized animal. (3) Animal azimuth.

The initial track files were not quality controlled and required further processing to remove errors in individual localization points (Figure 41). First, all negative depths (indicating the whale location to be above the surface of the water) were removed, as were all depths greater than the bottom, usually about $1200 \mathrm{~m}$. These data were regraphed and compared with the raw data to ensure that the integrity of the profile was intact and that no points were incorrectly removed. Secondly, outliers and portions of the dives that were not likely to be accurate given the vertical distance traveled over the time period were removed (Figure 42). For example, it is unlikely that a sperm whale would change vertical location by more than $500 \mathrm{~m}$ in less than 5 minutes, as this would exceed the average dive speed of 60-90 meters per minute (Whitehead, 2003; Watwood et al., 
2006). Because the accuracy of the calculated whale position decreases with depth, I accepted more vertical movement for dive depths below $500 \mathrm{~m}$ than for shallower dives in what appears as box and whisker plots, whales are assumed to be within the 'whisker' at the deeper depths, but not actually moving their vertical location at such extremes. Lastly, the dive profiles were overlaid with the backscatter data creating plots showing whale location in relation to scattering layers identified by the $38 \mathrm{kHz}$ ADCP (Figure 43).

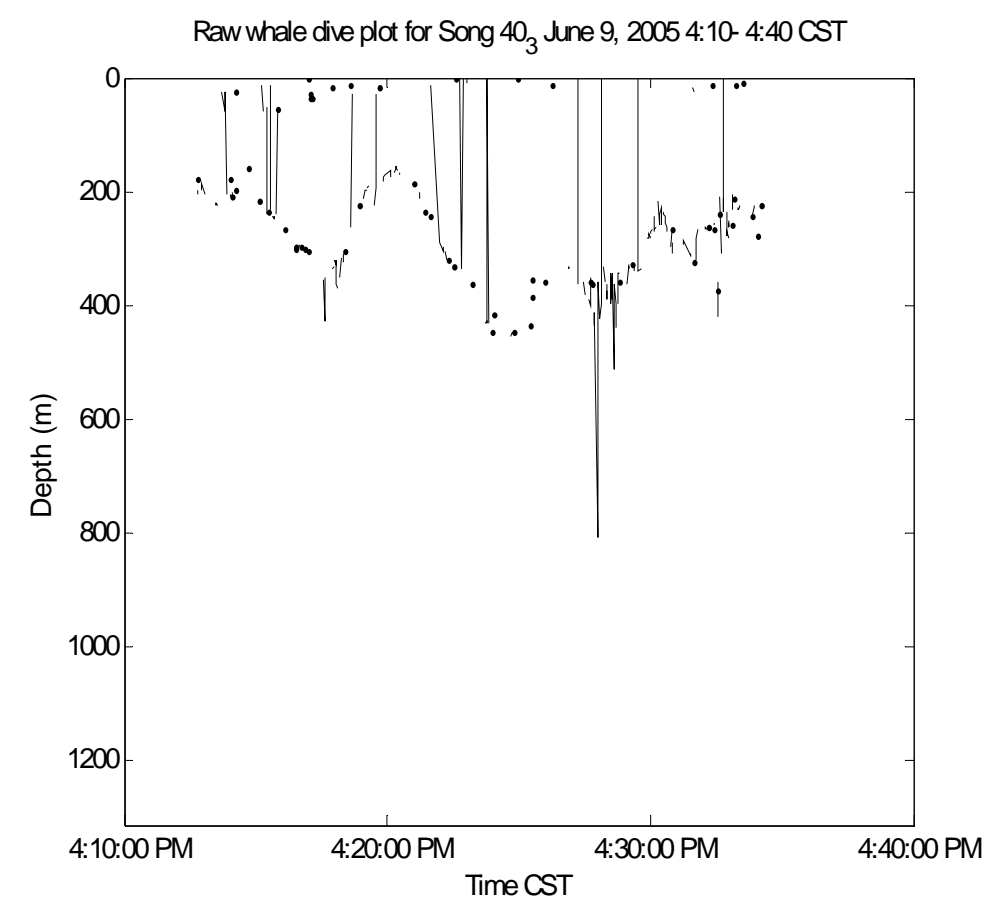

FIG.41. Raw whale dive profile June 92005. 


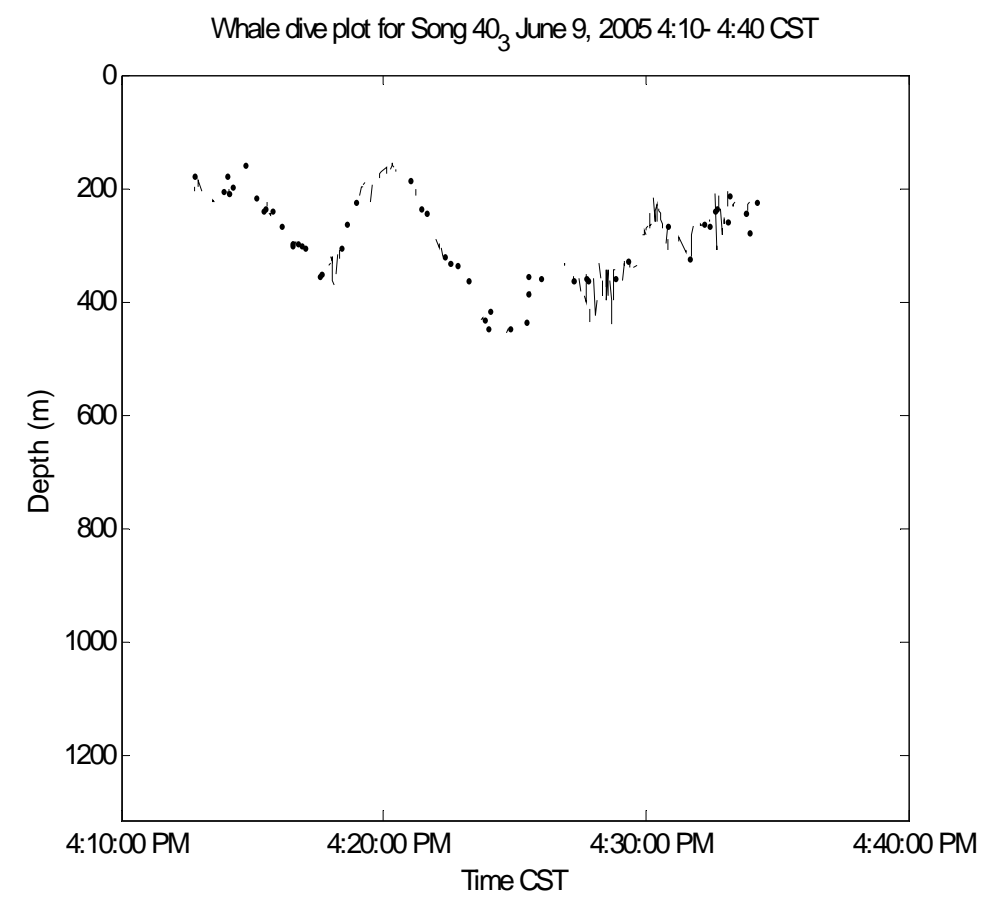

FIG.42. Quality controlled (edited) whale dive profile 9 June 2005.

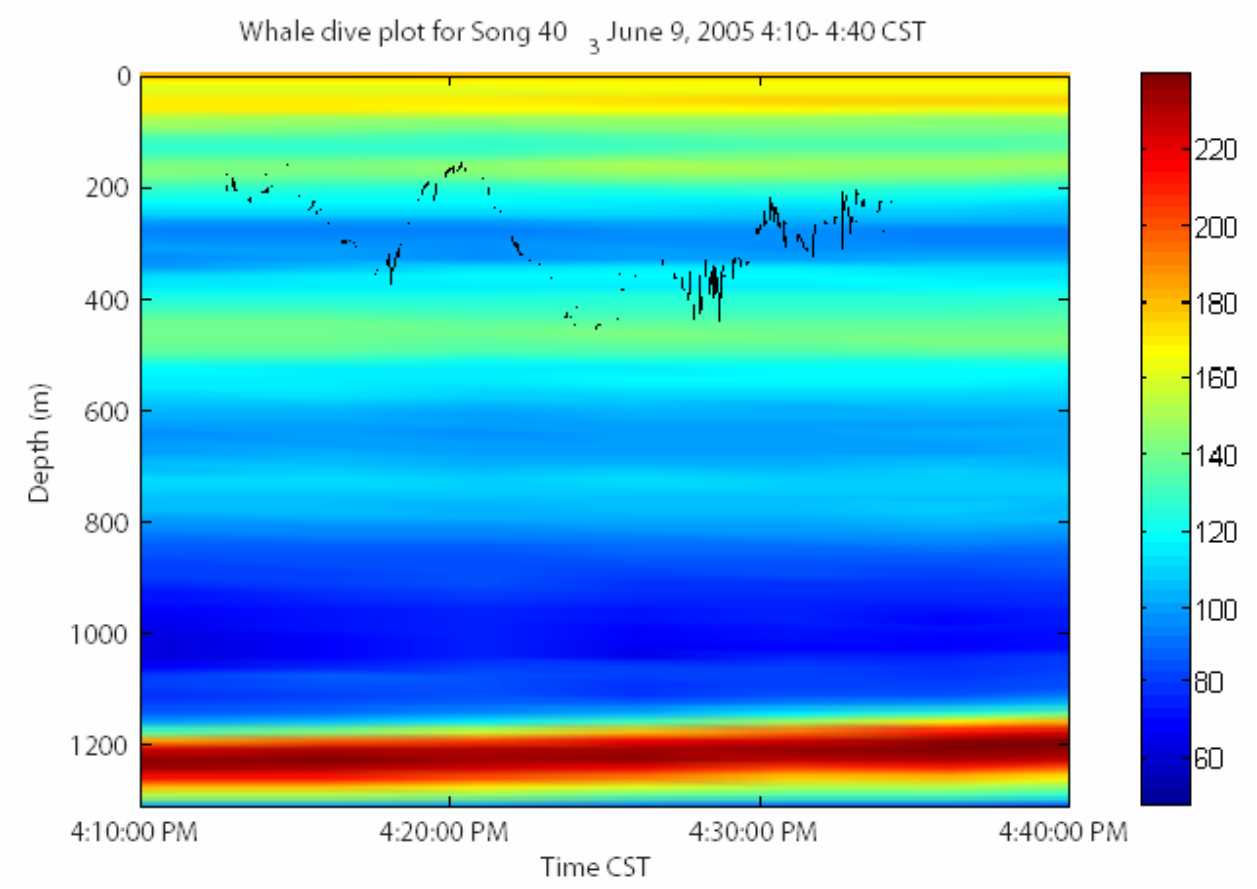

FIG.43. Superimposed plot of quality controlled localized dive profile over ADCP backscatter for 9 June 2005. 
The depth accuracy of the dive profiles is dependent on two factors, the precision of the timing measurements and the accuracy of the modeling assumptions to convert these measurements into localizations. The localization is highly dependant on the assumptions made of the array shape and sound speed profile. Sound speed profiles are dependent on the density of the water. In areas off the continental slope water density is dependent on temperature more than salinity. While sound refraction does occur in the water column it would only affect localizations more than $1 \mathrm{~km}$ away and thus is not expected to be an issue for the localization of whale dive profiles in 2005. The two largest parameters contributing to possible inaccuracies are the unknown tilt of the arrays and the distance of the whale from the ship.

The figures included in the results section show increasing variability associated with whale distance below surface (i.e. increased distance from ship). The localizations when sperm whales are closer to the surface are more detailed and more continuous. Dive profiles showing a lot of whisker vertical range at depths below $500 \mathrm{~m}$, tend to be patchier with times when the profile disappears. A large distance means that triangulation of the measurements from the forward and rear sub-arrays become more sensitive to small uncertainties in the measurements. The increased distance from the paired array also means that the arrival time of the direct path and the surface reflection to the arrays will be closer in time and thus more prone to measurement error.

\section{Results}

The profiles presented in this thesis are listed in Table 14 along with the date, dive duration, and minimum and maximum dive depths. Thirteen daytime profiles and three 
nighttime profiles were localized for this analysis. My analyses showed that some sperm whales are diving below the main scattering layer, in a combination of deep dives $(>500$ $\mathrm{m})$ as well as shallower dives $(<500 \mathrm{~m})$ and occasionally a combination of both during any one dive. Figure 44 shows this type of combination dive. The black line indicates the sperm whale dive track and the heavy red line at the base of the graph is the bottom. The main scattering layer is the heavy green horizontal line between 400 and $600 \mathrm{~m}$, while near surface scattering shows up as green and yellow shades from the surface to $250 \mathrm{~m}$.

TABLE 14. Figure number, Date, Time, Duration, and Min and Max dive depth for each dive profile.

\begin{tabular}{|c|l|l|c|c|c|}
\hline Figure Number & Date & Time & Duration & Min Dive Depth & Max Dive Depth \\
\hline Figure 44 & June 9 2005 & $4: 15 \mathrm{PM}$ & $30 \mathrm{~min}$ & $\sim 150 \mathrm{~m}$ & $\sim 1100 \mathrm{~m}$ \\
\hline Figure 45 & June 9 2005 & $4: 50 \mathrm{PM}$ & $30 \mathrm{~min}$ & $\sim 75 \mathrm{~m}$ & $\sim 1100 \mathrm{~m}$ \\
\hline Figure 46 & June 9 2005 & $4: 10 \mathrm{PM}$ & $30 \mathrm{~min}$ & $\sim 200 \mathrm{~m}$ & $\sim 450 \mathrm{~m}$ \\
\hline Figure 47 & June 12 2005 & $11: 00 \mathrm{AM}$ & $30 \mathrm{~min}$ & $\sim 100 \mathrm{~m}$ & $\sim 900 \mathrm{~m}$ \\
\hline Figure 50 Black & June 9 2005 & $10: 50 \mathrm{PM}$ & $30 \mathrm{~min}$ & $\sim 100 \mathrm{~m}$ & $\sim 1100 \mathrm{~m}$ \\
\hline Figure 50 Blue & June 9 2005 & $11: 50 \mathrm{PM}$ & $30 \mathrm{~min}$ & $\sim 200 \mathrm{~m}$ & $\sim 1000 \mathrm{~m}$ \\
\hline Figure 51 & June 8 2005 & $11: 00 \mathrm{PM}$ & $30 \mathrm{~min}$ & $\sim 100 \mathrm{~m}$ & $\sim 750 \mathrm{~m}$ \\
\hline
\end{tabular}




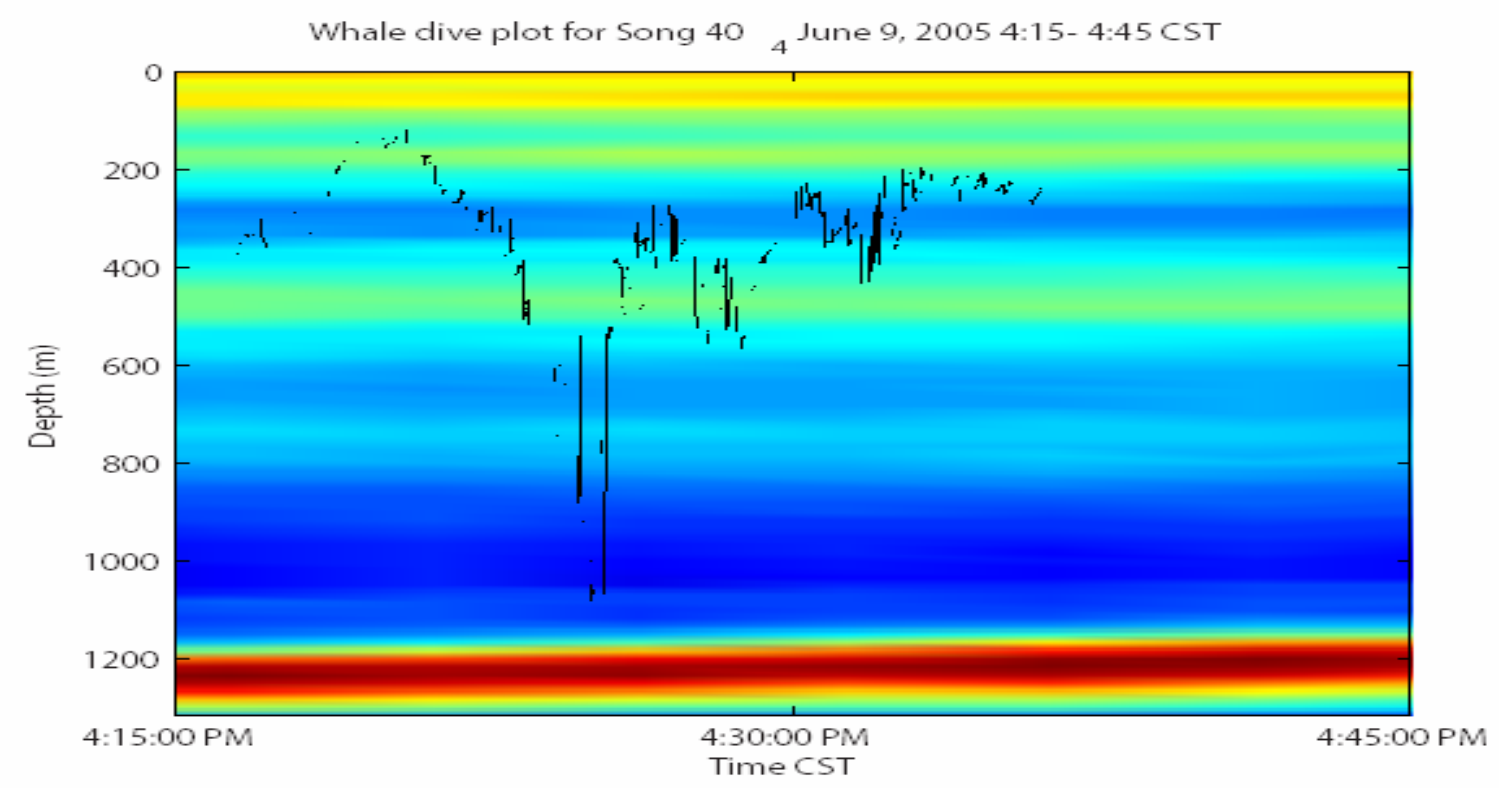

FIG.44. A combination sperm whale dive of deep and shallow movement recorded 9 June 2005 in the late afternoon from 4:15 to 4:45 PM. The black line shows the whale dive profile. Dive shows movement to depths as great as $1100 \mathrm{~m}$ with passage through main and secondary scattering layers. ADCP data are averaged into 5 -minute intervals.

Most deep dives of the sperm whales observed went to 500 to $800 \mathrm{~m}$ (Figures 44, 45, and 47). It appears that whales may presumably be foraging below the main deep scattering layer in the patchier layers found between 600 and $800 \mathrm{~m}$ and sometimes up to 100 meters off the bottom. There is no apparent change in this dive depth between horizontal locations or inside or outside of divergent areas. The shallower dives sometimes show whales moving up and down through the near surface scattering to $500 \mathrm{~m}$ and also moving in and out of the deep scatter layer from 400 to $600 \mathrm{~m}$ (Figure 46). These shallower dives do not usually show a combination of extended shallow dives followed by deep dives, but often show shallower movement with a deep dive ( $>500 \mathrm{~m})$ towards the middle of the dive, followed by a rapid ascent to shallower depths. 


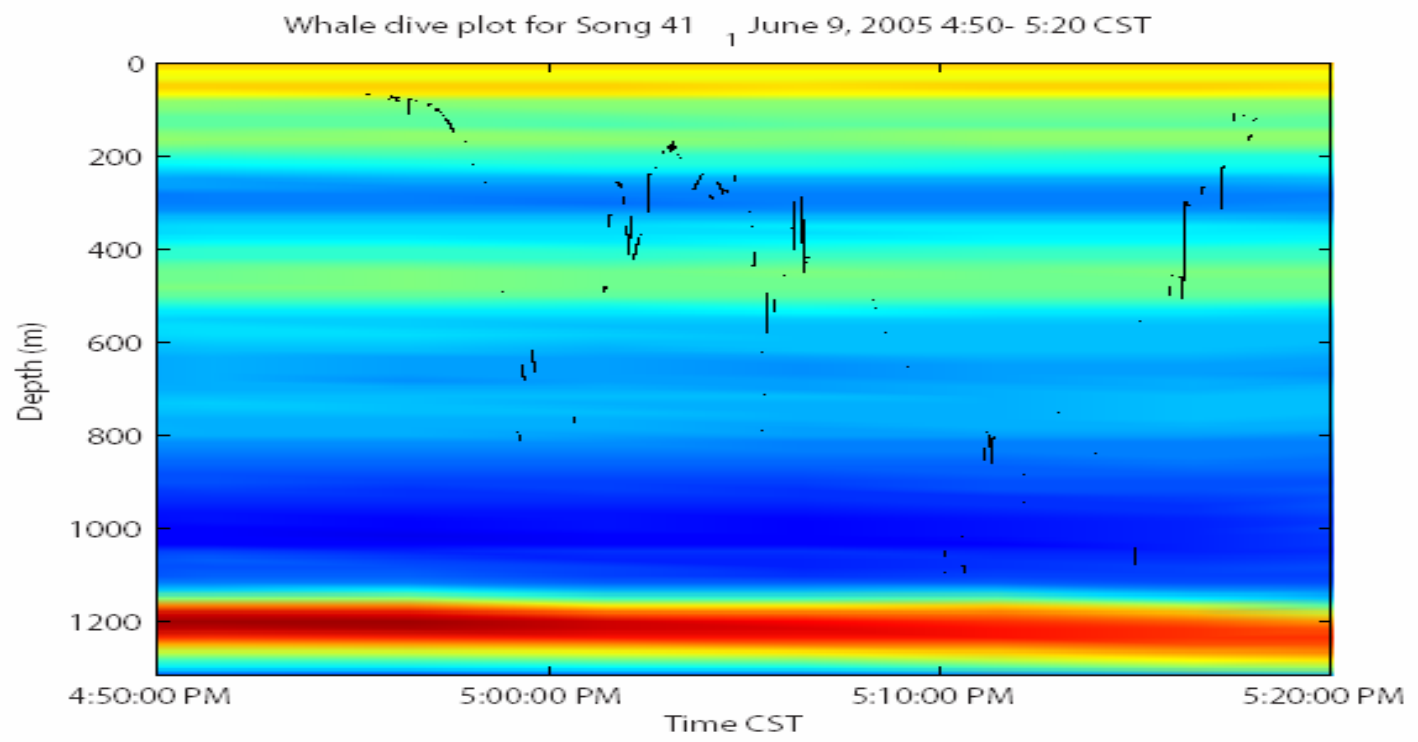

FIG.45. Deep dive recorded 9 June 2005 from 4:50-5:20 PM. Profile shows sperm whale diving twice to depth of 500-800 $\mathrm{m}$ and perhaps as deep as $1100 \mathrm{~m}$. This plot is one of few examples where the complete sperm whale dive is tracked from the surface to depth and back to the surface. Appearance of whale track at $50 \mathrm{~m}$ is attributable to typical absence of clicks for the first 5 seconds of a dive.

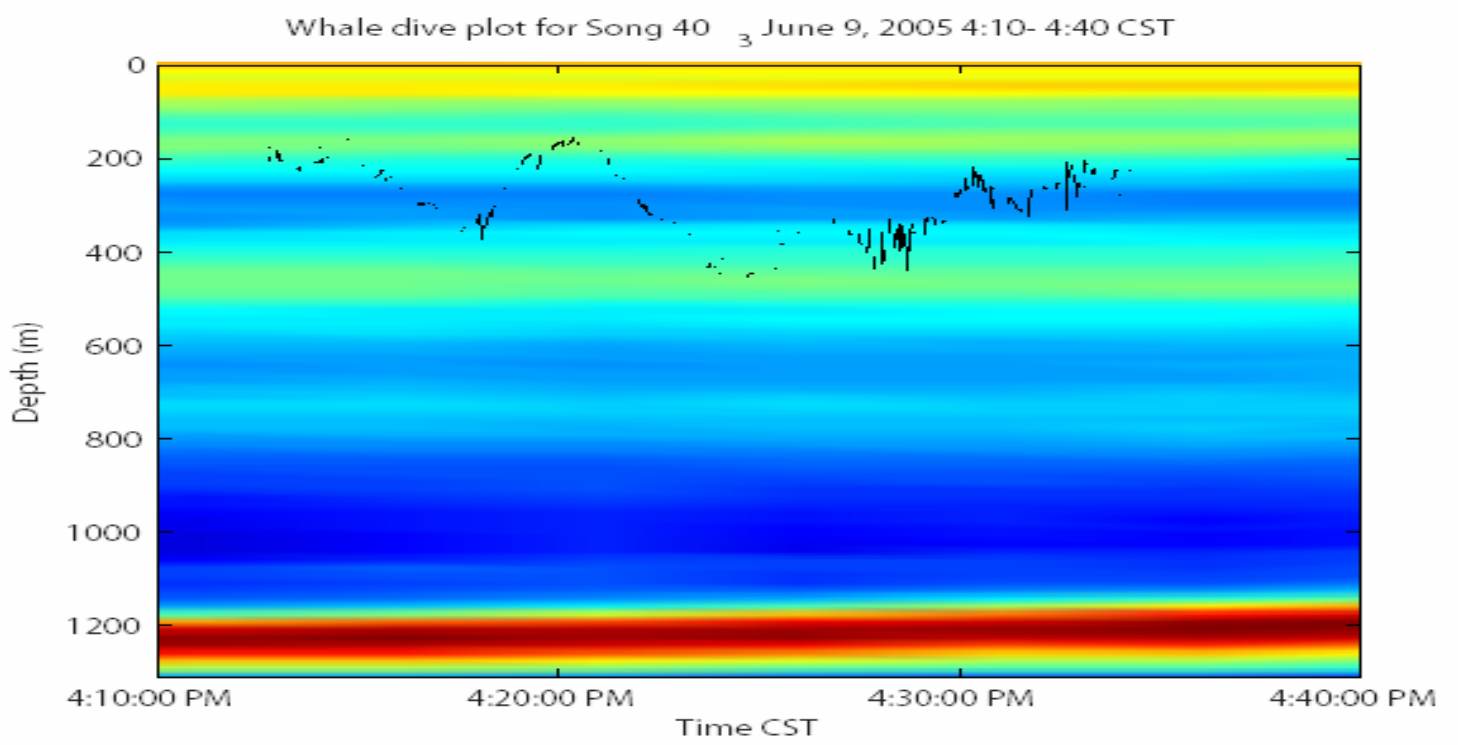

FIG.46. Example of extended shallow diving on 9 June 2005 from 4:10 to 4:40 PM. This dive shows a sperm whale moving in and out of the near surface scattering layer. 


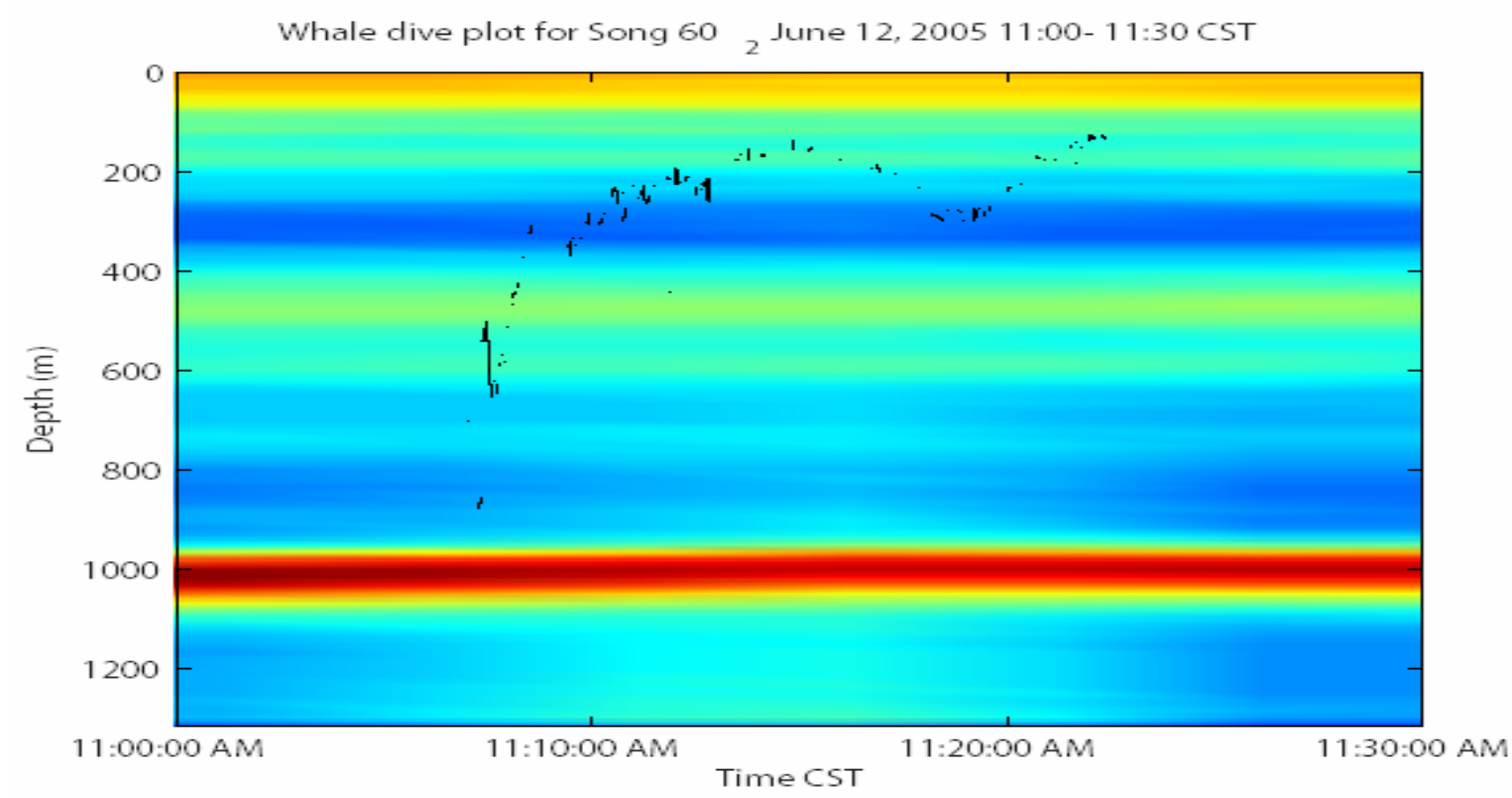

FIG.47. Dive profile from 12 June 11:00-11:30 AM. Whale track of a sperm whale beginning its ascent after a deep dive of about $900 \mathrm{~m}$. The sudden appearance of whale at depth is likely due to the ship suddenly being able to triangulate the location as it arrives within a kilometer of the animal's location.

The use of passive acoustic array recordings allows another avenue of whale behavior to be explored. Previously, it has only been possible to create whale tracks of one animal during any one period of space and time. Because the array set up allows the recording of multiple whales during the same time period, it is also possible to localize several whales and plot them simultaneously. Figure 48 is a dive profile containing three individual whales. The whale tracks from Figures 44 and 46 overlap considerably making them difficult to distinguish at times. The third whale in the plot is located near the surface and is completely separated from the other two profiles. 


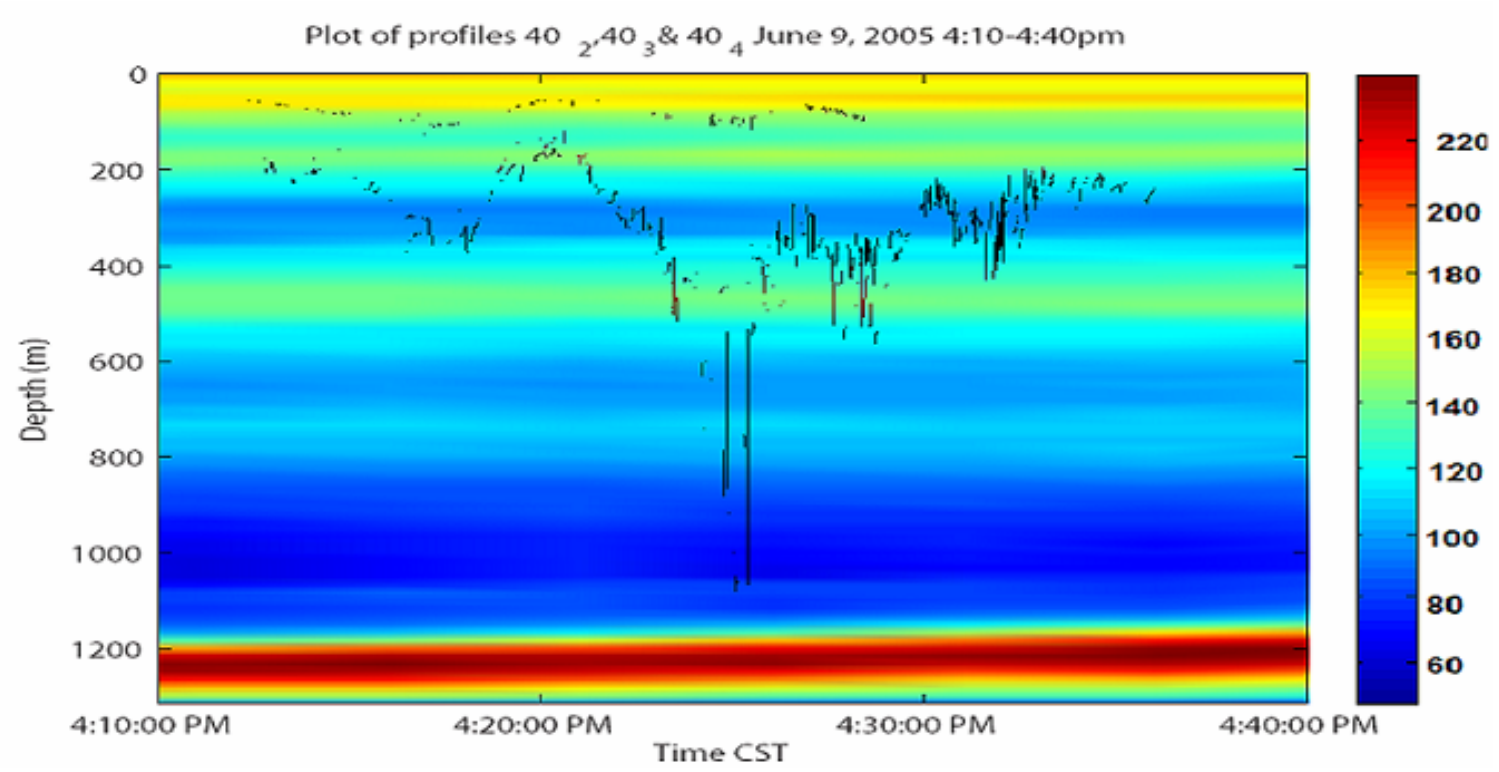

FIG.48. Whale dive profile of three simultaneous dives superimposed over ADCP backscatter 9 June 2005.

Because the hydrophone array was recording continuously, it was also possible to localize whale profiles at night. Figures 49, 50 and 51 show whale dive profiles localized from nighttime recordings. Figure 49 shows two simultaneous dive profiles separately. Figure 50 is an additional example of a simultaneous dive profile. Nighttime survey efforts to keep pace with whales or search for new groups of whales were often punctuated by periods of increased speed, resulting in very noisy ADCP data. Because of this, the nighttime dive profiles were not superimposed over nighttime ADCP profiles. 


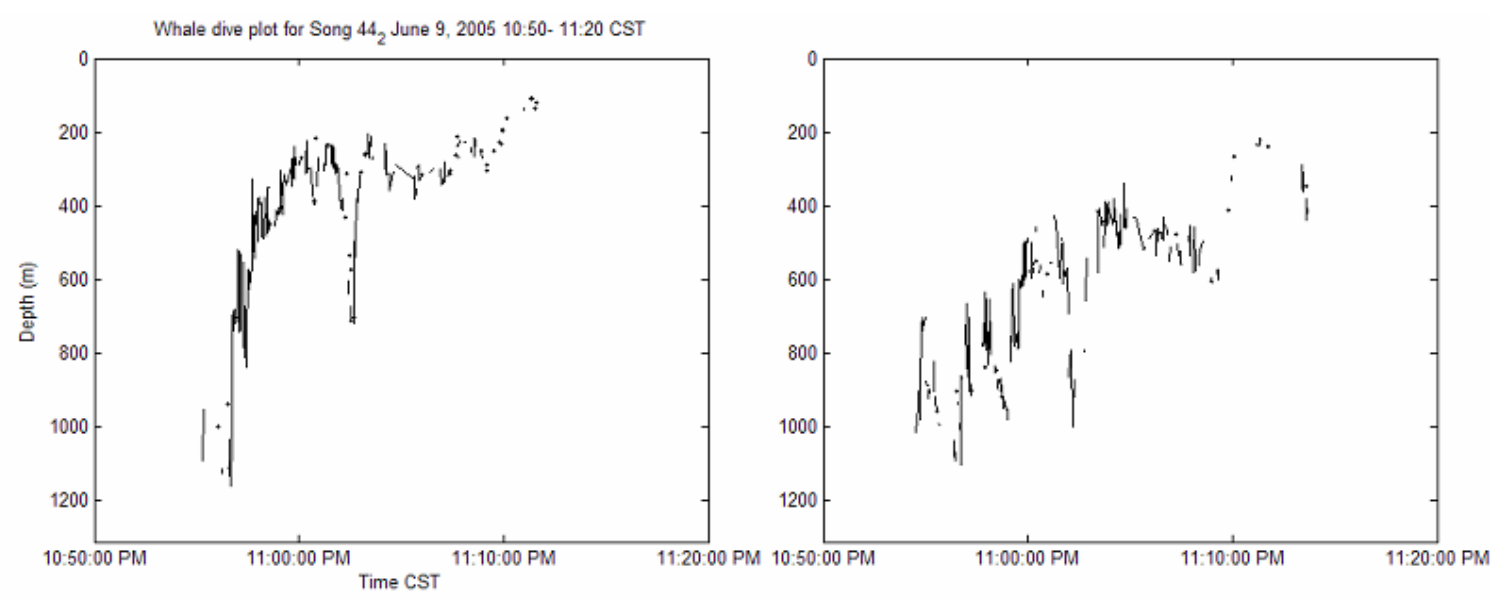

FIG.49. A pair of nighttime whale dive plots from 9 June 2005 during the same time period from 10:50 -11:20 PM.

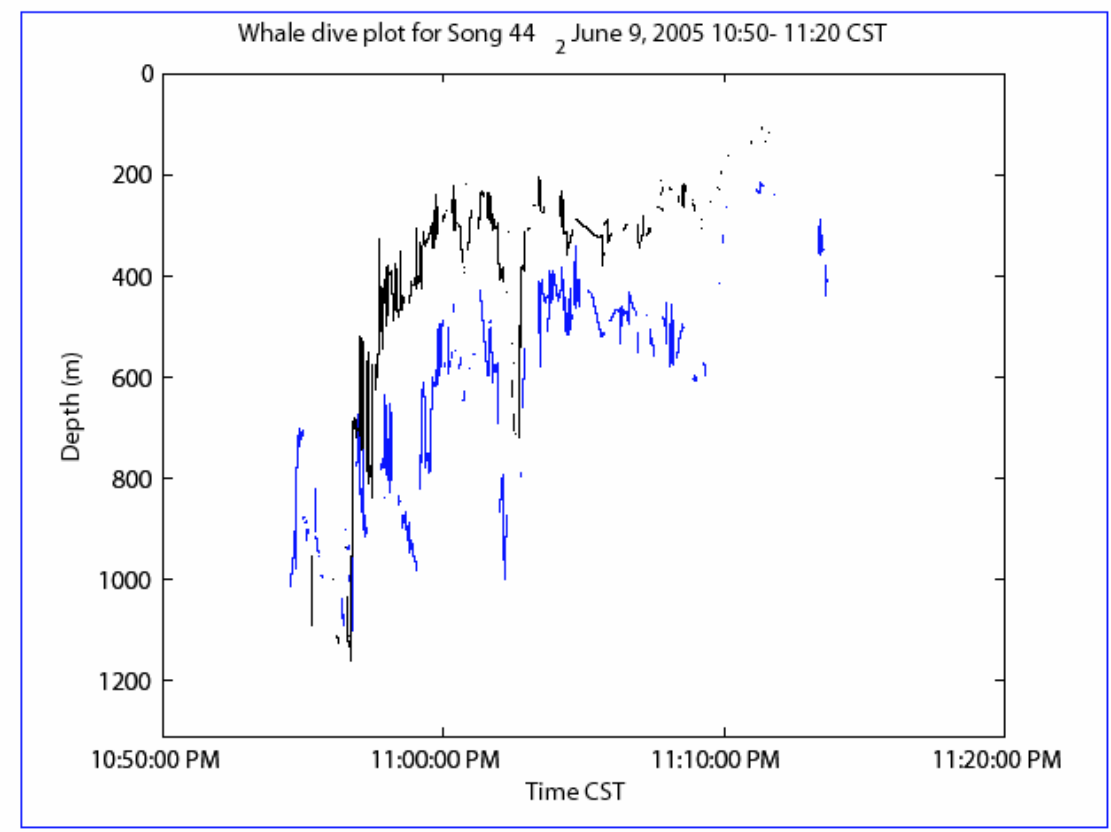

FIG.50. Superimposed simultaneous dive profiles from Figure 49 on 9 June 2005. 


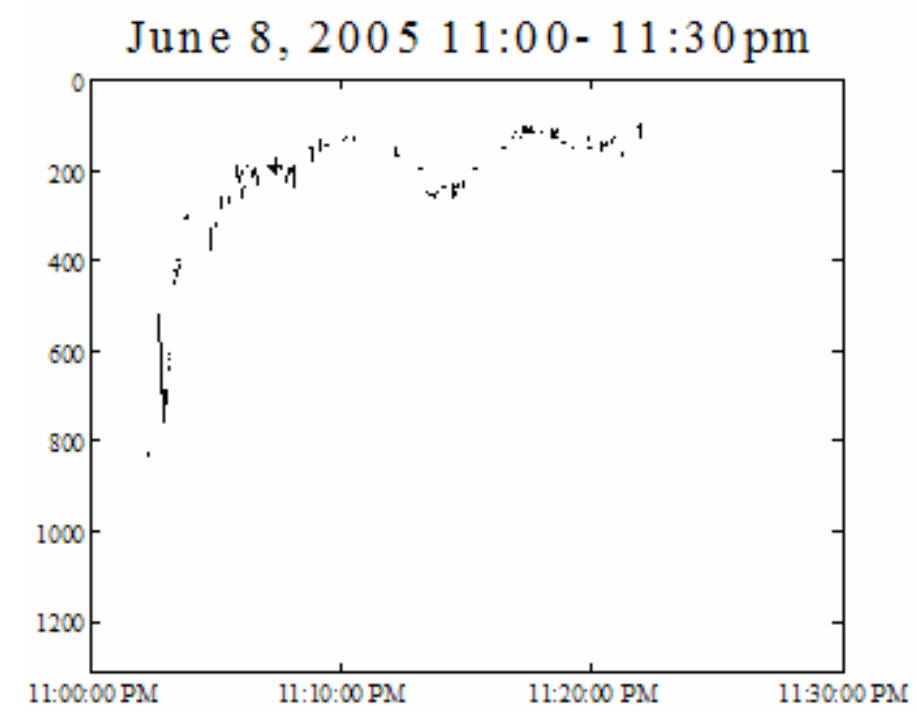

FIG.51. Plot of nighttime profile from 8 June 2005 11:00 -11:30 PM.

Comparison between the nighttime plot in Figure 51 and the daytime plot in Figure 47 are strikingly similar suggesting that whales are not changing their dive patterns based on time of day. This supports sperm whale dive profiles collected by researchers at Woods Hole Oceanographic Institution (WHOI) shown in Figure 52 (Mark Johnson, 2003). The discrepancy in dive patterns between the WHOI dive plots which show multiple repeated deep dives and the profiles from 2005 can be attributed to the incomplete representation of data from the 2002 and 2003 WHOI research. Figure 52 is specifically designed to investigate whether sperm whales changed their diving behavior based on time of day. Because the full data set is currently unpublished it is not possible to tell whether those dives presented in Figure 52 are representative of general dive behavior. It is also possible that the proximity of the ship may affect sperm whale behavior, which would influence all dive profiles presented. 

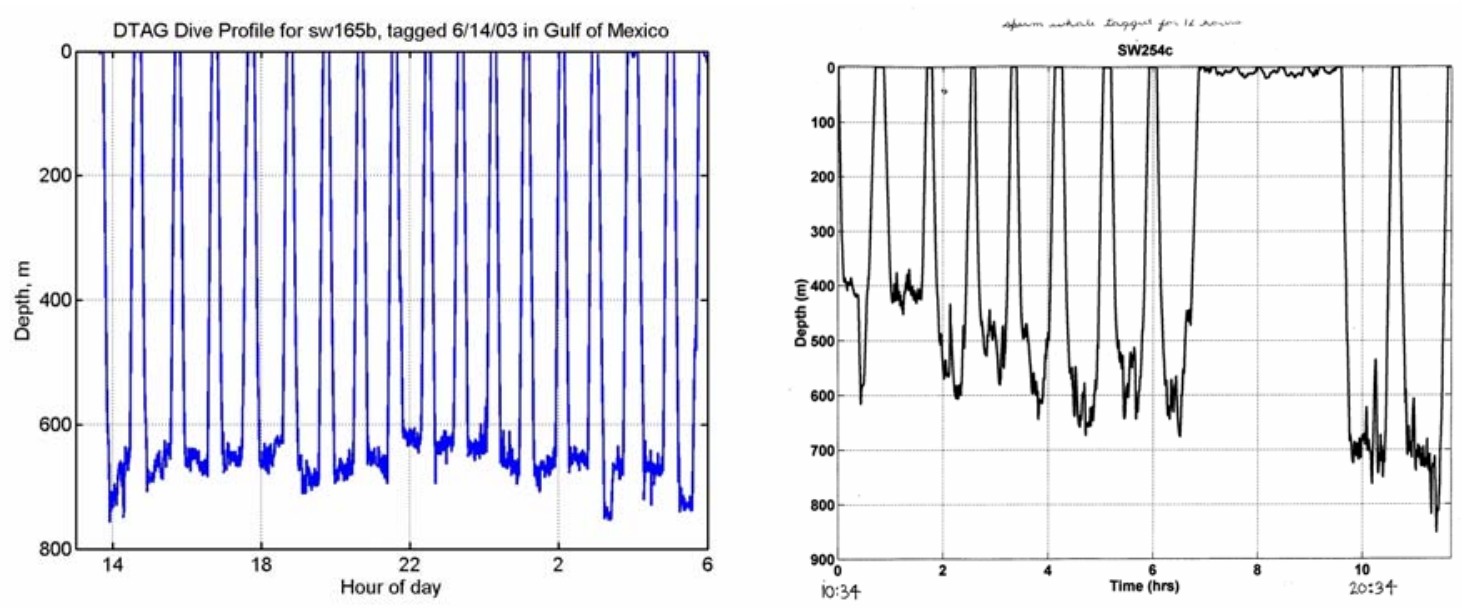

FIG.52. Dive plots of sperm whales D-tagged by WHOI in the northeast Gulf of Mexico, June 2003 and September 2002, respectively (These are unpublished data of Mark Johnson, 2003).

Based on the results of the Chapter III investigation of main deep scattering layer characteristics, I did not compare differences in dive profile depths between divergent and non-divergent location since they were not significantly different. The conservative number of dive profiles I was able to localize prevented any meaningful statistical analysis of dive depth preference. Based on the variety of profiles types the division of dive profile depths into categories may not be statistically significant. In light of this, the analysis done on the dive profiles was qualitative rather than quantitative.

An analysis of creak data, designed to detect incidences of whales creaking, indicates that whales diving to depths greater than $500 \mathrm{~m}$ are actively creaking (buzzing). My analysis also indicates that whales actively making shallower dives are also creaking. Whales traveling horizontally or with little vertical movement do not appear to be actively foraging, since there is a lack of creaks during those times. These data are still preliminary and will be the focus of continued research. 


\section{Discussion}

The dive profiles obtained from the 2005 hydrophone passive acoustic data concur with previous observations of diving sperm whales and exhibit similar dive depths although the dive patterns are not identical (Watwood et al., 2006). The deeper dives of sperm whales in 2005 went to between 500 and $800 \mathrm{~m}$, which is within the range of data recorded from the WHOI D-tags deployed in previous summers (Figure 52) and from an S-tag outfitted with a depth sensor that was deployed by Oregon State University in summer 2005. The data from those deployments showed an average dive depth of between 400 and $778 \mathrm{~m}$, but on 10 dives the S-tagged animal reached depths of 1000$1300 \mathrm{~m}$ (Ladd Irvine, communication). Several of the localized GUI profiles showed sperm whales diving to depths greater than $1000 \mathrm{~m}$, which is also why not all dives showing fast rates of vertical change were removed during the second QA/QC pass.

Unlike results found from D-tags done by WHOI (Mark Johnson, unpublished data, 2003), the mobile passive acoustic tracking cannot follow one whale across multiple deep dives like those observed in 2002 and 2003 in the northeast Gulf of Mexico (Figure 52). Instead, it can obtain snapshots of dive profiles of multiple whales simultaneously for relatively short periods of time. The preliminary interpretation of these results suggests that sperm whales are potentially foraging at multiple depths and it is probable that they are foraging for different species at different depths. The ability to superimpose multiple dive profiles at the same time also indicates that whale diving behavior is linked to individual preference and is not uniform across spatial or temporal scales. This may reflect dive preferences connected to age of animals, available food supply, and prey preference. 
Whitehead and Rendell (2004) discuss the possibility of foraging strategies and diving patterns being unique to individual sperm whale clans (groups). This difference may also be due to differences in prey distribution and species which would affect the location in the water column where foraging would be successful. The whales tagged in 2002 and 2003 by WHOI were from the northeastern Gulf. This area is located near the Mississippi River Delta and is a more productive area as indicated by the comparison of scattering layer characteristics in Chapter IV. The more eutrophic conditions may support a different prey field and potentially influence foraging behavior. The western Gulf of Mexico is a more oligotrophic area and may support a different or sparser prey field, resulting in differences in foraging behavior (Biggs and Ressler, 2001). Additionally, the area in the western Gulf is a deep, open water environment, which is different from the northeastern Gulf that I hypothesize is more closely linked with coastal processes.

It is probably not a good idea to ascribe different dive patterns to different behaviors since the recordings are based on opportunity and the range is limited. The independent movement of the ship and the animals often results in patchy dives or recording only parts of the dive. Rarely is a complete dive recorded, and often the animal is detected as it begins its post deep dive ascent (Figure 47). Absence of whale tracks at the beginning of the dive is a result of typical absence of clicking within the first 5 seconds of a dive (Aaron Thode, communication).

Interpretation of the dive data also leads to some interesting observations about ultimate whale dive depth. While the deep dives show a range of depths, the deepest of these dives usually end approximately $100 \mathrm{~m}$ from the bottom. That dive depth depends on the 
ultimate depth of the bottom, however, regardless of the bottom depth, maximum dive depths appear to be $100 \mathrm{~m}$ from the bottom (See Figures 44, 45 and 47). The possibility of whales foraging for a specific food source known to inhabit depths of $100 \mathrm{~m}$ from the bottom could potentially explain this pattern. There is evidence to suggest that certain species of deep living squid like Architeuthis live on or very close to the bottom, since several specimens have actually been caught in bottom trawls or recorded on video (Kubodera and Mori, 2005). These squid would provide a meal for any sperm whale agile enough to capture one, and may explain why some sperm whales are diving to depths only $100 \mathrm{~m}$ or so off the bottom. While these squid are capable of large vertical migration, they are not likely to be found in the mesopelagic area of the deep scattering layer during the day (John Wormuth, communication). Several examples of mid-water whale dives in summer 2005 during the day also suggest that some sperm whales foraging at shallower depths may target other species of squid (John Wormuth, communication). Once again, these variations in dive patters could also be influenced by the presence of the $R / V$ Gyre and small tagging boats in the area and may not be representative of dive behavior independent of these outside stimuli.

The next step for future research is to determine when and at what depths sperm whales are creaking. This technique is being developed as a secondary part of the GUI used to track whale dive profiles. By combining whale dive patterns with patterns of creaks, it may be possible to determine where whales are actively hunting and the frequency of foraging dives to different depths. Comparisons between locations and clans could answer questions about differences in foraging patterns between geographical locations, or about patterns depending on the sex and maturity of the foraging groups. Passive 
acoustic monitoring from moored listening stations may also allow an independent analysis of sperm whale dive behavior without the influence of immediate ship traffic or tagging efforts. 


\section{CHAPTER VII \\ SUMMARY AND CONCLUSIONS}

Local abundance of sperm whales in 2005 around the divergent eddy implies these areas are more attractive to sperm whales than other areas. These areas are known to be more productive at the surface but differences at depth must play a role in the local associations of whales with these eddies based on knowledge of their deep diving behavior. The lack of significant differences between the cyclonic and anticyclonic areas in 2005 suggests that the main DSL may not be a good indicator for differences in sperm whale prey field that attract animals to these cyclonic events.

As mentioned in work by Kaltenberg (2004), deeper secondary scattering layers were observed in the 2002 and 2003 field seasons predominantly in the cyclonic areas surveyed. In 2005, those secondary layers were observed in 9 out of 16 ADCP plots collected over a 30-day period. Unlike the findings in 2002 and 2003, these layers were not limited to the cyclonic events but rather occurred under both cyclonic and anticyclonic conditions including data sets where the vessel traversed frontal areas between the two conditions. While sampling of whales was not random, there was no conscious effort to seek out areas where secondary scattering specifically occurred. Based on the appearance of secondary scattering layers throughout the cruise sample represents the type of distribution possible during June in the western Gulf of Mexico when there is the convergence of cyclonic and anti-cyclonic eddies. However, it should not be used as a proxy to predict the occurrence of secondary layers due to the large variability in conditions possible in the area. Considering that whales were sighted in areas within both 
conditions, this suggests that the whales are more attracted to the organisms contained within these deeper secondary layers rather than the main DSL.

Differences between the 2004 and 2005 DSL mean depth to the bottom of the scattering layer were negligible indicating that factors attracting sperm whales to those locations may be based on similarities between the locations rather than their differences. A brief investigation of secondary scattering layers in 2004 showed that only 7 out of 24 plots gave an indication of secondary layers, and only 2 of those 7 were well defined. The majority of the plots showed indications of very patchy and irregular secondary aggregations. These layers were often no deeper than 600 meters, which is shallower than the secondary layers recorded in 2005. The most well defined layers appeared in the plots of the DeSoto Canyon area. Once again these layers were recorded independent of whale survey efforts and were not used to determine the ship track for legs of the cruise. These secondary layer recordings are representative of the $800-1000 \mathrm{~m}$ isobath along the Mississippi Shelf during June of 2004. The near absence of whales in 2004 from DeSoto Canyon, the most similar area to the cyclonic eddy in 2005, suggests that the appearance of a well-defined main DSL or secondary layers may have little effect on what attracts whales to an area. Also, it may not be the individual cyclonic systems that produce the attractive prey field, but perhaps the interactions at frontal boundaries that produce the conditions attracting sperm whales to the area.

Whale encounters in summer 2005 showed that whales are found in non-cyclonic areas, which implies that our paradigm of preferential aggregation around cyclonic eddies could be biased by non-random sampling. Whale sighting data from 2005 were analyzed to 
determine the percent of sightings within divergent areas versus other areas. The sightings were analyzed based on time intervals and distance from the ship to address the issue of pseudo-replication. Animals sighted at the same approximate distance from the ship within 4 hours were considered to be the same animal. The bearings of the animals were not used in this analysis because it is difficult to distinguish whether the animal moved in relation to the ship or the ship in relation to the animal and would increase the likelihood of counting the same whale twice. Based on the results of the analysis, 99 individual sightings of whales occurred over the course of the cruise. Of those sightings, $60 \%$ were within the defined limits of the divergent eddy (see Chapter II), $20 \%$ were in non-divergent areas, and the last $20 \%$ were in undefined areas.

This indicates some sperm whales in the Gulf of Mexico are using areas other than upwelling areas for foraging, and it implies that while their preferred prey field may be linked with upwelling, they are not limited to these areas. The lack of significant difference between depth range characteristics of the main DSL and the presence of secondary deeper scattering layers in both cyclonic and anti-cyclonic areas supports this. Because the majority of studies have been designed to locate and tag sperm whales, either with photo ID or satellite tags, the null hypothesis that sperm whales prefer cyclonic areas may be biased by non-random sampling from the practice of returning to historical areas of tagging rather than random sampling of unexplored areas. In this sense, the characterization of sperm whale habitat is incomplete and their presence at divergent eddies unexplained by any prey field distribution differences based on ADCP scattering layer surveys. 
The future use of fishery echosounders to further investigate the main DSL and deeper scattering layers should allow a better idea of the types and locations of prey aggregations that sperm whales are hunting. Based on the limited comparison presented in Chapter V, the ADCP is clearly able to locate some areas of more dense scatterers and estimate the location and spread of scattering layers. The fishery echosounders are able to resolve smaller scale aggregations and even potentially give input on the type of aggregations based on their location and their scattering profiles. In addition to the use of more specialized technology, it will become more important to be able to ground truth these instruments with net tows producing species identification and counts. Although it may not be possible to sample the larger prey items sperm whales feed on due to net avoidance and more sparse distribution, assessing the composition of lower trophic levels may give insight into the types of predators know to feed at those levels. Also, the capture of lower numbers of higher trophic level prey may provide opportunities for isotope analysis and the creation of more complete food webs for the different areas of the Gulf of Mexico.

The whale dive profile analysis provided exciting new insight into the diving behaviors of some sperm whales in the western Gulf of Mexico. Based on the analysis of multiple dive profiles from the 2005 field season, three particular dive categories were identified. Whales were shown to dive to depths below 800 meters and sometimes to approximately 100 meter off the bottom. This corroborates historical stomach content analysis that sperm whales are feeding on deep living squid species like Architeuthis, which have been observed at similar depths. Dive profile analysis also showed whales diving into and through the main scattering layers and secondary layers $(500-800 \mathrm{~m})$. It also showed 
whales performing shallow dives that only partially entered the upper limits of the main DSL but instead stayed within the shallower scattering layers $(<500 \mathrm{~m})$. The differences in these dive patterns, discussed in Chapter VI, offer insight into between animal variability, most notably, sperm whales in the western Gulf of Mexico are not all diving to the same depths. Sometimes individual whales are diving differently from other whales within their group during the same time period. These differences suggest that sperm whales are not always foraging at the same depths and that their prey field may include items other than squid species.

In order to more fully understand when and where sperm whales are foraging it is necessary to compare dive profiles using creak (buzz) analysis. Currently, the GUI program is able to detect creaks based on bearing tracks of animals, but cannot connect those tracks with localized dive profiles. This makes identifying individual whales and their creak patterns very difficult. If it were possible to connect whale dive patterns and depths with creak frequency and location then, it may also be possible to develop a better understanding of where sperm whales are foraging and whether the multiple dive categories are all examples of foraging dives.

By combining the results of net trawls with creak patterns it may be possible to connect stratification of organisms in the water with whale foraging attempts. It may also be possible to distinguish whether whales are potentially feeding on vertically migrating organisms and whether that migration has an effect on whale dive behavior between night and day. Although the dive profiles have shown little difference between night and day, it is impossible at this point to say whether their main prey items change between times of 
day. This type of analysis would require the isolation of many more dive profiles and the statistical analysis of dive depth preference between night and day. It would also entail detailed knowledge of the specific organisms in an area and their daily vertical migration habits. Additionally, the ability to use an echosounder system to identify specific types of scattering profiles from known organisms is necessary. Scattering profiles are available for some types of organisms, however, other scattering profiles, like squid, remain elusive. Another factor to also consider are the potential differences in prey densities and composition between different cyclonic areas and frontal zones that were not apparent in the ADCP data.

There is a lot of investigation still necessary to understand the behavior of sperm whales. The results presented in this thesis provide previously unavailable insight into some of the more complex aspects of sperm whale dive behavior. The ability to superimpose dive profiles over backscatter plots gives information on spatial and temporal variations in foraging behavior and insight into the behavior relative to the distribution of scattering layers. Although these scattering layers are volume backscatter aggregations, they are likely to be indicators for the location of other larger prey items as well. The development of more advanced echosounder technology and the constant improvements in passive acoustic observation techniques will continue to expand the understanding of sperm whale dive behavior and their feeding and foraging preferences. 


\section{REFERENCES}

Baumgartner M.F, Mullin K.D., May L.N. and Leming T.D. (2001). “Cetacean habitats in the northern Gulf of Mexico," Fisheries Bulletin. 99, 219-239.

Biggs D.C. and Ressler P.H. (2001). "Distribution and abundance of phytoplankton, zooplankton, ichthyoplankton and micronekton in the deepwater Gulf of Mexico," Gulf of Mexico Science 1, 7-29.

Brierley A.S., Brandon M.A., and Watkins J.L. (1998). “An assessment of the utility of an acoustic Doppler current profiler for biomass estimation,” Deep- Sea Research I 45, 1555-1573.

Clarke M.R. (1996). “Cephalopods as prey,” Philosophical Transactions: Biological Sciences 351, 1053-1065.

Colorado Center for Astrodynamics Research (CCAR) (2004) "Hind-cast SSH and Cphyll concentration,” http://argo.colorado.edu/ realtime/gom_modis/

Colorado Center for Astrodynamics Research (CCAR) (2005) "Hind-cast SSH and Cphyll concentration,” http://argo.colorado.edu/ realtime/gom_modis/ 
Davis R. W. and Fargion G. S., eds. (1996). "GulfCet I: Distribution and Abundance of Cetaceans in the North-Central and Western Gulf of Mexico, Final Report; Vol. II: Technical Report," OCS Study MMS 96-0027. Prepared by the Texas Institute of Oceanography and the National Marine Fisheries Service. U.S. Dept. of the Interior, Minerals Management Service, Gulf of Mexico OCS Region, New Orleans, LA.

Davis R.W., Evans W.E and Wursig B. (2000). "GulfCet II: Cetaceans, seat turtles and seabirds in the northern Gulf of Mexico: Distributions, abundance and habitat associations, Volume 1: Executive Summary," OCS Study MMS 2000-002 U.S Department of the Interior, Minerals Management Service, Gulf of Mexico Region, OCS Region, New Orleans, LA.

Davis R. W., Ortega J. G., Ribic C. A., Evans W.E, Biggs D. C., Ressler P. H., Cady R. B., Leben R. R., Mullin K. D., and Wursig B. (2002). "Cetacean habitat in the northern oceanic Gulf Of Mexico,” Deep-Sea Research I 49, 121-142

Ditchburn, R.W. (1963). Light, $2^{\text {nd }}$ edition (Black and Sons).

Duvall G.E. and Christiansen R.J. (1946). "Stratification of sound scatterers in the ocean," Journal of the Acoustical Society of America 20, 254. 
Fielding S., Griffiths G., and Roe S.J. (2004). "The biological validation of ADCP acoustic backscatter through direct comparison with net samples and model predictions based on acoustic-scattering models," ICES Journal of Marine Science 61, 184-200.

Fish J.P, and Carr H.A. (1991) "Sound underwater images: A guide to the generation and interpretation of side scan sonar data," (Lower Cape Pub Co).

Foote K.G., Vestnes G., Maclennan D.N. and Simmonds E.J. (1987) “Calibration of acoustic instruments for fish density information: A practical guide," Coop. Res. Rep. Cons. Int. Explor. Mer. 144,144-169.

Franceschini G.A, Bright T.J, Caruthers J.W, El Sayed S.Z, Vastano A.C. (1970). "Effects on migration of marine organisms in the Gulf of Mexico," Nature 266, 11551156.

Greene C.H., Wiebe P.H., Pelkie C., Benfield M.C. and Popp J.M. (1998). “Threedimensional acoustic visualization of zooplankton patchiness," Deep Sea Research II 45, 1201-1217.

Griffiths G. and Diaz J.I. (1996). “Comparison of acoustic backscatter measurements from a ship-mounted acoustic Doppler current profiler and EK500 scientific echosounder," ICES Journal of Marine Science 53, 487-491. 
Hamilton, P. (1992). "Lower continental slope cyclonic eddies in the central Gulf of Mexico,” Journal of Geophysical Research 97, C2 2185-2220.

Hays G.C., Kennedy H. and Frost B.W. (2001). "Individual variability in diel vertical migration of a marine copepod: Why some individuals remain at depth when others migrate," Limnology and Oceanography 46, 8, 2050-2054.

Jochens A.E. and Biggs D.C. (2006). "Spatial variability in sperm whale encounters in summer 2005 in and upwelling regime in the northern Gulf of Mexico," in review.

Jochens A.E., and Biggs D.C., editors (2006a). "Sperm whale seismic study in the Gulf of Mexico; Annual Report: Years 3 and 4,” U.S. Dept. of the Interior, Minerals Management Service, Gulf of Mexico OCS Region, New Orleans, LA. OCS Study MMS.

Jochens A., Biggs D., Engelhaupt D., Gordon J., Jaquet N., Johnson M., Leben R., Mate B., Miller P., Ortega-Ortiz J., Thode A., Tyack P., Wormuth J., and Würsig B. (2006b). "Sperm whale seismic study in the Gulf of Mexico; Summary Report, 2002-2004," U.S. Dept. of the Interior, Minerals Management Service, Gulf of Mexico OCS Region, New Orleans, LA. OCS Study MMS 2006-XXX.

Johnson M. (2003) "Dive plots of sperm whales D-tagged by WHOI in the northeast Gulf of Mexico, June 2003 and September 2002, respectively," Woods Hole Oceanographic Institution (WHOI), unpublished data. 
Kaltenberg A.M. (2004). “38 kHz ADCP investigation of deep scattering layers in sperm whale habitat in the northern Gulf of Mexico," M.S. thesis, Texas A\&M University, College Station, TX.

Kubodera T. and Mori K. (2005). "First-ever observations of a live giant squid in the wild,” Proc. R. Soc. B 272, 2583-2586.

Leben, R. R. (2005) “Altimeter derived loop current metrics," Circulation in the Gulf of Mexico: Observations and Models. (American Geophysical Union, 181-201).

Levinton J. (2001). Marine Biology: Function, Biodiversity, Ecology, (Oxford University Press).

Miller P.J., Johnson M.P., and Tyack P.L. (1991). " Sperm whale behavior indicates the use of echolocation click buzzes 'creaks' in prey capture,' Proceedings. Biological Science 271, 2239-47.

Muller-Karger F.E., Evans R.H., and Myers M.E. (1991). “On the seasonal phytoplankton concentrations and sea surface temperature cycles of the Gulf of Mexico as determines by satellites," Journal of Geophysical Research 96, C7, pp 12, 645-12, 665.

Picard G., and Emery W. (1990). Descriptive Physical Oceanography: An Introduction. (Butterworth and Heineman). 
Qian Y., Jochens A.E., Kennicutt M.C. and Biggs D.C. (2003). "Spatial and temporal variability of phytoplankton biomass and community structure over the continental margin of the northeast Gulf of Mexico based on pigment analysis," Continental Shelf Research 23, (1), 1-17.

R.D. Instruments. (1996). Doppler Current Profilers. Principles of operation: A Practical Primer, (R.D. Instruments).

Ressler P.H. (2001). “Acoustic estimates of zooplankton and micronekton biomass in cyclones and anticyclones of the northeastern Gulf of Mexico," Ph.D. dissertation, Texas A\&M University, College Station, TX.

Ressler P.H. (2002). “Acoustic backscatter measurements with a $153 \mathrm{kHz}$ ADCP in the northeast Gulf of Mexico: Determination of dominant zooplankton and micronekton scatterers,” Deep Sea Research I 49, 2035-2051.

Ressler P.H. and Jochens A. E. (2003). "Hydrographic and acoustic evidence for enhanced plankton stocks in a small cyclone in the northeastern Gulf of Mexico," Continental Shelf Research 23, 41-61. 
Sindlinger L.R. (2003). “ADCP backscatter measurements in the northeastern Gulf of Mexico: comparison of near-surface with near-bottom biological backscatter," M.S. thesis, Texas A\&M University, College Station, TX.

Stanton T.K, Chu D., and Wiebe P.H. (1996). “Acoustic scattering characteristics of several zooplankton groups,” ICES Journal of Marine Science 53, 289-295.

Sturges W. and Leben R.R. (2000) “Frequency of ring separation from the loop current in the Gulf of Mexico: A revised estimate,” Journal of Physical Oceanography 30, 18141819.

Thode A. (2004). "Tracking sperm whales (Physeter macrocephalus) dive profiles using a towed passive acoustic array," Journal of the Acoustical Society of America 116 (1), 245-253.

Thode A. (2005). “Three-dimensional passive acoustic tracking of sperm whales (Physeter macrocephalus) in ray-refracting environments," Journal of the Acoustical Society of America 118 (6), 3575-3584.

Thode A., Millinger D., Stienessen S., Martinez A., Mullin K. (2002). "Depth-dependant acoustic features of diving sperm whales (Physeter macrocephalus) in the Gulf of Mexico," Journal of the Acoustical Society of America 112 (1), 308-321. 
Tynan C.T., Ainley D.G., Barth J.A, Cowles T.J., Pierce S.D., and Spear L.B. (2004). "Cetacean distributions relative to ocean processes in the northern California current system,” Deep Sea Research II 52,145-167.

University of South Florida (USF) (2005). "Moderate resolution imaging dpectroradiometer (MODIS) images," http://imars.marine.usf.edu.

Watwood S., Miller P.J., Johnson M., Madsen P.T., and Tyack P.L. (2006). "Deep-diving foraging behavior of sperm whales (Physeter macrocephalus)," Journal of Animal Ecology 75, 814-825.

Whitehead H. (2003), Sperm Whales: Social Evolution in the Ocean, (University of Chicago Press).

Whitehead H. and Rendell L. (2004) "Movements, habitat use and feeding success of cultural clans of South Pacific sperm whales," Journal of Animal Ecology 73, 190-196.

Wormuth J.H., Ressler P.H., Cady R.B., and Harris E.J. (2000). “Zooplankton and micronekton in cyclones and anticyclones in the northeast Gulf of Mexico," Gulf of Mexico Science 1, 23-34.

Zimmerman R.A. (1993). "Bioacoustics survey of planktonic sound scatterers and of the diel and seasonal variability in the northwest Gulf of Mexico," M.S. thesis, Texas A\&M University, College Station TX. 
Zimmerman R.A. and Biggs D.C. (1999). "Patterns of distribution of sound scattering zooplankton in warm- and cold-core eddies in the Gulf of Mexico, from a narrow band acoustic Doppler current profiler," Journal of Geophysical Research 104, (C3), 52515262.

\section{Supplemental Sources Consulted}

Jaquet N. and Gendron D. (2002). "Distribution and relative abundance of sperm whales in relation to key environmental features, squid landings and the distribution of other cetacean species in the Gulf of California, Mexico," Marine Biology 141, 591-601.

Kinzer J. (1969). "On the quantitative distribution of zooplankton in the deep scattering layers,” Deep Sea Research 16, pp117-125.

Ryther J.H. (1969). "Photosynthesis and fish production in the sea," Science 166, 3901, 72-76.

Watkins W.A and Schevill W.E. (1972). "Sound source location by arrival-times on a non-rigid three-dimensional hydrophone array," Deep Sea Research 19, 691-706.

Worthington L.V. and Schevill W.E (1957). "Underwater sounds heard from sperm whales," Nature (London) 180, 291-293. 


\section{APPENDIX}

ADCP acoustic Doppler current profiler

ANOVA A statistical test that stands for analysis of variance between groups.

Attenuation The process of weakening or reducing the amplitude of a sonar signal. The attenuation of a sonar signal makes its detection more difficult.

Backscatter The deflection of acoustic radiation in a scattering process through an angle greater than 90 degrees (Fish and Carr, 1991); also a reflection of energy by particles smaller than the wavelength of the energy emitted in which energy is reflected in all directions including back in the direction in came from (Ditchburn, 1963).

Click $\quad 6-10 \mathrm{~ms}$ pulse of sound created by sperm whales.

Coda Rhythmic set of clicks made by sperm whales. Codas are thought to possibly be associated with socialization.

Creak Rapid succession of clicks together that sound like creaking or buzzing. Creaks are thought to be an indication of a foraging effort.

CTD Conductivity-Temperature -Depth recorder

dB The decibel is a unit for measuring sound intensity on a logarithmic scale.

DSL Deep Scattering Layer

Effective The Number of degrees of freedom for a data set once

Degrees of all autocorrelation of data points has been removed.

Freedom

GUI Graphical user interface

K- S test The Kolmogorov-Smirnov test tries to determine if two datasets differ significantly from a normal, or Gaussian distribution. A normal distribution within a data set allows parametric statistic test to be conducted.

MMS Minerals Management Service

MODIS Moderate Resolution Imaging Spectroradiometer 
MOCNESS Multiple open and closing net and environmental sensing system.

Pearson's

Correlation Measures the strength of the linear relationship between two variables.

Ping A single output pulse of a sonar system.

Pulse A short burst of sonar, typically measured as a function of time, distance or power. It is used to describe the length in time and width in meters of a sonar ping.

RABI relative acoustic backscatter intensity

RHIB ridged hulled inflatable boat

$\mathrm{S}_{\mathrm{A}} \quad$ Area Scattering $\left(\mathrm{m}^{2} / \mathrm{n} \cdot \mathrm{mi}^{2}\right)$

$\mathrm{S}_{\mathrm{v}} \quad$ Mean volume backscattering strength of the domain being integrated ( $\mathrm{dB}$ re $1 \mathrm{~m}^{2} / \mathrm{m}^{3}$ ). An analysis domain defines a set of data points (samples) or single targets (echoes) that are included in analyses.

Scattering The diffusion of the sonar signal in many directions through refraction, diffraction, and reflection. Scattering is one of the causes of attenuation in sonar, resulting in signal weakening (Fish and Carr, 1991).

Sound The loss of energy from a sonar beam as it propagates through

absorption the water.

Spherical Spherical spreading describes the decrease in level when a sound wave spreading propagates away from a source uniformly in all directions.

Students Is a statistic for measuring the difference of means between two t-test distributions. The t-test tells us if the variation between two groups is significant.

SWSS Sperm Whale Seismic Study

Wavelength The distance, measured in the direction of propagation, between two successive points in a wave that with the same phase of oscillation.

WHOI Woods Hole Oceanographic Institution

XBT Expendable bathythermograph 


\title{
VITA
}

\author{
Alyson Julie Azzara \\ C/O Dr. Douglas Biggs \\ Department of Oceanography \\ Texas A\&M University \\ College Station, TX 77843-3146 \\ alygirl@tamu.edu
}

\section{Education}

- December 2006: M.S. in oceanography, Texas A\&M University, College Station, TX

- June 2004: B.A in biology, Temple University, Philadelphia, PA

\section{Research Interests}

- Passive acoustic observations of cetaceans and categorization of vocalizations and diving and foraging behavior.

- Investigation of the effects of changes in anthropogenic noise levels on the behavior of marine mammals.

\section{Presentations}

- "Comparison of Deep Scattering Layer Characteristics to Sperm Whale Dive Behavior in the Gulf of Mexico" Oral presentation given by Alyson Azzara at the American Society of Limnology and Oceanography Meeting Summer 2006 in Victoria, B.C.

\section{Cruises}

- October 2005: 26 day Cruise to Galapagos Islands on cooperative research cruise with the Navy of Ecuador.

- August 2005: Oceanographer on TABS buoy deployment cruise.

- June 2005: Oceanographer on MMS funded SWSS research cruise in the Gulf of Mexico.

- April 2005: Oceanographer on TABS buoy deployment cruise.

- June 2004: Oceanographer on MMS funded SWSS research cruise in the Gulf of Mexico.

\section{Short Courses}

- April 2006: National Environmental Policy Workshop through Texas A\&M University.

- August 2005: Bioacoustics Workshop through the University of Washington. 